Florida International University

FIU Digital Commons

$10-8-2019$

\title{
The HPST Framework: A Case Study on an Organizational Tool Used to Understand Historical Narrative in a Social Studies Classroom
}

jose m. pombo

Florida International University, jpomb001@fiu.edu

Follow this and additional works at: https://digitalcommons.fiu.edu/etd

Part of the Curriculum and Instruction Commons

\section{Recommended Citation}

pombo, jose m., "The HPST Framework: A Case Study on an Organizational Tool Used to Understand Historical Narrative in a Social Studies Classroom" (2019). FIU Electronic Theses and Dissertations. 4357. https://digitalcommons.fiu.edu/etd/4357

This work is brought to you for free and open access by the University Graduate School at FIU Digital Commons. It has been accepted for inclusion in FIU Electronic Theses and Dissertations by an authorized administrator of FIU Digital Commons. For more information, please contact dcc@fiu.edu. 


\section{FLORIDA INTERNATIONAL UNIVERSITY \\ Miami, Florida}

THE HPST FRAMEWORK:

A CASE STUDY ON AN ORGANIZATIONAL TOOL USED TO UNDERSTAND HISTORICAL NARRATIVE IN A SOCIAL STUDIES CLASSROOM

A dissertation submitted in partial fulfillment of the requirements for the degree of DOCTOR OF PHILOSOPHY

in CURRICULUM AND INSTRUCTION

by

Jose M. Pombo 
To: Dean Michael R. Heithaus

College of Arts, Sciences and Education

This dissertation, written by Jose M. Pombo, and entitled The HPST Framework: A Case Study on an Organizational Tool Used to Understand Historical Narrative in a Social Studies Classroom, is referred to you for judgment.

We have read this dissertation and recommend that it be approved.

Benjamin Baez

James Burns

Sarah Mathews, Co-Major Professor

Eric Dwyer, Co-Major Professor

Date of Defense: October 8, 2019

The dissertation of Jose M. Pombo is approved.

Dean Michael R. Heithaus

College of Arts, Sciences and Education

Andrés G. Gil

Vice President for Research and Economic Development and Dean of the University Graduate School

Florida International University, 2019 


\section{DEDICATION}

To: Mami, Papi, Alex and Jose David, I could not have done this without you. Thank you so much for your support and inspiration.

All my love,

Jochi 


\section{ACKNOWLEDGMENTS}

I would like to thank Dr. Sarah Mathews and Miss Yuliese Mena for all their

participation, hard work, and absolute belief in the HPST Framework. Without their help, support, and dedication this would not be possible. Moreover, I would also want to mention, Dr. Eric Dwyer, my dissertation chair, who lovingly guided me through this at times — taxing and unending labyrinth. 


\section{ABSTRACT OF THE DISSERTATION}

THE HPST FRAMEWORK:

A CASE STUDY ON AN ORGANIZATIONAL TOOL USED TO UNDERSTAND HISTORICAL NARRATIVE IN A SOCIAL STUDIES CLASSROOM

by

José M. Pombo

Florida International University, 2019

Miami, Florida

Professor Eric Dwyer, Co-Major Professor

Professor Sarah Mathews, Co-Major Professor

This dissertation chronicled a multifaceted study utilizing the Historical, Philosophical, Societal and a Takeaway (HPST) Framework, an organizational tool used for document analysis. Utilizing a case study format, this research unpacked how a charter school teacher used HPST within her own ninth grade Advanced Placement World History class. As a starting point, I offered an account of my own autobiographical narrative, chronicling through my attempt at ethnographic writing and infused with scholarly literature as needed. Consequently, this personal narrative was coupled with my professional experiences within the Social Studies field. Upon this foundation, this study explored the use of the HPST Framework for analyzing narratives and its complexities beyond the textbook. The intent of HPST was to help students analyze the interaction of the author, the text, and the reader. The research was geared to see to what degree students might draw out historical, philosophic, and socio-cultural frames reflected as 
complicated conversations. In particular, I was interested in examining U.S. students' portrayals of marginalized groups within a context of world history and how these roles changed after students used the HPST Framework to analyze narrative passages.

The study uncovered that HPST could add to literature by prioritizing historical narratives to convey information through stories which humanize the people involved in significant world events. For this teacher, HPST served as a platform for student discussion because it took the existing classroom discourse about philosophy, politics, society, or power and cognitively arranged it in two levels for students to engage with the text and the author. This was followed by an analytical layer to enhance comprehension and critical thinking. With that said, students could easily identify the $\mathrm{H}$ and $\mathrm{S}$; however, challenges were found in their understanding of the P. Moreover, HPST allowed students to engage in discovery learning instead of prescribed analysis by the teacher.

Additionally, discussions were offered as to how this teacher with limited time or a restricted curriculum could modify HPST and still use it. Lastly, discourses were given as to how this educator used narratives in the past and how her teaching changed because of the HPST. 


\section{TABLE OF CONTENTS}

CHAPTER

PAGE

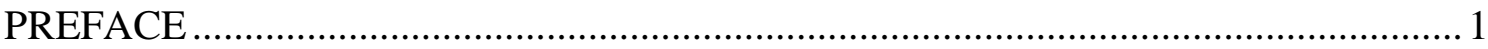

My Story: Exile, Miami, and Social Studies..................................................... 4

First Wave of Cuban Immigration .................................................................. 5

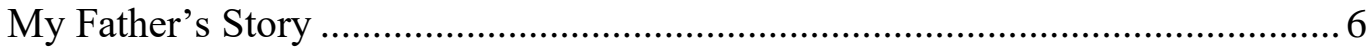

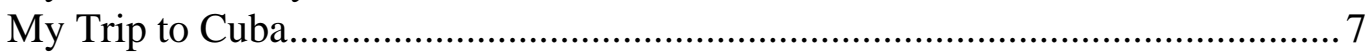

My Visit and HPST.................................................................................... 10

My Wonderful Teachers …………………………………............................... 11

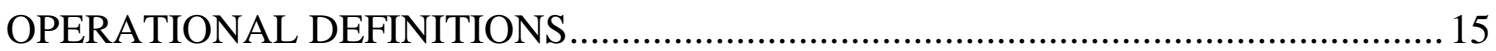

CHAPTER ONE-TEACHING HISTORY: SPACE FOR NARRATIVE .....................20

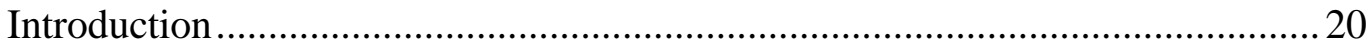

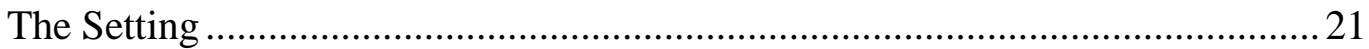

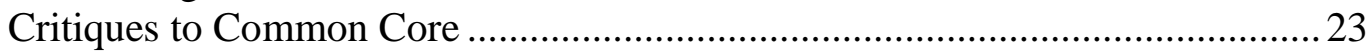

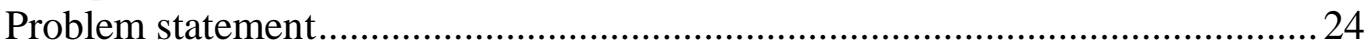

Teachers, Students, and Social Studies textbooks ...............................................26

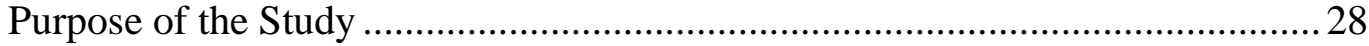

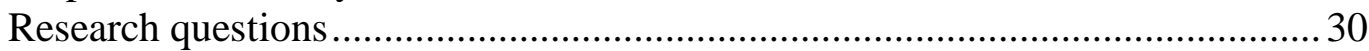

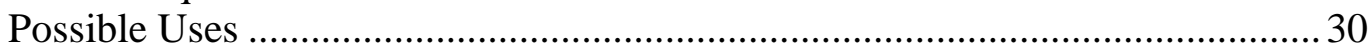

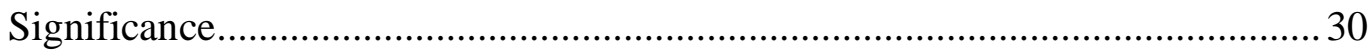

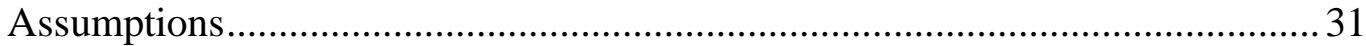

Possible Benefits ....................................................................................... 31

Historical Philosophical Societal and a Takeaway Framework..............................32

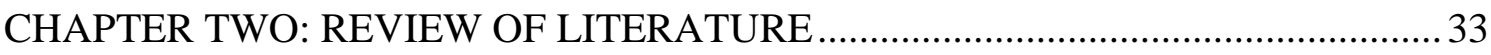

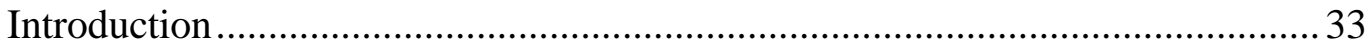

Conceptual Framework: Hermeneutical justification for HPST Framework .......33

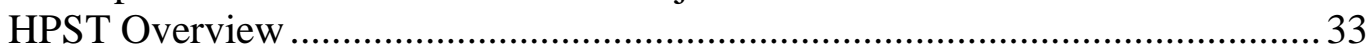

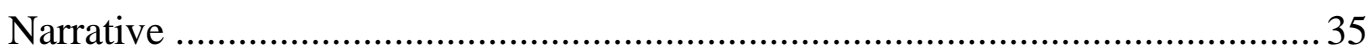

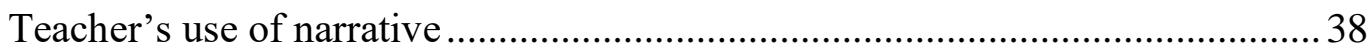

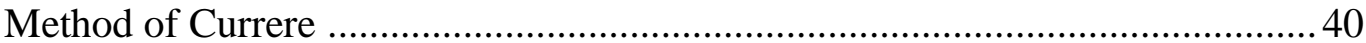

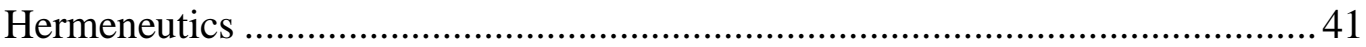

Critiques to Hermeneutics................................................................................ 47

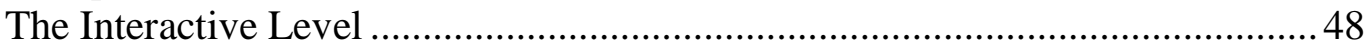

The Analytic Level .................................................................................... 51

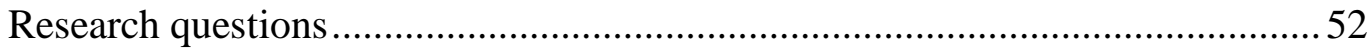

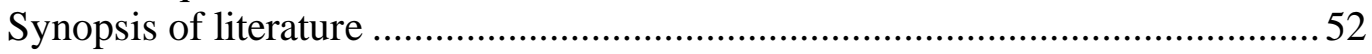




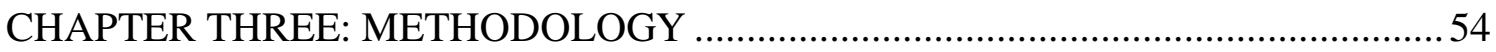

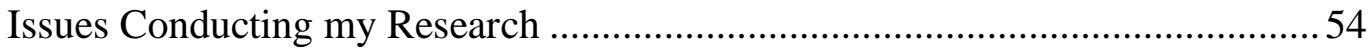

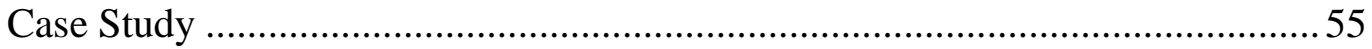

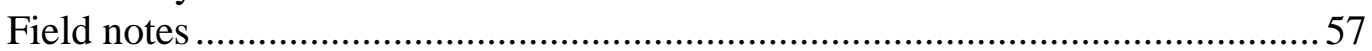

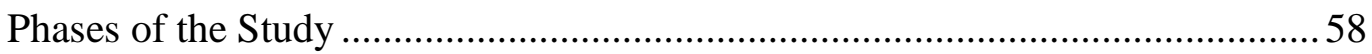

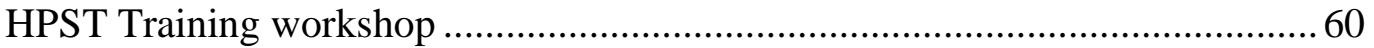

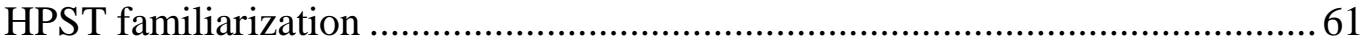

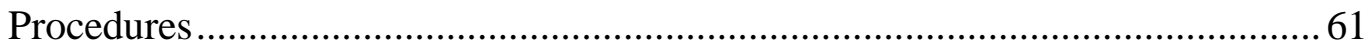

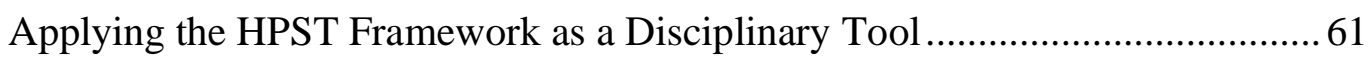

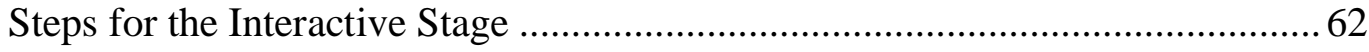

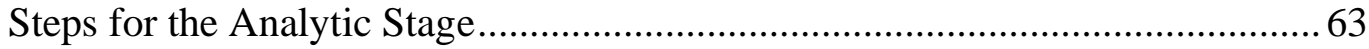

Lesson plan development with HPST implementation............................................. 64

Recruitment of participants for case study observation .........................................64 64

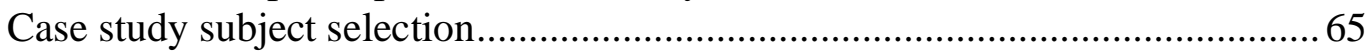

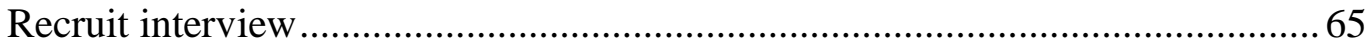

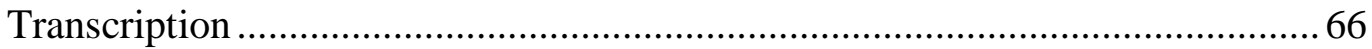

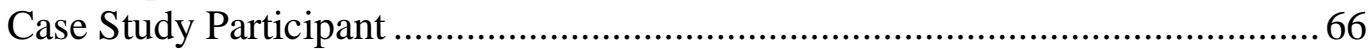

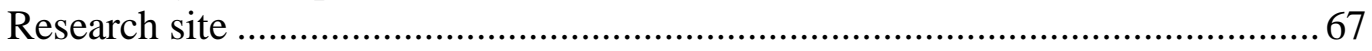

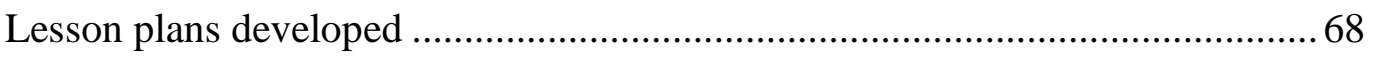

Researcher input on lesson plans or HPST implementation .................................69

Lesson plans in action ................................................................................. 71

Researcher/subject interviews.................................................................... 71

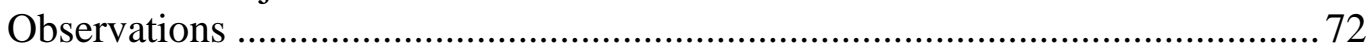

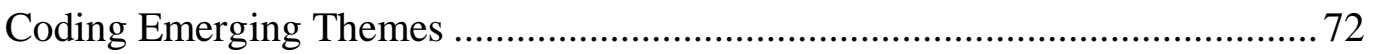

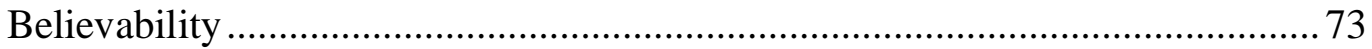

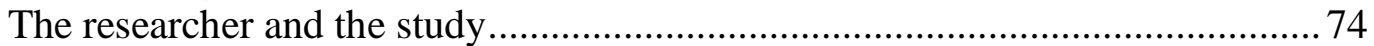

Synopsis of research methodology ................................................................. 75

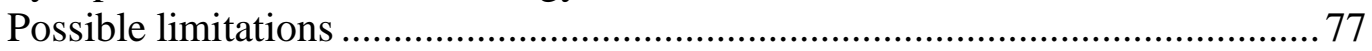

\section{CHAPTER FOUR: PRESENTATION OF DATA}

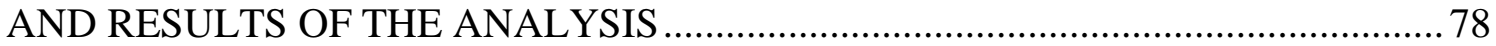

RQ1: How does a Social Studies teacher use HPST........................................... 78

Implementation Protocol............................................................................ 78

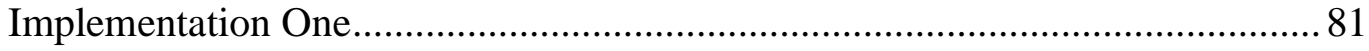

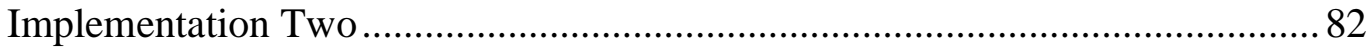

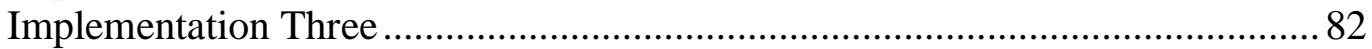

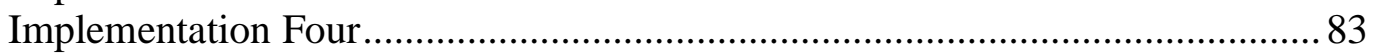

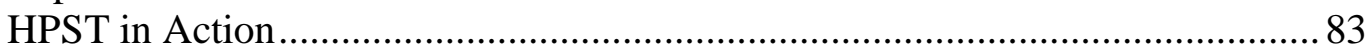

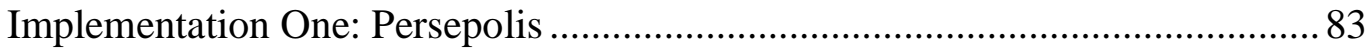

Follow-up interview on Implementation One ................................................... 97

Implementation Two: Persepolis Again ……………………………………... 98

Discussion on Implementations One and Two ……………............................ 102

Implementation Three: 1492 Diary of Christopher Columbus ........................... 105

Implementation Four: Peter the Great............................................................. 116

RQ2: What role can narrative play for a Social Studies teacher.......................... 126 


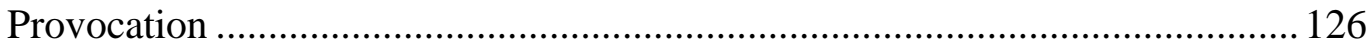

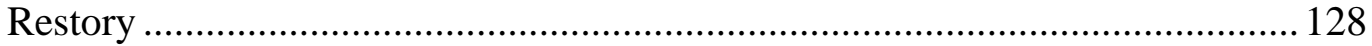

RQ3: To what extent has the use of the HPST changed the teacher's

Thinking about curriculum and/or her teaching................................................. 130

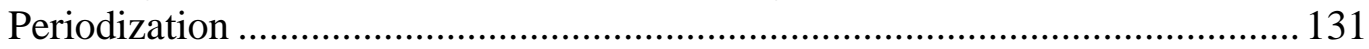

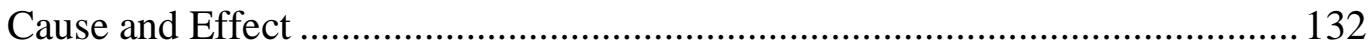

HPST, Document Based Questions and End-of Course Exams ......................... 133

CHAPTER FIVE: DISCUSSION OF DATA AND

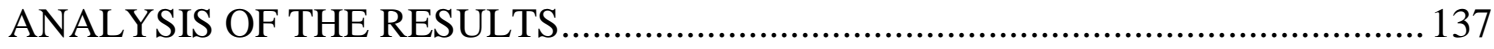

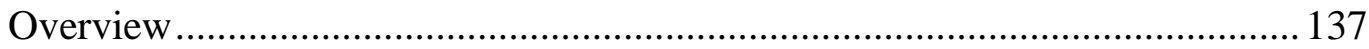

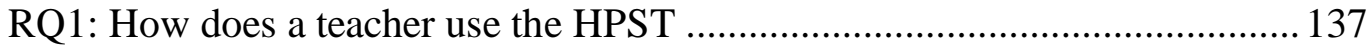

Questions Pondered ..................................................................................... 139

RQ2: What role does narrative play for a teacher.............................................. 149

Restory and Provocation ............................................................................. 149

Implications for Future Research.................................................................. 150

RQ3: To what extent has the use of the HPST changed the teachers

thinking about curriculum and or her teaching .................................................. 151

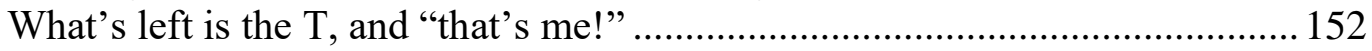

Advanced Placement (AP) Courses in a High School Setting ............................ 153

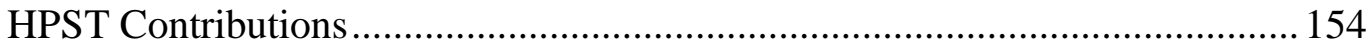

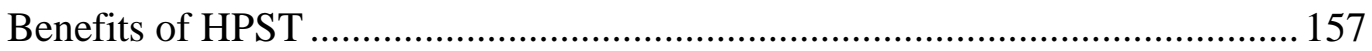

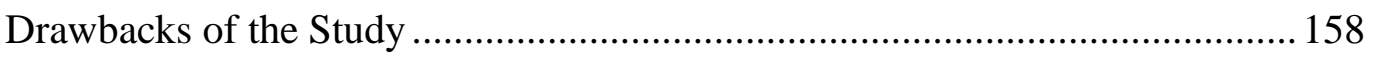

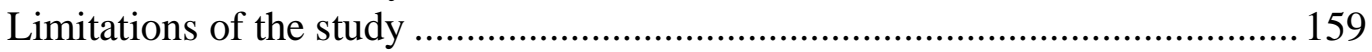

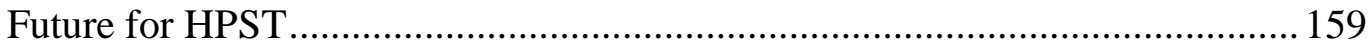

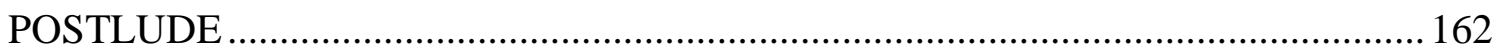

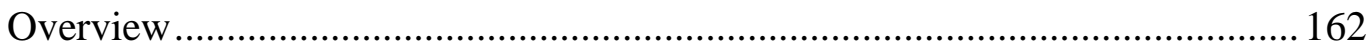

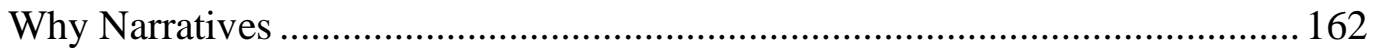

My views about myself as a researcher .......................................................... 164

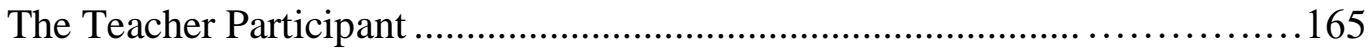

Social Studies Teachers' Awareness of their Students' Attitudes

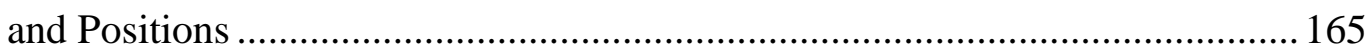

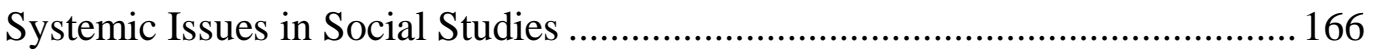

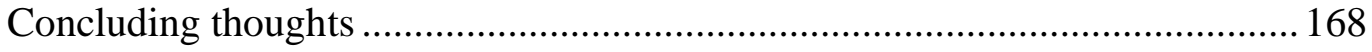

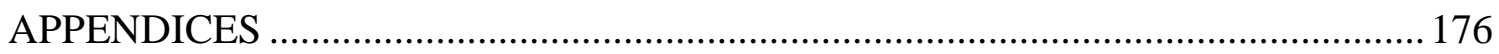

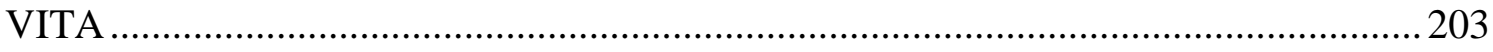




\section{LIST OF TABLES}

TABLE

PAGE

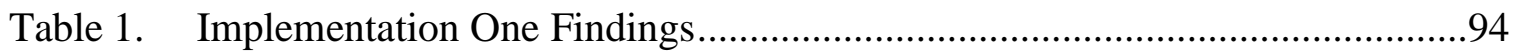

Table 2. Implementation Two Findings ........................................................ 101

Table 3. Implementation Three Findings ........................................................111

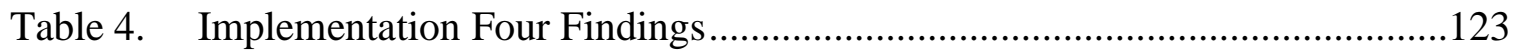

Table 5. Brazofsky (2019). Miami-Dade County Public Schools Social Studies Pacing Guide: Summer Week \#1 (course code 2109010) 


\section{LIST OF FIGURES}

FIGURE

PAGE

Figure 1. The Historical, Philosophic, Societal, and a Takeaway (HPST)

Conceptual Framework .34

Figure 2. Howe's (2011) representation of the Hermeneutic Circle based on Osborne (1991). .44

Figure 3. Interactive level. .49

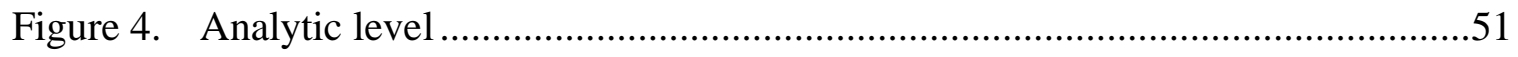

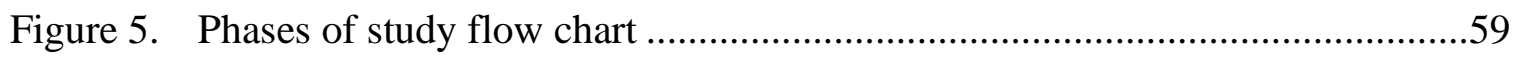

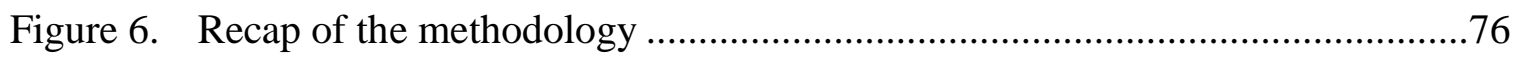

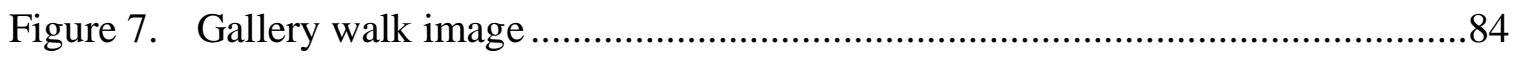

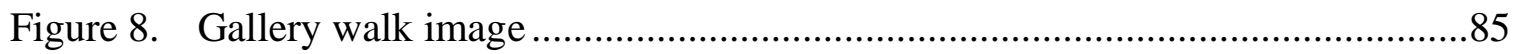

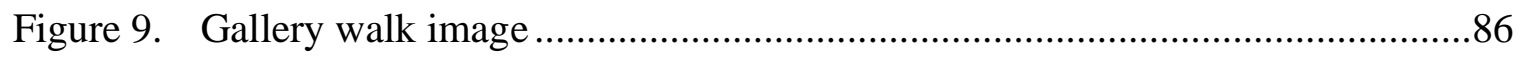

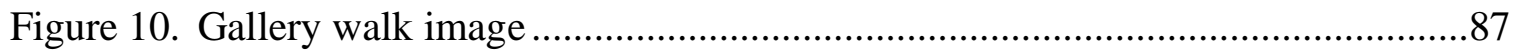

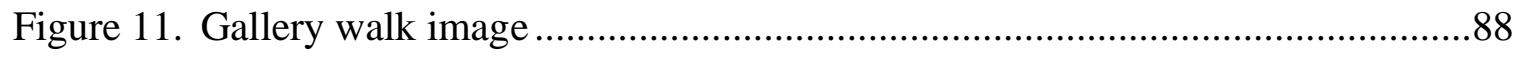

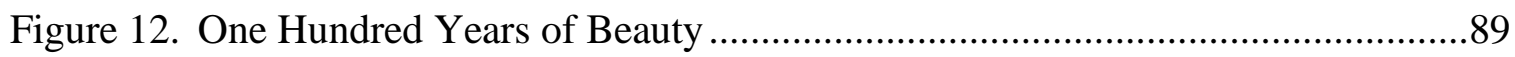

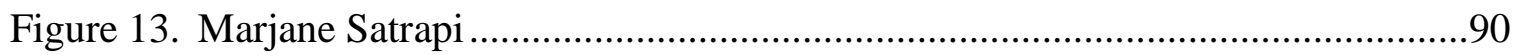

Figure 14. Satrapi (2003) Persepolis text excerpt ................................................. 91

Figure 15. Satrapi (2003) Persepolis text excerpt .................................................92

Figure 16. Satrapi (2003) Persepolis text excerpt ................................................93

Figure 17. Tolin (1862). The First Landing of Christopher Columbus in America........106

Figure 18. Diary of Christopher Columbus (1492) excerpt .......................................109

Figure 19. Diary of Christopher Columbus (1492) excerpt ......................................110

Figure 20. Paul Delarouche (1838) Peter the Great Image .......................................117 
Figure 21. Massie (1981) Peter the Great excerpt ................................................... 120

Figure 22. Klyuchevsky (1958) Peter the Great excerpt ..........................................121

Figure 23. Chubarov (1999) The Fragile Empire:

A History of Imperial Russia excerpt ....................................................121

Figure 24. Implementation Three student restory ................................................ 129

Figure 25. Example of student restory in Implementation One .................................129

Figure 26. Example of student restory in Implementation Two..................................129

Figure 27. Example of student restory in Implementation Four .................................130

Figure 28. Example of Periodization in Implementation Three ..................................132

Figure 29. Example of Periodization in Implementation One.....................................132

Figure 30. Example of Cause and Effect in Implementation Two ..............................133

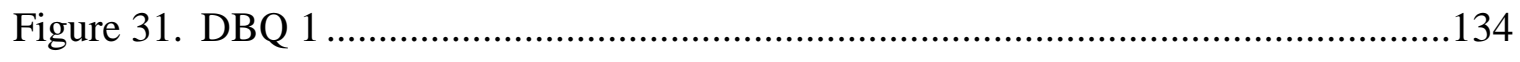

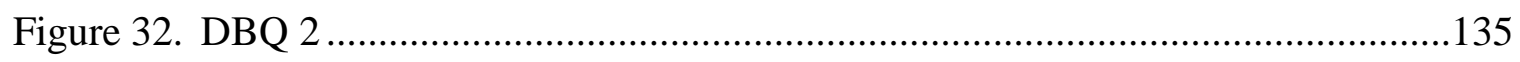

Figure 33. Provocation and restory in other disciplines ...................................... 151

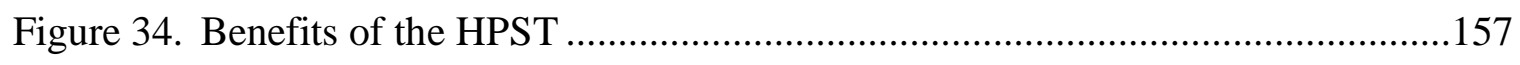

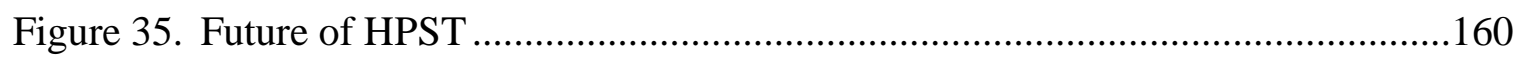




\section{PREFACE}

For millennia, humans have synergistically engaged with each other and their respective physical environments to produce a distinct and concretized stream of consciousness which recount their personal and shared experiences. Initially, these human experiences morphed into the spoken word which eventually created an oral tradition that was, in turn, passed from one generation to the next. As time and humanity progressed, these stories took shape and not only were physically written down and recorded but also detailed, shaded, and chronicled every facet of our human experience. Roland Gérard Barthes (Barthes, 1957), French literary theorist, essayist, philosopher, and linguist, described narratives as

numberless and able to be carried by articulated language, spoken or written, fixed or moving images, and gestures. They are present in every age, place, or society. Nowhere are there a people without them. Moreover, these stories are international, trans-historical, and trans-cultural: it is simply like life itself (p. 79).

Barton and Levstik (2004) define narrative as any form of historical stories that follow marked patterns of causal events that are chronological and include a setting or schema, characters, agent, a goal, and that utilize an instrument. Narratives predominately encompass aspects dealing with psychological reality and of historiography, vis-à-vis people, places, and epochs. Additionally, narratives are cultural tools which individuals can utilize to make sense of history, distilling the information acquired by them into a catalyst of cause and effect.

I grew up in a family with many stories. My family's narratives became an essential part of my own history. I realized, though, that my at-home narratives 
encompassed an integral part of the Social Studies which ultimately led me to this field because of my interest in them.

The use of historical narratives is a staple in my teaching because document analysis has become a key element required by the Common Core (NCSS, 2010). Often, I have asked students to perform a kind of self-reflection narration in order to attend to their history lessons as put forward by this legislation. Hence, inspired by what has been said thus far, this study began when I decided to write my own autobiographic narrative which elaborated on significant events not only of my personal life, but also of my professional experiences as a teacher educator. As my study materialized, drawing from both my passion for narratives and the need students have to be able to analyze them, I eventually created a framework whose purpose was just that. At the heart of this framework is Barton and Levstik's (2004) definition of narrative highlighting the historiographical, philosophical, and social cultural components they possess. These frames are significant because students can seemingly use them to organize, deconstruct, and synthesize analysis from historical narratives — or, at least, this study hopes to shed light on whether this occurs or not.

As I said previously, narratives have always colored my own reality. Being the first generation born to exiled Cuban parents in Miami, I came to understand that family narratives have played a substantial role in my life. It is my belief that narratives offer a powerful mechanism for understanding Cuban American relations because they help readers organize information and connect with experiences through common themes of humanity (Czarniawska, 2004, p. 7). Moreover, narratives give voice to people, places, and events that perhaps historical textbooks and state-mandated curricula silence or just 
do not address at all (Hilburn, \& Fitchett, 2012, pp. 35-65). Since childhood, I can remember family members recounting a multitude of personal stories that not only made them relive their colorful past in Cuba, but also asserted that I understood the sense of continuity family narratives offer. They were teaching me about the importance of my own family's history through these stories. Nevertheless, my family gave me, through these stories, the ability to analyze the past, so as to make sense of my present reality, and in turn, hopefully create a better future for myself.

For me, concretely, these narratives taught me how to be Cuban. Some stories discussed Cuban history and the philosophical underpinning that entailed; others dealt with societal issues, culture, traditional food, and holidays. Most importantly, the remainder of the stories painted a family portrait. These personal narratives were helpful to me because I technically was not born in Cuba. Because of that fact, my mother would say that I needed these stories even more to help me understand the proper comportment of a true Cuban. Still, the narratives that evolved from my family's history helped me understand the purpose of my own existence in relation to that of my ancestry, as well as my overall place within Cuban-American society. Consequently, I was mesmerized and hooked on the unending barrage of family stories. They were inescapable. I was immersed by narratives without actually being aware of them.

At this point, one might ask a pertinent question: What is the purpose of all this storytelling? Well, the answer was rather simple: to give all those who read these humble words a window into my own personal reality — or perhaps, to offer windows for students to examine their own personal realities. William Pinar's (1975) approach to education known as the Method of Currere stipulated that "one must regress and there find the 
past...intact...entered and lived in...thus the object of this part of the method is to observe oneself or others functioning, in the past" (pp. 8-9). Thus, I have chronicled my family's history through autobiographical writing encompassing aspects dealing with psychological reality. Personal stories, such as autobiographies, convey experiential discourses that students can use to understand history better. Writing and analyzing their own narratives was an activity I asked my own students to perform in the classes I have taught. Moreover, they are a means of understanding social-cultural phenomena. O'Reilly (2009) articulated that "personal accounts of one's own experience convey experiential and autobiographical understanding of a phenomenon...in some cases the self is the only data source...and the story can be used to illuminate sociological themes and illustrate discourses" (p. 171).

I wrote my narrative after seriously reflecting on my lived experiences. Moreover, I realized that these personal and professional experiences aligned with, what will be discussed primarily in this study: the Historical, Philosophical, Societal and a Takeaway Framework (HPST). HPST is an organizational framework that utilized the H, P, S, and T frames to possibly analyze historical narratives. Specifically, my narrative represents or was exemplary of the above mentioned frames. Additionally, the following text could serve as an example of kinds of readings that can be analyzed by the use of HPST.

\section{My Story: Exile, Miami, and Social Studies}

In this story, two frames of the framework are highlighted, namely the Historical (H) and Philosophical (P). H seeks to identify the historical event or phenomena itself. It is important to mention that the identification of the historical event also extends to 
pinpointing the geographic location(s) where this history occurred. Moreover, this perspective becomes significant when linked to real world stories. The second element of this frame was the evaluation of the timeline associated with the history in question. Additionally, the changes, if any, of this event or phenomena over time were taken into account. P is made up of the beliefs associated with historical event or occurrence, schools of thought, public opinion, economic, the psychological paradigm or ramification this belief incurred, and the a distinctive doctrine, cause, theory or "-isms" of the period.

\section{First Wave of Cuban Immigration}

In 1959, numerous tragic political events transpired in Cuba, which ultimately changed the course of my life forever. Communism and its authoritarian grip lead by Fidel Castro overtook the island and effectively began a Cuban Diaspora that catapulted thousands of immigrants away from their island homeland to distant shores. Cubans embarked on a transformative quest for liberty because the freedom they once knew was unfortunately interrupted. Among the many were my parents and a troop of colorful relatives, who unequivocally influenced my existence to what it is today.

For Cubans leaving the island, this departure was a traumatic experience that left deep emotional scars. Lisandro Pérez (2001) in his piece "Growing Up in Cuban Miami" offered a chronology of the Cuban immigration process. According to Pérez, the first waves of Cubans who departed the island were those individuals pertaining socially to the upper and middle classes. He resultantly baptized this first generation of the Cuban exodus as Golden. Initially, Cubans believed that the fleeing of Flugencio Batista and the subsequent coup implemented by Castro was a transient political condition. 
Unfortunately, the reality was that it was not. This exodus was to be absolutely permanent: there was definitely no turning back. This migratory wave ushered my parents and a group of colorful relatives out of Cuba forever.

My family left everything behind. And by everything, I do not only mean material wealth or physical possessions, for it was truly much more than that. What was completely stripped from my family, and countless of other Cuban families, was part of their cultural identity by way of the emotional and spiritual connection Cubans have to actual Cuban soil. It was a metaphysical bond to the motherland that was severed and lost. My father's Cuba does not exist anymore: a fleeting, sepia-colored menagerie etched into an old man's memory. I was ten years old when my father shared with me, for the first time, the story of his departure from Cuba in the early 1960s.

\section{My Father's Story}

The following two stories below are most indicative of evidence of the Societal (S) frame. Within this frame people were chronicled and examined. Also, the underpinnings and nuances of culture were explored, such as food, fun or entertainment, religion, tradition celebrations, morals, and values (Perez, 2001, p. 3). People are actors, and history is their stage.

My father recalled arriving to Rancho Boyeros Airport in the early afternoon under a torrential downpour on March 10, 1960. Unfortunately, he did not realize while waiting to exit the cab that this day was the last day he would ever see Cuba again. Unceremoniously, he paid the cab driver, collected his luggage, and made a run for the airport entrance. Once inside the airport terminal, my father tried to focus so as to locate 
his departure gate, but his eyes wondered and were distracted by the violent tapping cyclonic rain and gusty winds made on the airport's plate glass windows. My father said that it was as if Cuba mourned his departure, crying uncontrollably.

Finally he located his departure gate and took a seat in the waiting area. Prior to boarding the plane, the miliciano, or more specifically the Castro operative who served as the customs official, took his Cuban passport and stamped Nulo on it. The passport was annulled. At that point, my father said he stopped being Cuban. This departure, from the island, marked a seminal event in his life because it ignited the catalyst of absolute change and opened the proverbial migratory doors for the remainder of my family. As he boarded the airplane, he said his life completely changed. Unknown to him at that moment, a total metamorphosis occurred: the spoiled, rich kid playboy, who was educated, suave, always dressed to the nines (commissioning at least 25 new French and Italian suits made a year) was to be replaced by a generic, struggling, cash poor immigrant trying simply to survive. Roughly four hours later, my father arrived at O’Hare Airport in Chicago alone. My mother joined my father in Chicago shortly after his departure from Cuba. While there, mother gave birth to my older brother. Eventually, in the late 60s, the trio settled in Miami, where I was born in 1971.

\section{My Trip to Cuba}

On December 5, 1998, I was able to travel to Cuba for the first time. As I mentioned previously, being the first generation born to Cuban parents automatically categorized me to dwell forever in a social cultural limbo of sorts. I was too American or white acting for my Cuban relatives, but I was seen as a Latino by my white friends. So, 
as one might expect, the idea of this trip was incredibly exciting because it afforded me the chance to connect directly with my Cuban roots. Finally, I was going to visit the elusive Isla that was only 90 miles from American shores. Still, the idea of going there after 27 years of family narrative was surreal to me: Dorothy left Kansas and used a tornado to arrive at Oz. Alice had the rabbit hole to get to Wonderland. And a non-stop service United Airlines flight took me to Havana.

I arrived at José Marti Airport (formally called Rancho Boyeros) in the early afternoon. It was as if Cuba had been waiting so long for my arrival. In gratitude, she sent beaming rays of sunshine and turquoise blue skies to officially welcome me. While on the plane, my mother's sister mentioned that Cuba had a distinct odor — an amalgamation of sugar cane, tobacco, red soil, palm trees, and smog. At that point, it was difficult to fully comprehend the scent my aunt was describing, but as we descended the plane's stairwell and walked out onto the tarmac, she uttered, "Now, take a deep breath. That's Cuba!"

My arrival to Cuba could have been a scene from a John Water's movie. First, I was greeted warmly by a group of Cuban doctors asking how I felt and if I needed any medical attention. They also reminded me that medical treatment was completely free of charge even for those individuals who were tourists to the island. Consequently, these doctors escorted me to a large waiting area. I found it rather surreal to hear boarding calls for domestic flights leaving to other cities such as Camaguey or Matanzas. Large video screens peppered this arrival area, displaying the wonders of Cuba: the beautiful white sand beaches of Varadero and the sultry Havana nights under the stars at the Tropicana 
Nightclub. I was finally in Cuba, with sensory overload, and I had not even left the airport yet.

Second, I was led by another group of airport personnel to what I assumed was to an immigration checkpoint. I waited in queue until told to enter a private cubicle where an immigration officer asked for passports, travel visas, and other documentation. The customs officer was pleasant and only asked me where I was to reside during my stay. Once I had responded to this question appropriately, the officer officially welcomed me to Cuba and asked me to exit his cubicle. Finally, I was approached by yet another airport personnel agent asking how many individuals were in my party and what the estimated monetary value of my luggage was.

I had been forewarned by my travel agent that this was commonplace and that if we did not cooperate, our bags would be indefinitely sequestered. So prior to leaving the US, I figured that roughly $\$ 100$ dollars per bag would suffice. This individual instructed me to pay the aforementioned amount and precede to yet another window labeled impuesto de equipaje (baggage tax). The Cuban government imposed harsh weight limits for baggage of Cuban American tourists visiting the island. To circumvent this mandate, I purchased large duffle bags made from a very light weight material. Duffle bags, referred to as gusanos (worms), were readily available in many Cuban American pharmacies and discount stores throughout Miami. The term gusano has a double entendre as it also was a pejorative used by the Castro dictatorship to describe Cubans leaving the island during the different phases of Cuban immigration. Now, the Cuban American Exile Community in Miami had expropriated the word and empowered a new meaning. 
I witnessed a Cuban immigration officer take the gusanos of a family, who did not want to pay the baggage fee, slash them with a knife and begin removing personal items the Cuban government did not allow into the country. Having learned well from his Commander-in-Chief's example, the customs officer expropriated most of the items in that bag. Luckily, once all fees were paid, my gusano was delivered in a single unhacked piece.

A different customs officer escorted me to the airport exit and explained that if I was waiting for any family members to pick me up, they would be located in the upcoming area just outside of the actual airport. When the exit doors automatically opened, it was as if Moses parted the Red Sea. Seemingly hundreds of people were waiting anxiously to get a glimpse of relatives coming from distant lands. I froze breathless at the sight of this crowd. Within this sea of faces, I saw a woman (who was vaguely familiar) running towards us shouting “iEsos son mis primos! (Those are my cousins)." Her shouting elicited a reaction within me, and I began breathing again. She was immediately stopped and pulled back by military officials guarding the area. This madwoman was a cousin who stilled lived on the island and who I had not met before. As could be expected, this family encounter was completely emotional. I cried. People around me cried. Even the staunch Castro operative serving as a security guard got teary eyed. I was amazed at how I instantly connected with my cousin, who I had only seen in pictures until that moment.

\section{My visit and HPST}


My visit to Cuba was significant because it offered a historical (H), philosophical (P), and socio-cultural (S) experience - concretizing within me a sense of family continuity. This occurred even though technically I broke the vow my family made to never return to Cuba so long as the Castros were still in power. Of course, this was a silent pact, and it was assumed that I would comply. Honestly, this trip was the missing piece to my puzzle and my main goal was to visit all those places that made up the plethora of family stories that were shared with me throughout the years. Additionally, this trip served, within my mind, as closure and reconciliation. Exiled Cubans, like my family, were offering a symbolic gesture of peace to Cubans living on the island.

This last narrative aligned most with the Takeaway $(\mathrm{T})$ frame. Here is where a critical reflection takes place. Weimer (2012) suggested that "critical reflection is highest level of reflection and implies the transformation of a perspective. Many of our actions are governed by a set of beliefs and values that have been almost unconsciously assimilated from our experiences and environment. To undergo a change in perspective requires us to recognize and change these presumptions" Most importantly, T answers the why question.

\section{My Wonderful Teachers}

As time passed and my formal education progressed, I was fortunate to be taught by wonderful teachers. Pinar (1975) stated that the regression portion of his Currere Method was "to observe oneself functioning, in the past...one takes special notice of one's past life-in-schools, with school teachers, books, and other school-related artifacts...observe, record, and include present responses to what is observed" (p. 8). My 
parents decided that I needed a private tutor to aid with homework and other academic endeavors because they were not available to do so. They set their eyes upon Dr. Carmen Urrechaga, a good friend of my mother's, who had owned several schools in Cuba during the 40s and 50s. Affectionately, I called her Tita. Tita was a renaissance woman and well rounded academic: proficient in everything from the humanities, sciences, math, and especially Cuban history. As an eight-year-old boy, I remember learning my first words in French from Tita because she spoke it fluently.

For the tutoring sessions, I needed only to bring a notebook and a number two pencil. She was one of those old school teachers that really did not use textbooks. All Tita needed was to know your grade level. She filled my notebook with age and subject level appropriate exercises — from memory - which I completed during a single session. Then she offered me feedback, and I would make as many needed corrections to ultimately receive a perfect score. I always thought that Tita had beautiful handwriting, and when she scored my work, a 100\% Excellent Job A+ would usually crown the top of page. This revision process entailed working directly with the student and offering him or her feedback as needed to eventually produce an error free product. It was much later, when I started teaching, that I realized how much Tita influenced the revisionary practices within my own classroom.

I always gravitated towards subjects such as Social Studies, History, or the humanities because those offered courses including narratives of some sort. I resonated with these stories and found myself recalling the occurrences of the narrative and using them as study guides in preparation for tests. During my junior year of high school, I took World History from a teacher named Ms. Rodriguez. To me, she was a bastion of 
knowledge, as she interwove historical stories to formalized content lecture. Such mélanges made history real and tangible for me. When I asked her to sign my yearbook at the end of the term, she began the dedication with the following phrasing, "To the shining star of my classroom." Of course, I got an A in her class, but more importantly, this teacher's influence set me toward inquiries regarding narrative.

At the age of 19, my parents decided to send me to Europe. Narratives materialized for me there because I was able to put a face on what I was reading. Previously in preparation for my arrival in France, I had read primary source literature written by the Duc de Saint Simon, who was Louis XIV's court chronicler. When I went to the Château de Versailles for the first time, I was able to follow in the footsteps of Louis XIV just by referring to Saint Simon's writing while at the palace. I felt I was in direct communion with the past. It was there when I decided to return stateside and begin my undergraduate degree in history.

While at the university, of all my history teachers, one by far was the most impressive. Physically, Dr. Peterson was very quiet, mild mannered, and somewhat conventional, but this professor was far from that. He was a powerhouse. I took a course with him on the French Revolution. As usual with history courses, on the first day of class, Peterson handed out the syllabus and explained all the readings and assignments. But something was missing: the course's textbook. I questioned how one could learn about the necessary content on the French Revolution without having an expository textbook detailing the elaborate nuisances. Additionally, he mentioned that whole group direct instruction via content lecture would be would be minimal. Perplexed, I could not fathom how we were to learn anything if our teacher was not going to deposit knowledge 
directly into our brains. Until that point, I had not had a teacher who would not lecture. I did not understand the method to this professor's proverbial madness.

The professor divided our class into three-person cohorts and assigned certain topics to be researched and presented throughout the semester. One of the topics assigned to my group was fashion. He really did not offer much in the way of explanation or guidance on what our presentation should include. All he advised was that the assignment be thorough and include quotes, concepts, and themes expressed in the class readings and any pertinent outside sources.

Because of the cryptic nature of this assignment, I decided to organize the information extracted from readings — as well as videos, films, blogs, and internet resources - into groups according to the major theme. Over the course of several assignments, where I found myself regularly grouping themes, I came to understand that I was able to categorize resources into three interconnected spheres: historical, philosophical, and social. Doing so seemed to foster a more complete analysis of the sources.

In one paper, I decided to use my own personal reflection on the process to be the conclusion of our paper. Peterson loved it. And I witnessed the birth of what eventually was going to be my doctoral thesis. Of course, I did not know until much later that this was happening at the time. Again, drawing from the expertise of my professors, I questioned them on how I could use my personal and professional experiences for my dissertation, in such a way, that the end result would be a classroom application.

Pinar (1975) articulated that he wanted to try to understand the contribution my formal studies make to my understanding of my biography...I can look at my life in a linear way, 
acknowledging its actual multi-dimensional character, but limiting my view to a linear one, to make it more manageable...And if I chart these choices and circumstances on a time line, and then begin to describe (as I remember it now)...I see that there is coherence. Not necessarily logic alone, but a lived one, a felt one. The point of coherence is the biography as it is lived (p.1).

The above mentioned quote was very significant to me because I was doing what Pinar suggested without even knowing it yet or having read him then.

\section{OPERATIONAL DEFINITIONS}

The following are operational definitions that may readers in understanding the scope of this research:

\section{Autobiography}

Lejeune (1975) called "autobiography the most retrospective narrative in prose that someone makes of his own existence when he puts the principle accent upon his life" (p. 4). Smith and Watson (2010) simply called this term, "life writing” (p. 2).

\section{Auto-ethnography}

Ellis, Adams \& Bochner (2011) defined auto-ethnography "as an approach to research and writing that seeks to describe and systematically analyze personal experience in order to understand cultural experience...challenging canonical ways of doing research and representing others and [treating] research as a political, socially-just and socially-conscious act” (p. 1). Reed-Danahay (1997) described auto-ethnographies (which are ethnographies written by a person during his or her lifetime) to "vary in their emphasis on the writing and research process (graphy), culture (ethnos), and self (auto)" (p. 2). Wall (2006) suggested that auto-ethnographies are personal stories extracted from 
the author that gives meaning to social cultural experiences. Anderson (2006) viewed auto-ethnography where the "researcher is a full member of the research group or setting.... and is focused on improving a theoretical understanding of a broader social phenomena" (p. 375).

\section{Case Study}

Stake (1995) articulated that a "case study is the study of the particularity and complexity of a single case, coming to understand its activities within important circumstances" (p. xi). Eckstein (1995) stipulated that the case studies "play in the development of theories concerning phenomena, are useful in all stages of theory building process, and are best conducted for the purpose of devising theories" (p. 119).

\section{CPALMS}

"The Curriculum Planning and Learning Management System (CPALMS) is the State of Florida Department of Education's source for standards information and course descriptions. It provides access to standards-aligned, instructional/educational resources that have been developed specifically for the standards. CPALMS was built primarily for Florida's educators but it is also a resource with users from more than 200 countries around the world" (CPLAMS, 2017, par. 2).

\section{Document Based Questions (DBQ)}

DBQs are questions students must answer at the end of an exam based on the reading of a text. Student responses to these are either in essay or short answer formats. In their responses, students must use literary and/or contextual evidence from the text which is anchored by an overarching essential question or prompt.

\section{End-of-course Exams}


"End-of-course (EOC) assessments are computer-based, criterion-referenced assessments that measure the Florida Standards (FS) or the Next Generation Sunshine State Standards (NGSSS) for specific courses, as outlined in their course descriptions" (fldoe.org, 2019, par. 1).

\section{Ethnography}

O’Reilly (2009) describes ethnography as "a methodology-theory or set of ideaswhich involve direct and sustained contact with human agents, within the context of their daily lives and cultures, watching what happens, listening to what's said, and asking them questions" (p. 3). Moreover, "Narayan (1993) elaborates that every anthropologist carries both a personal and ethnographic self-simultaneously belonging to both personal and professional worlds- and that these worlds should not be seen as distinct entities" (Collins and Gallinat, 2010, p. 45-46).

\section{Hermeneutics}

Crusius (1991) articulated Hermeneutics as "In its most common use, both now and in the past, hermeneutics designates the art or science of text interpretation. Writing preserves discourse over time and allows, especially with the advent of print, wide distribution over space. The inevitable result is some degree of alienation, as texts speak to a situation and an audience that no longer exist" (p.16).

\section{Narratives}

Winter (1985) espoused that narratives are a solution to the problem of "how to translate knowing into telling...to make use of third-person cases and of past tenses, such that the teller of the story stands somehow outside and separate from the action...narrative cannot be equated with the story alone; it is content (story) structured by the telling, for 
the organization of the story is what turns it into narrative" (p. 1). Czarniawska (2004) described narrative texts as a bastion of social life, articulating that individuals try to understand and make sense of their own lived experiences (and or personal reality) by creating biographical, auto-biographical, and ethno-autobiographic narratives. These types of text act as a source for knowledge because they serve as an organizing catalyst for "experiences using a schema that assumes the intentionality of human action" (Czarniawska, 2004, p. 7).

\section{HPST Frames}

\section{Historical (H)}

There are several elements or perspectives that compose and emerge from this frame. First, this frame seeks to identify the historical event or phenomena itself. It is important to mention that the identification of the historical event also extends to pinpointing the geographic location (s) this history occurred. Moreover, this perspective becomes significant when it is linked to true real world stories. The second caveat to this frame was the evaluation of time $\&$ date (s) and timeline associated with the history in question. Additionally, the changes (if any) of this event or phenomena over time were taken into account.

\section{Philosophic (P)}

This frame is made up of the belief (s) associated with historical event or occurrence, school (s) of thought, public opinion, economic, the psychological paradigm or ramification this belief incurred, and the "-isms" of the period.

\section{Societal (S)}


Within this frame people were chronicled and examined. Also, the underpinnings and nuances of culture were explored; such as: food, entertainment, religion, tradition celebrations, morals, and values.

\section{Takeaway $(T)$}

This frame was where students critically reflect what has been learned after using the framework in relation to the lesson content. Weimer (2012) suggested that "critical reflection is highest level of reflection and implies the transformation of a perspective. Many of our actions are governed by a set of beliefs and values that have been almost unconsciously assimilated from our experiences and environment. To undergo a change in perspective requires us to recognize and change these presumptions" It is intended to give them an active and participatory voice or platform for classroom discussions. 


\section{CHAPTER ONE}

TEACHING HISTORY: SPACE FOR NARRATIVE?

\section{Introduction}

The Common Core Initiative (NCSS, 2010) has its roots in two previous

educational reform policies, namely Race to the Top and No Child Left Behind (NCLB).

NCLB developed

under the President George W. Bush-era education law, [which asked] the federal government [to] require states to test, disaggregate and report data on student performance, but allowed states to continue deciding on their own which standards and tests to use" (Bidwell, 2014, para 6).

Additionally, Race to the Top during the Barack Obama's administration

ushered in significant change in our education system, particularly in raising standards and aligning policies and structures to the goal of college and career readiness. Race to the Top has helped drive states nationwide to pursue higher standards, improve teacher effectiveness, use data effectively in the classroom, and adopt new strategies to help struggling schools" (Race to the Top, para 1).

Both of these educational legislations served as a precursor that homogenized curriculum and opened the proverbial classroom door for Common Core to be developed.

Consequently, Common Core legislation (NCSS, 2010) articulated literacy competencies which must be met. Because of this mandate, state and local authorities created standards based on reading material that must be analyzed by students so that a greater understanding of content can be achieved. As a result, teachers were charged with giving students skills, knowledge, and resources to complete this task. Moreover, in light of Common Core, I researched the theoretical underpinnings of my own experiences with personal narrative and how historical narrative serve as a critical organizational teaching 
tool in a social studies classroom setting. The outcome was an idea called the Historical, Philosophic, Societal, and a Takeaway (HPST) Framework.

\section{The Setting}

At the state level, the Florida Core Standards not only organizes Social Studies content from Kindergarten through 12 th grade, but also delineate knowledge and skills students need to acquire. The following standards are examples of this requirement at the secondary level:

- SS.912.W.1.3 Interpret and evaluate primary and secondary sources.

- SS.912.S.5.9 Conduct research and analysis on an issue associated with social structure or social institutions.

- $\quad$ SS.912.H.2.3 Apply various types of critical analysis (contextual, formal, and intuitive criticism) to works in the arts, including the types and use of symbolism within art forms and their philosophical implications.

- $\quad$ SS.912.A.1.2 Utilize a variety of primary and secondary sources to identify author, historical significance, audience, and authenticity to understand a historical period. (CPALMS, 2017).

Document analysis is one of these skills. Historical narratives are generally considered to be either primary or secondary source documents (Colby, 2008). In short, because of Common Core, students would need to acquire skills to analyze historical narratives effectively.

In addition, at the national level, the National Council for the Social Studies (NCSS) established ten themes that organized Social Studies content into distinct areas: 
- Standard 1: Culture \& Cultural Diversity

- Standard 2: Time, Continuity, \& Change

- Standard 3: People, Places, \& Environments

- Standard 4: Individual Development \& Identity

- Standard 5: Individuals, Groups, \& Institutions

- Standard 6: Power, Authority, \& Governance

- Standard 7: Production, Distribution, \& Consumption

- Standard 8: Science, Technology, \& Society

- Standard 9: Global Connections

- Standard 10: Civic Ideals \& Practices (NCSS, 2010).

These standards purportedly assist students in understanding Social Studies content in terms of people, places, and environments, as well as how individuals develop their identities. NCSS, through these themes, articulated that "student experiences will encourage the use of data and apply skills in analyzing human behavior in relation to its cultural environment and the exploration, identification, and analysis of how individuals and groups are alike and how they relate to each other in supportive and collaborative ways" (NCSS, 2010; Ch. 2). Moreover, NCSS suggested that Social Studies content has “(a) meaningfulness via building curriculum networks of knowledge, skills, beliefs, and attitudes that are structured around enduring understandings, essential questions, and learning goals; (b) integration via drawing from history, political science, and sociology to increase the understanding of an event or concept and to provide opportunities for students to conduct inquiry, develop and display data, synthesize findings, and make 
judgments; and (c) activity via developing new understanding through a process of active knowledge construction through interaction in cooperative groups" (p. 12).

Another aspect of overall social studies curriculum is the College, Career, and Civic Life (C3) Framework. This resource, also created by the NCSS, provides the "skills, key concepts, and guides the choice of curricular content necessary for a rigorous social studies program" (p. 6). Individual state leaders collaborated in the four core social studies content areas: civics, economics, geography, and history. The C3 Framework was written by experts in the academic disciplines and social studies education in collaboration with classroom teachers, state social studies education leaders, and representatives of professional organizations (p. 8).

Teachers using historical narratives that align with the required Social Studies content coupled by giving students the skills, resources, beliefs, and attitudes can then develop learning opportunities promoting comprehension, catalyzing synthesis, and establishing higher order thinking. At this point another very pertinent question arises: What does this mean for Social Studies teachers? Moreover, it is important to note that Common Core has not been seen as a panacea by all teachers. Some educators have openly criticized this legislation as flawed and feel that it will lead to more student failure. This past year with the election of Florida Governor Ron DeSantis, Common Core has been evaluated for possible changes (Mahoney, 2019).

\section{Critiques of Common Core}

Finn (2012) listed a series of critical observations that he felt Common Core possessed. He cited that standards are substantively flawed. Finn saw this to be the case, especially with English standards that do not contain enough content material or use literature to its fullest potential. Because of this, he postulated that teachers either 
minimize or fail altogether to address the processes of analysis. Moreover, Finn felt that this legislation would be difficult and expensive to implement and would not make any difference in student achievement. His argument was that these

may cause a politically-unacceptable level of student failure... standards per se do not boost achievement. Of course, standards per se don't carry costs or failure rates, either...And failure rates will worsen only if (a) the new assessments are truly rigorous and (b) schools neglect preparing their pupils to pass them" (Finn, Fordham Institute's Flypaper blog, 2012).

Next, Finn suggested that this "nationalistic" turn which the Common Core Initiative (NCSS, 2010) offered was highly politicized and corrupted by outside interests such as the Gates Foundation, which has allegedly "bankrolled much of this work" (Finn, Fordham Institute's Flypaper blog, 2012). Ultimately, he said that this legislation would turn the American Education System into a federally regulated and coercive entity.

\section{Problem statement}

Public school Social Studies courses are usually products of state and national standards, as they must comply with legislated regulation. The State of Florida adopted 99 Common Core Standards referred generally as Florida Core Standards (CPALMS, 2017). The "Curriculum Planning and Learning Management System (CPALMS) website is the State of Florida's official source for standards information and course descriptions" (CPALMS, 2017). Additionally, the standards included in CPALMS delineate what knowledge and skills students in Florida need to acquire.

As mentioned earlier, NCSS has issued ten standards dedicated to the area of Social Studies. "These thematic standards are based on the NCSS document Expectations of Excellence: Curriculum Standards for Social Studies (1994), which describes NCSS 
expectations of what pre-K-12 learners should know and be able to do" (p. 17). The content extracted from these standards is usually accompanied by a series of traditional textbook-based classroom lectures given by the teacher, as well as a battery of in-house or at-home activities performed by students (Bruner, 2002). Nokes (2013) reminded us that "in spite of the efforts of social studies teachers, traditional instruction, consisting of lectures, videos, and textbook readings, does not yield significant long term learning for most students...this historical content knowledge that students passively receive will be rarely used and is quickly forgotten" (p. 8). Indeed, content lectures can be long, monotonous, and filled with complicated and difficult facts, leading to a classroom where students are not focused on learning processes (Nokes, 2013). Fitchett and Heafner (2012) stipulated that "by encouraging the dismantling of social studies, federal legislators have been complicit in trivializing content such as civic and economic literacy, historical thinking, and geographic understanding, thus discouraging critical inquiry" (p. 117). Zhou and Hoge (2010) stated that "most children said that they did not like Social Studies because it is boring and useless, it's reading the textbook, and it doesn't apply" (p. 218).

The actual problem for students may lie with the Common Core State Standards Initiative (NCSS, 2010) itself, which delineated literacy competencies (or standards in the strand) which must be met. These standards in the strand are based on reading material to be analyzed by students so that a greater understanding of content can be achieved. Moreover, an anthology of readings that should augment, enrich, and solidify the courses content are often unassigned (CPALMS, 2017). Unfortunately, as a result of a multitude of issues - chief among them the timing associated with the successful completion of 
standardized tests - teachers do not really expect a thorough reading or full

comprehension of these texts by students (Fitchett \& Heafner, 2012).

\section{Teachers, Students, and Social Studies textbooks}

There were several characters that played essential roles in this research. Chief among them were students and teachers. As discussed above, Common Core legislation espoused literacy competencies (or standards in the strand) which must be met by both teachers and their students. Textbooks are crucial in understanding the dynamics underlying Social Studies. Traditionally, the use of Social Studies textbooks is an essential part of Social Studies teaching. Bruner (1990)_delineated the following:

movement has resulted in state standards for United States and World History courses which are quite content specific, requiring students to develop higherorder understanding based on a foundation of factual knowledge. Textbooks are an important source for that content, moreover, some traditional classroom techniques (such as the usage of the said text) are also important... and a significant amount of teaching time should be highly structured, teacher directed, and make use of a good textbook (p. 1).

In an effort to recognize the degree to which standards play roles in textbook composition, I conducted a precursory review of several secondary level Social Studies textbooks. This informal review consisted of examining the textbook, identifying (a) how historical narrative was portrayed in the text, (b) whether the textbook unpacked skills students needed to analyze narratives, and (c) whether teachers were offered any analytic tools and or resources that could be passed on to students to improve overall quality of their teaching method. I found that while historical narrative was utilized, its use and application seemed minimal. Higher order essential questions were provided, but they apparently were accompanied by a limited number of excerpts from historical texts. 
Often, these excerpts were reduced to a one- or two-line quote from the selected piece. No organizational tools or other resources were offered for document analysis.

Would Pinar (2012) be surprised by such a conclusion? He reminds us that "we teachers are always, to some extent, conceived by others, by the expectations and fantasies of our students and the demands of parents, administrators, policymakers, and politicians" (p. 39). As mentioned previously, national, state, and local authorities often pass legislation that regulate teachers' behavior within their classrooms, curtailing autonomy and ultimately imposing more standardization. More pointedly, Pinar (2012) stated that "because standardized tests measure nothing meaningful, they represent a perverse form of accountability" (p. 31). He suggested that teachers adopt a separate but connected approach. "This permits us to enter the work world larger, more complex, than the roles prescribed for us, making less likely that we will collapse upon the social surface of our profession" (Pinar, 2012, p. 39). Additionally, Pinar articulated that the field of education is a subjectively informed intellectual undertaking. "Most understand that the performance of their professional obligations as scholars and teachers requires us to retain the academic - that is, the intellectual-freedom to choose those texts and topics we deem, in our professional judgment, most appropriate" (Pinar, 2012, p. 40).

In sum, two opposing attitudes arise: the positive notions of appropriately applied standards versus the political positionalities of the policy makers that directly affect such application and the students and teachers who must live them. At the heart of this dissonance then is how teachers and students make sense of the tasks confronting them. Do they simply just fight through the monotony that Nokes (2013) describes? 
A possible answer to this question would entail challenging and encouraging Social Studies teachers to find innovative ways to meet these governmental demands. Moreover, teacher would give their students organizational tools and resources that tap into the skills needed to accomplish the aforementioned demands, as suggested by the NCSS standard itself: "Student experiences will encourage increasingly abstract thought as they use data and apply skills in analyzing human behavior in relation to their physical and cultural environment" (NCSS, 2010, Ch. 2). This study examines the role that a particular organizational tool may play in helping students and teachers meet state requirements while promoting clear learning.

With these caveats in mind, one may then look toward narratives. Stories are unquestionably an integral part of Social Studies classes. Lindquist (2010) enumerated several reasons why educators teach with historical narrative, namely because "it piques kids' curiosity, hammers home everyday details, puts people back into history, presents the complexity of issues in an interesting and engaging way, and connects Social Studies learning to the rest of our school day" (pp. 1-2). Moreover, historical narratives are full of enriching elements that bring Social Studies alive in the eyes of students (Czarniawska, 2004). These texts give voice to people, places, and events that are often omitted or marginalized. Bogdan and Biklen (1998) articulated that the voices of historical narratives are "empowering people to be heard who might otherwise remain silent" (p. 204).

\section{Purpose of the Study}


The purpose of this research is multifaceted. O'Reilly (2009) suggested that "ethnographies are constructed by human beings who make choices about what to research, interpret what they see and hear, decide what to write and how, and that they do all this in the context of their own personal biographies and often ensconced in scientific and disciplinary environments" (p. 189). With respect to addressing the analysis of historical narrative, I followed O'Reilly, as well as Pinar (1975), who reflected

I take myself and my existential experience as a data source. The method of data generation is the psycho-analytical technique of free association (p. 4).

As a starting point, I offered an account of my own autobiographical narrative, chronicling through my attempt at ethnographic writing and infused (hopefully) with scholarly literature as needed. Consequently, this personal narrative was coupled with my professional experiences within the Social Studies field.

With these ideas in mind, I proposed a framework for document analysis in a Social Studies classroom. Additionally, this study was to explore the use of the HPST Framework for analyzing narratives and its complexities beyond the textbook. The intent of the framework was to help the participant's students analyze the interaction of the author, the text, and the reader. The research was geared to see to what degree can the participant's students might draw out historical, philosophic, and socio-cultural frames reflected as complicated conversations. In particular, I was interested in examining how the participant's students' portray marginalized groups within a context of world history and how these roles changed after the participant's students used the HPST framework to analyze narrative passages. 


\section{Research questions}

The following were the research questions driving this research study:

1. How does a Social Studies teacher use the HPST Framework?

2. What role can narrative play for a Social Studies teacher?

3. To what extent has the use of the HPST changed a teacher's thinking about curriculum and or teaching?

\section{Possible Uses}

This research project was established because literature suggested that an HPST approach might assist in analyzing historical texts in the following fashions:

1. helped extract content knowledge

2. created higher order connection making,

3. was used as a platform for student dialogue,

4. was utilized as a deliverable form of student assessment.

\section{Significance}

The HPST framework was put forward in this research as a possible contribution to the literature by prioritizing narratives. HPST takes existing classroom discourse such as discussion about philosophy, politics, and society and power and cognitively arranges it in two levels for students to engage with the text and the author followed by an analytical layer to enhance comprehension and critical thinking. The HPST was researched as it such an approach might expand the arsenal of tools available to educators. 


\section{Assumptions}

The following instances are possible assumption of this study:

1) students' experiential knowledge yields stories;

2) narratives themselves possess historical, philosophic and societal components;

3) the experiences of local South Florida/Miami students are not necessarily aligned to those experiences presumed by standards authors; and

4) the school used in this study had access to all workshop implementation materials and the means to not only present these in class, but also had access to funds to photocopy them.

\section{Possible Benefits}

The anticipated benefits of this study were categorized in several fronts. First, students may be able to use this framework to acquire necessary skills for analyzing historical narratives. This framework has the potential to create a deeper understanding of historical texts for both instructors and their students. Moreover, this study could engage students in the learning of Social Studies and foster higher order thinking within that discipline. Second, my research could enrich teacher educators' and future teachers' range of strategies for teaching Social Studies. Teachers and students using this tool may ultimately be co-creators of curricula, stimulating enhanced interest for both teachers and students while acquiring content knowledge needed. Lastly, other researchers may be able to formulate other analytical tools based on this research that can be used for the betterment of the field. 


\section{Historical, Philosophical, Societal and a Takeaway Framework}

School administrators need to have students comply with educational policies, coupled with a teacher's use of historical narrative in a Social Studies classroom, can provide space for a solution for this problem. In this dissertation, one possible solution, involving narratives, is examined, namely a form of document analysis called, the Historical, Philosophic, Societal, and a Takeaway (HPST) Framework. In a nutshell, this research explored how a Social Studies teacher utilized this framework in her classroom in order to comply with mandates of the Common Core State Standards Initiative (NCSS, 2010).

The HPST Framework outlines a process whereby students engage in document analysis of complex or controversial issues. Through this framework, information is organized cognitively, allowing for complicated explanations to occur, ultimately culminating with students offering a personal takeaway. This framework works on the assumption that narratives possess historical, philosophical, and socio-cultural components. When students apply this framework to class readings, they should be able to operate among standards-based curricular requirements, including the extracting of content knowledge, engaging in higher-order thinking, and discussing implicit and explicit socio-cultural aspects within a text. Each of these aspects should create an individual's personal "takeaway" and serve as assessment of student learning. 


\section{CHAPTER TWO \\ REVIEW OF LITERATURE}

\section{Introduction}

Narrative analysis can be possibly viewed as a polemic topic fueled by the politics behind Social Studies education in academia today. The first part of this discussion will define narrative by articulating its nuances and intricacies. Additionally, discourses will be offered as to how narrative is portrayed in academic literature. Narrative will then be articulated in terms of its use by Social Studies teachers. The effects on students with respect to implementing narrative will be elaborated upon, and the analytic skills needed to accomplish this will be unpacked. Most specifically, a contemplation of hermeneutics, the art or science of text interpretation, will be highlighted to include critiques of this theoretical paradigm (Crusius, 1991). Finally, the conceptual and background of HPST Framework will be showcased and situated in literature.

\section{Conceptual Framework:}

\section{Hermeneutical justification for HPST Framework}

\section{HPST Overview}

Horsdal (2012) reminds us that "narratives are both created and understood from cultural, social, and historical perspectives" (p. 30). Therefore, based on Horsdal's definition of narrative, it is plausible to deconstruct these perspectives and consequently 
use them as a bridge for document analysis. This research is based on a composition of several key elements, as displayed within Figure 1:

Figure 1. The Historical, Philosophic, Societal, and a Takeaway (HPST)

\section{Conceptual Framework}
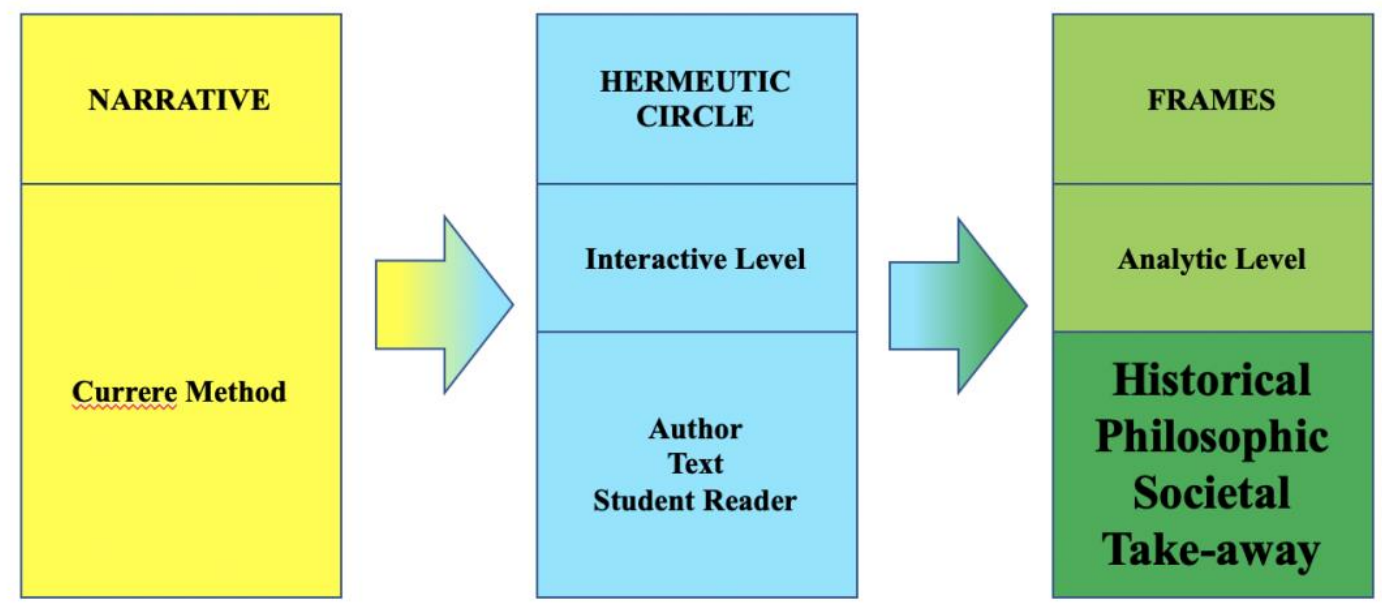

Moreover, the following outline further explained HPST's Conceptual Framework:

1. Narrative.

a. Method of Currere.

2. Hermeneutics

b. HPST Frames.

1. the interactive level - known as author, text, student reader; and

2. the analytic level-known otherwise as historical, philosophical, societal, and take-away perspectives. 


\section{Narrative}

The elusive term narrative has been defined by many literary and educational theorists. These definitions have inspired several important conversations. Roland Barthes (1972) defined narrative to be

numberless expressed through various forms such as written or spoken language, images, and gestures. They are present in every age, place, or society. Nowhere are there a people without them. Moreover, these stories are international, transhistorical, and trans-cultural: it is simply like life itself (pp. 302-306).

Moreover, Barton and Levstik (2004), using a socio-cultural perspective of history, use the term narrative to encompass any form of historical story following marked patterns of causal events, that are chronological, and that include a setting or schema, characters, agent, a goal, and an instrument. As such, narratives predominantly encompass aspects dealing with psychological reality and of historiography by way of people, places, and epochs.

According to Currie (2010), students resonate with narratives, positing that they be incorporated into the classroom to motivate and facilitate historical understanding. $\mathrm{He}$ reminds us that "narratives are the product of agency; they are the means by which someone communicates a story to someone else" (p. 1). Colby (2008) indicated that

historical narratives possess an untapped, multi-linear potential through the interweaving of human action, motives, social constructs, group dynamics, disruptions, and deviations. The multiple layers of the historical narrative facilitate analytical thinking through the principle of repetition - patterns of repeated experiences... and the time that is shared by society; thus, public time establishes a sense of community between the reader and the agents described (pp. 63-64).

Bruner (1991) defined narrative as an organizing tool for "our experience and memory of human happenings...transmitted culturally and constrained by each individual's level of mastery...achieving verisimilitude...and are a version of reality 
whose acceptability is governed by convention and necessity rather than empirical verification and logical requiredness" (p. 4). Here, Bruner categorized narratives as a vehicle which facilitated thought and discussion. Barrios (1989) saw narratives as transformative because these texts answered the question: How am I involved? She also warns us that the author's voice is paramount and should offer and elicit a metamorphosing discourse; however, Barrios reminds us that these important discussions about change are often omitted or silenced by institutions or individuals not in agreement.

Richardson (2000) suggested that personal narratives possess several primal themes, namely

- substantive contribution: whether the piece contributes to our understanding of social life;

- reflexivity: how the author came to write this text and became both a producer and a product of it;

- overall impact: whether the text affects the reader emotionally or intellectually and whether it generates new questions or moves the reader to action; and

- expression of reality: whether this text embodies a fleshed out sense of lived experiences (pp. 15-16).

The points made by Richardson were valid assumptions. Tapping into their own experiences is a valuable skill students are required to develop for overall academic success. Moreover, O’Reilly (2009) postulated students' narratives are "personal accounts of their own experiences (sometimes alongside those of others) [forwarded] in order to convey their experiential and autobiographical understanding of a phenomena 
[sic]" (p. 171). With this definition, another layer was unpacked. O'Reilly, like Richardson, saw narrative as having experiential elements. Therefore, the harnessing of this experiential knowledge can lead teachers to an engaged classroom environment filled with students creating significant and meaningful comprehension through their use of narrative. White (1984) stated that narrative was "a form of discourse which may be used for the representation of an historical event depending on whether the primary aim is to describe a situation, analyze a historical process, and or tell a story" (p. 2). The acts of analyzing and eventually synthesizing interconnected parts or nuances of narrative are important skills students must develop and master. The combination of analysis and synthesis resonates with the literacy competencies espoused by the Common Core Initiative (NCSS, 2010).

Vygotsky's Socio-cultural Theory (1997) suggested that narratives possess social, cultural, and historic components that when harnessed properly can directly foster comprehension. The term comprehend can be construed to mean the understanding of a difficult or complex subject. Interpretation can be defined as the action of explaining the meaning of something. A mental representation is a cognitive theoretical construct which identifies processes, meaningfully translates information, and stores it in long term memory. Vygotsky suggested that these three terms must be understood in order to extrapolate how narratives can be used as a pedagogical tool to enhance students' overall comprehension of Social Studies content. Students are asked to create a mental schema from the usage of an interpretative tool that ultimately will result in their comprehension of a historical narrative. Moules (2002) reminds us that "for Heidegger, experience was already out in the world; experience is not a thing, but a movement in the 
world...understanding is deeply entrenched in the profound ontological makeup of Da-sein: care, existence, temporality...or being-in-the-world, as a thereness of being that is distinguished by the capacity for self-reflection concerning its own existence (Heidegger, 1996, p. 7). In sum, the tacit or implied nature of narrative, which includes comprehension and interpretation, most likely enhanced when operationalized, expressed, and defined in reflective ways, seemingly provides a foundation upon which Social Studies topics may connect to students' lives.

\section{Teacher's use of narrative}

Historical narrative reflects an individual's social environment, usually chronicling day-to-day occurrences which articulate experiential knowledge. Vygotsky's Socio-Cultural Theory postulated that human development can only occur when individuals directly interact with the social, cultural, and historical factors of their surrounding environment. Moreover, "Vygotsky considered a social environment critical for learning and thought that social interactions transformed learning experiences" (Schunk, 2012, p. 242). Therefore, learning and development cannot be dissociated from this interpersonal context, as articles by Martell and Hashimoto (2011), Elias (2010), Bryski (2009), and Baumann and Bergeron (1993) have demonstrated. Moreover, these articles had one common overarching theme: the utilization of narrative in the learning environment to promote comprehension of historical content being taught.

Martell, Hashimoto, and Elias (2011) utilized content-specific reading packets or units to promote comprehension. Their study was set within the context of $11_{\text {th }}$ grade U.S. History classes. The authors asked: Did their reading packets have a positive impact 
on the students learning and understanding of history? The researchers utilized a ten-item Likert style survey and personal interviews as data gathering tools. Meanwhile, Elias (2010) specifically stated that the mission of her research was to use narrative as a curricular tool for teaching U.S. history. Additionally, the author explored how this use of narrative affected students' comprehension of history. Elias employed a literature-based Social Studies unit called Bloodlines. The main component of Bloodlines was the reading of historic fiction. Both of these studies concluded that the reading packets or units improved students' overall ability to recall information, complete homework, synthesizing students' deep emotional connection to historic subjects, as well as a measurable understanding of the periods being studied.

Story mapping — an educational strategy using graphic organizers to identify important aspects of the narrative to promote comprehension-was employed by Bryski (2009) and Baumann and Bergeron (1993). Bryski’s research focused on disabled students who shared a common deficit in reading and comprehension. Three male students participated in a self-contained eighth grade U.S. History classroom. The content studied was the U.S. Civil War. Bryski found that using these graphic organizers helped students remember content, thereby improving their comprehension of the readings. Similarly, Baumann and Bergeron employed multi-text instruction that included the reading of the Emancipation Proclamation, a story map, and poems. They investigated the effects of story mapping as a means to promote first-grade students' comprehension of central story elements in children's literature. In this study, 74 children in four first-grade classrooms participated and were randomly assigned to several test groups. In group one, students constructed story maps for children's literature they had read. Group two did the 
same as group one but used story maps to compose additional stories. Group three utilized standard direct instruction and was the control group. Baumann and Bergeron used qualitative data, in the form of student interviews, to support their findings. Both of these research studies supported the belief that the multi-text instructional strategy helped students with learning disabilities increase their reading comprehension. Notably, they showed that story mapping was an effective instructional strategy for promoting the ability to identify central narrative elements in authentic children's literature. Therefore, Social Studies teachers can use historical narrative and organizational schemas as a platform for highlighting content.

\section{Method of Currere}

In 1975, at the annual meeting of the American Educational Research Association, William Pinar first presented his original work entailed, the Method of Currere. Pinar took himself and his own formal educational experiences as the data source. To this he applied free association, the mental process by which one word or image may spontaneously suggest another without any apparent connection, and the result was a linear and multi-dimensional biography (Pinar, 1975). This method is composed of four steps: regressive, progressive, analytical, and synthetical.

In the regressive phase, a foretelling and recording of future educational experiences occurs. Pinar postulated that "one return to the past, to capture it, as it hovers over the present" (p. 6). He suggested that a person's present was divided into two elements: conceptual and subjective. The pairing of these elements determines future outcomes. "My hypothesis is that to the extent one dwells in the conceptual present, and 
the subjective present, is the extent one dwells in the past...not just the literal past...but the biographical past... which is often ignored, but present" (p. 7). The progressive step describes an individual's present educational experiences. During this phase "we look the other way... using Sartre's language... at what is not yet the case, what is not yet present...the future is the present in the same sense that the past is the present" (p. 9). In the analytical step, the existential meaning of present was unpacked. Pinar stated that this section "describes the biographic present, exclusive of the past and future, but inclusive of responses to them" (p. 11). The synthetical step spoke about the bringing together of the past and the present that might affect the future.

Look at oneself concretely, as if in a mirror. Who is that? What is the contribution of my scholarly and professional work to my present? Do one's intellectual interests biographically permit ontological movement or increased conceptual sophistication and refinement, to deeper knowledge and understanding" (p. 12).

The Currere Method described how Pinar coupled the experiences acquired through his formal education and applied them to produce a method to can be seen to reconceptualized the meaning of curriculum. Drawing upon Pinar's work, I also infused my personal narrative with elements of Currere.

\section{Hermeneutics}

Dederen (1974) described Hermeneutics as

the science of interpreting literary documents. We use this term when attempting to understand the writings of secular writers such as Homer, Plato, and Shakespeare as Hermeneutical rules help us understand what writers meant by what they said (p. 1-2).

Boyles (1994) stated that "Hermeneutics considers questions of methodology, understanding, and interpretation and is usually defined one of two ways: as the study of 
the principles of explanation (methodology) or the study of meaning

(interpretation/understanding)" (p. 2). Gadamer (1975) further described Hermeneutics as

the understanding and the interpretation of texts and added that the

hermeneutic phenomenon is not concerned with a method of understanding by means of texts being subjected to scientific investigation like all other objects of experience. It is not concerned primarily with amassing verified knowledge, such as would satisfy the methodological ideal of science-yet it too is concerned with knowledge and with truth. [It is concerned with] understanding the tradition of how texts are understood, insights are acquired and truths known" (p. 19).

Moules (2002) described this paradigm as interpretive inquiry which entailed

living a tradition of interpretation that has a rich legacy of theory, philosophy, and practice that leads to deeper understandings, and practices. Bingham (2010) articulated that Hermeneutics was more than just simple interpretation, but human understanding.

Martin Heidegger (1927) gave Hermeneutics an ontological turn. Simply put, he categorized interpretation as the nature of being, becoming, and existing in a given reality: "Understanding is a mode of being...something we consciously do or fail to do, but something we are...interpretation makes things, objects, the fabric of the world, appear as something” (Ramberg \& Gjesdal, 2005, para. 3-10).

To recap, Hermeneutical theory can be viewed as the force which can guide the interpretative process. Therefore, interpretation is the first essential aspect of this paradigm. Moreover, interpretation tries to answer the why questions.

During the Greco-Roman period, Hermeneutics was closely associated with Greek poetry and learning. "According to Plato...not only did poetry require interpretation, but poets themselves acted as interpreters (or Hermes of the gods)...providing educational value" (p. 2). Aristotle's De interpretatione, mirroring 
Plato, outlined what constituted knowledge, truth, and value arguing that these should be viewed and understood in a certain way.

Later, Philo of Alexandria and the Stoics used this Aristotelian discourse to analyze myths. During the Middle Ages, thinkers such as Augustine and Thomas Aquinas dealt with the universality claims of Hermeneutics. Simply put, they were the first to establish a connection between language, interpretation, and the individual. Moreover, during this period, the term exegesis took center stage. Exegesis, which is the actual process of critically interpreting a text to extract its meaning, became part and parcel to Hermeneutics. Frances Young (1987) cited that "the art of exegesis was taught as pupils read texts with their masters...spiritual exegetes sought meaning and truth in their texts just like literary exegetes did in classical texts" (p. 3). Exegesis analyzes the grammatical and contextual elements of narrative. Therefore, it can be construed to be praxis, practical, or the operational aspect of Hermeneutics. Martin Luther, in Sola Scriptura, not only questioned the legitimacy of biblical texts, but also the authority of the institution writing them.

By 1670, Benedict de Spinoza's Tractatus Theologico-Politicus reminded that "the understanding of the parts [of a text] hinges on our understanding of a larger whole...this hermeneutic circle, the movement back and forth between the parts and the whole of a text, is an important hermeneutical theme" (Ramberg \& Gjesdal, 2005, para.310). With this, Spinoza established the second essential aspect of Hermeneutics: the Hermeneutic Circle. This interpretative process marks or indicates the interaction between interconnected forces, namely a text, its author, and a reader. (Please see Figure 2, Howe's 2011 representation of this relationship). Mantzavinos (2009) categorized the 
"hermeneutic circle as an empirical phenomenon that arises when one does not manage to understand a linguistic expression (or other signs)...It is then necessary to create interpretative hypotheses, and it is during this activity that one gets confronted with the problem of the meaningful whole and its elements" (p. 299-311). Moreover, Heidegger (1927) determined that this "circle belongs to the structure of meaning... a phenomenon [which] is rooted in the existential constitution of Dasein — that is, in an understanding which interprets" (p. 195). Therefore, if a text is written, then it will have an author and possibly a reader. A text, reader, and author can be conceptualized as circular forces that can affect each other. Moreover, these forces can be used as a vehicle for interpretation.

Figure 2. Howe's (2011) representation of the Hermeneutic Circle based on Osborne (1991).

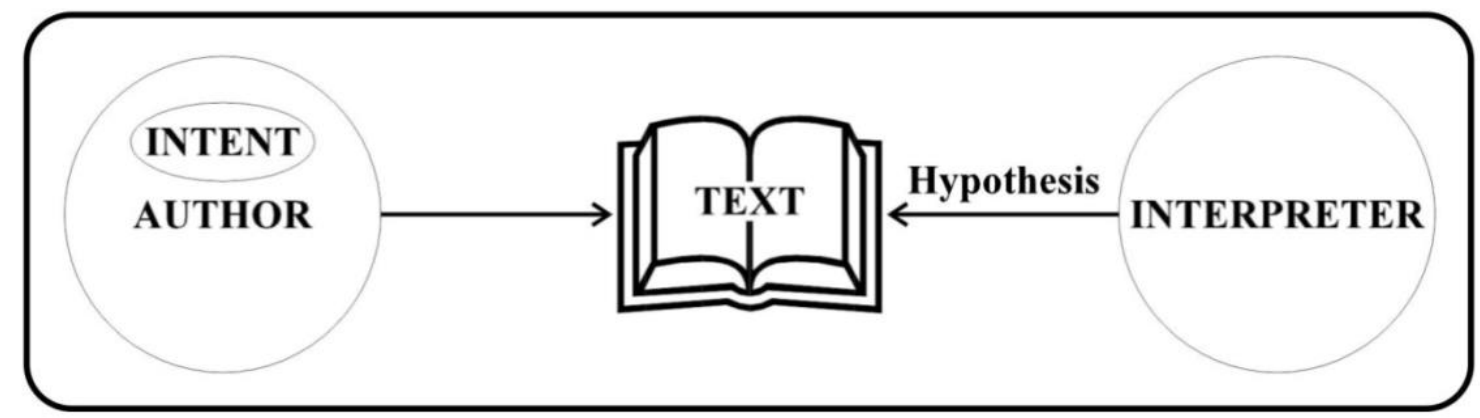

William Dilthey (1982) classified the interpretation offered by use of the Hermeneutic Circle to possess a nexus of meaning. This "nexus of meaning [is] connected with a specific linguistic expression or a specific text [and] is construed by the author against the background of his goals, beliefs, and other mental states while interacting with his natural and social environment: such a construal of meaning is a 
complex process and involves both the conscious and unconscious use of symbols" (p. 301-316). Moreover, the author's background, beliefs, and bias will affect the writing of the text. The reader should take these into consideration to fully comprehend the piece being read.

Scienza Nuova written by Giambattista Vico in 1752 elaborated on how Hermeneutics had a historical (or historiographical) dimension. He affirmed that the historian was immersed in history and could not be separate from it. He writes:

The historian does not encounter a field of idealized subject-independent objects, but investigates a world that is, fundamentally, her own. Appealing to tact and common sense, it is oriented towards who we are, living, as we do, within a given historical context of practice and understanding" (Ramberg \& Gjesdal, 2005, para. 3-10).

Moreover, Wolff (2005) concurred with Vico, stating that "historical writing should be judged according to [its] completeness, truthfulness, and sincerity because once history passes, it is impossible to have access to historical truth" (p. 7). Droysen (2005) also aligned with these theorists, assuring that the nature of interpretation was historiographical. "Yet in understanding history the researcher also understands something that is ultimately her own, the outcome of human freedom, goals, and desires... history is intelligible and meaningful — that the study of it permits a kind of objectivity that is different from but still comparable to the one at stake in the natural sciences" (Ramberg \& Gjesdal, 2005, para. 3-10). Finally, Von Ranke (2005) understood history to be an ongoing activity that can change or morph over time.

Chladenius (2005) conceptualized Hermeneutics as possessing philosophical aspects. He formulated a philosophical theory of understanding which distinguished hermeneutics from logic, but also elaborates a typology of points of view. Chladenius 
wrote that "the focus on the different points of view enables an explanation [on] how variations in our perception of phenomena and or problems may cause difficulties in our understanding of other people's texts and statements" (Ramberg \& Gjesdal, 2005, para. 310). Scholars equated Chladenius's theory to our modern definition of the term epistemology. Simply put, this can be seen as justification for a certain belief. This concept applied to historical narrative can be construed to mean the philosophical paradigm behind the history occurring in the piece.

During the mid 1800s, Ast (2005) theorized that there was a societal component to Hermeneutical interpretation. He articulated there was a social dimension to Hermeneutics because people brought forth the spirit behind their history. This view "extends the scope of the hermeneutic circle... to now include the text's relationship to historical tradition and culture at large" (Ramberg \& Gjesdal, 2005, para. 3-10). Resonating with Ast, von Ranke (2005) felt that proper interpretation of historical narrative had to include cultural understandings. He articulated that "doing historical work means actively participating in the cultural tradition that is being investigated; it means being historical in the most emphatic way" (Ramberg \& Gjesdal, 2005, para.310). Hans-Georg Gadamer also saw social-cultural aspects of Hermeneutics, stating that "Human beings... [are] beings in language....[that] we cannot fully understand ourselves unless we understand ourselves as situated in a linguistically mediated, historical culture...this is our second nature...this has consequences for our understanding of art, culture, and historical texts" (Ramberg \& Gjesdal, 2005, para.3-10). He said that language was a social construct and as such was a reflection of culture. Dilthey's concepts of Erlebnis (lived experience) and Verstehen (understanding) added to the social 
component of Hermeneutics: "Erlebnis is connected with the process of self-

understanding, whereas Verstehen relates to our understanding of others" (Ramberg \& Gjesdal, 2005, para.3- 10). Therefore, interpretation could be seen through a cultural lens. The application of the Hermeneutical interpretation to historical narrative can offer students the understanding of lived experience.

In retrospect, based on the above mentioned, Hermeneutics is an interpretative process which can be used to understand historical narrative. This process was facilitated by utilizing the Hermeneutic Circle. Moreover, the Hermeneutical interpretive process also can include an historical (or historiographical) as well as philosophical and socialcultural elements. Therefore, these elements or frames can be seen as an organizational tool and used to interpret or analyze.

\section{Critiques to Hermeneutics}

Betti (1964) in General Theory of Interpretation criticized the methodological aspects of Hermeneutics. He argued that the author's point of view can block the Hermeneutical interpretation process rendering it flawed, stating that

Speech and texts are objectified representations of human intentions. To interpret their meaning is to breathe life into these symbolically mediated intentions. This is possible because although the interpreter's individuality and the individuality expressed in the text are constitutively different, the interpreter may overcome her own point of view in order to get a grasp on the meaning of the text. At issue is an attempt to re-create the original process of creation: not in order to reach the psychological state or content of the author, but to get at the true and only meaning of the text" (Ramberg \& Gjesdal, 2005, para. 3-10).

Hirsch (1967) thought that the interpretive outcomes provided by Hermeneutics would not be reasonable or probable. Moreover, he assured that hermeneutics could not 
provide true knowledge that possessed complete objectivity. Ramberg and Gjesdfal (2005) compare Hirsch and Betti, stating that

Like Betti, Hirsch takes this idea to invoke a problematic epistemic relativism. Without a concept of validation, he argues, no interpretation would be more plausible than any other. Knowledge and objectivity would be impossible in the domain of hermeneutics" (Hirsch, 1967, p. 5)

Habermas (2014) felt that Hermeneutical interpretation was superficial and that it lacked critical analysis. He felt strictly following the Hermeneutical tradition felt no room for critical thinking. Moreover, Habermas postulated that Hermeneutics was not complete without a critical theory of society.

Traditionally, Hermeneutics has been associated with non-secular or religious texts. The Enlightenment period caused society to change. Society was pushed towards secularized thought or secularization (which is analysis based on the scientific method and reason). Moreover, this secularization has removed authority of and dependence on religious texts. Exegesis has been substituted by reason and the scientific method. Consequently, the use of Hermeneutics and its interpretive process has nearly disappeared.

\section{The Interactive Level}

The HPST Framework works on two levels aimed at complicating history through conversations about the multiple layers in each frame and the possible overlap all frames can encounter. The first was the interactive level, which is composed of three interconnected parts or elements. These parts are the author, text, and student reader. Please refer to Figure 3 below. 
Figure 3. Interactive Level.

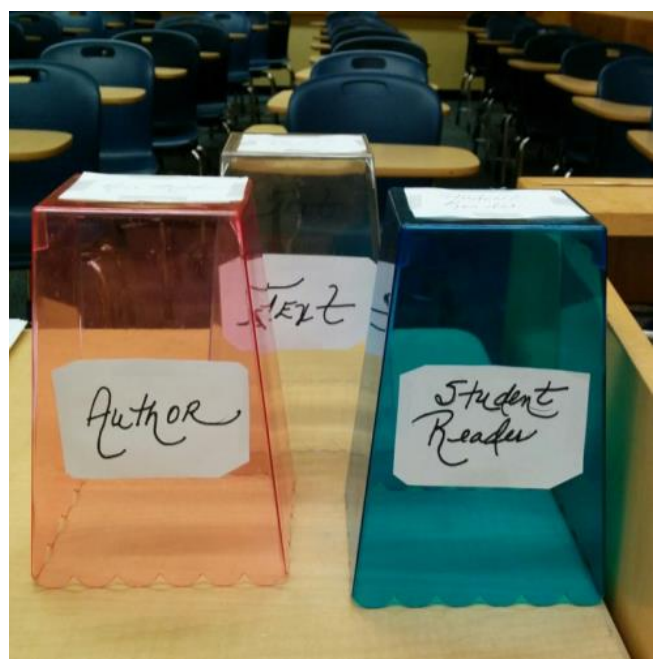

Schleiermacher (1973) referred to the dynamic between these forces as a

Hermeneutic Circle. Moreover, Schleiermacher felt that the key to understanding a text was establishing a real relationship between reader, text, and context of the reading. The author's background, bias, and point of view, for Schleiermacher, did not factor into the overall understanding of the text. This is where my view diverges from the aforementioned theorist and aligns with that of Martin Heidegger.

Heidegger (2002) argued that an author of a text and the text itself cannot be understood separately, stating that

The question of the origin of the artwork asks about the source of its nature...the work arises out of and through the activity of the artist...the artist is the origin of the work. The work is the origin of the artist. Neither is without the other. (p. 1).

By researching an author's personal and professional background, a student's inclusion of a visual representation and some information of possible biases and points of view will serve as a catalyzing force that will only bolster the bonds established by Hermeneutic 
Circle making the overall understanding and interpretation of the piece that much stronger.

In order to fully comprehend the HPST, it is necessary to define and understand the composition of each frame, its usage, and application. A frame is a mental schema with a specific definition that when applied to a narrative the end result will be analysis and synthesis of content (Vygotsky, 1997):

- Historical. It is important to note that this frame was created borrowing from the theoretical reasoning of Hermeneutical thinkers such as: Vico, Wolff, and Droysen. There are several elements that composed or emerged from this frame, namely: the identification of the historical event or phenomena itself; the time, dates, or timeline the history occurred; the changes (if any) of this event or phenomena over time, and the geographic location the historical event transpired.

- Philosophic. This frame is made up of the belief (s) associated with historical event or occurrence, school (s) of thought, public opinion, the psychological paradigm or ramification this belief incurred, and the "-isms" of the period. This frame was based upon Chladenius' Point of View theory.

- Societal. Within this frame people were chronicled and examined. Also, the underpinnings and nuances of culture were explored; such as: food, entertainment, religion, tradition celebrations, morals, and values. Theorists such as: Ast, Von Ranke, Gadamer, and Dilthey were used in developing this frame. 
- Takeaway. Here is where students critically reflect on what they have learned after using the framework in relation to the lesson's content. It is intended to give them an active and participatory voice or platform for classroom discussions.

Students using these frames are to create a deliverable (which can be an essay, paper, presentation, class discussion, knowledge showcase, or some artifact) using selected excerpts from the historical narrative itself that describe, exemplify, answer, and or justify the definitions or descriptions associated with each frame. Teachers can utilize this as a form of student assessment.

\section{The Analytic Level}

The second level is the analytic level and like its name sake the analysis of narratives begins here. Please refer to Figure 4 below.

Figure 4. Analytic Level.

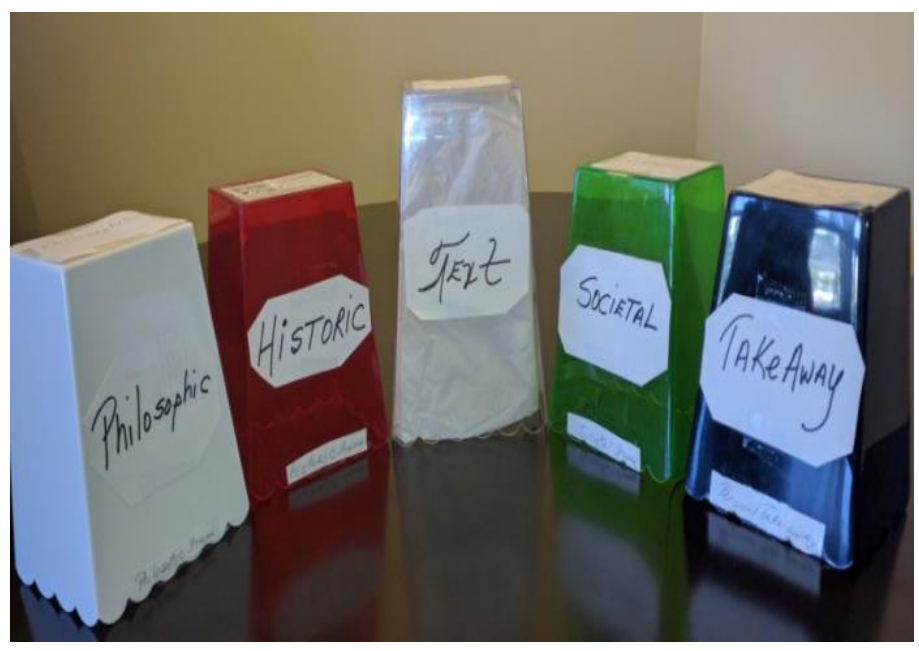


The analytic level was created by the use and application of four perspectives or frames, namely the historical, philosophic, societal, and a takeaway, or HPST.

The usage of the frames was based on a critical examination of the Five W questions, namely who, what, where, how, and why. This paradigm originated in the Greco-Roman period, but was reborn during the Middle Ages with Boethius's translations of Aristotle and Porphyry, coining the Latin version of the above mentioned terms: "quis, cur, quomodo, ubi, quando, and quibus" (p. 1). These were eventually translated into English, by Thomas Wilson in the 16th century, and W.C. Wilkinson applied the use of these questions to the field of journalism in the $1800 \mathrm{~s}$.

\section{Research questions}

The following were the research questions driving this research study:

1. How does a Social Studies teacher use the HPST Framework?

2. What role can narrative play for a Social Studies teacher?

3. To what extent has the use of the HPST changed a teacher's thinking about curriculum and or teaching?

\section{Synopsis of literature}

At this point, it is important to note, that because of Common Core, state and national educational institutions have issued legislation that articulated the need for $\mathrm{K}$ through $12_{\text {th }}$ grade students to be able to analyze historical texts. As mentioned previously by (Barrios 1989, Bruner 1991, Moules 2002, O'Reilly 2009, Pinar 1975, Richardson 2002,) and my perusal of texts, traditional Social Studies textbooks do not 
comprehensively address this need. Moreover, teachers need resources that they can offer their students to achieve this. Part and parcel to addressing this need seems to be an incorporation of students' own lives, namely their own narratives, in making connections between curriculum demands and their understanding of them (Pinar 1975, Moules 2002, Richardson 2002, O’Reilly 2009). Therefore, I proposed the use of the HPST Framework as possible approach toward addressing this issue. 


\section{CHAPTER THREE}

\section{METHODOLOGY}

This study explored how the HPST Framework may be implemented within a

participating Social Studies teacher's classroom. More specifically, it examined the following research questions:

1. How does a Social Studies teacher use HPST?

2. What role can narrative play for a Social Studies teacher?

3. To what extent has the use of the HPST changed a teacher's thinking about curriculum and/ or teaching?

\section{Issues Conducting my Research}

There were several obstacles that initially plagued my research. First, I was not a Miami Dade County Public Schools (MDCPS) teacher and two, because of this, I did not have direct access to students in the Kindergarten through 12th grade setting. Since my $\mathrm{PhD}$ program specialized in Curriculum and Instruction, a professor suggested that $\mathrm{I}$ focus the study on the perceptions of pre and in-service teachers residing in Miami Dade County (MDC) instead of actual MDCPS students. These individuals were all Florida International University students which I had access to because they were taking a course with one of my professors or me. 
Another challenge was that, in the study's infancy, I had conceptualized my research to possess a large sample size of individuals actually participating. The idea behind this was to have a broad cross section of pre and in-service teachers that taught students in elementary, middle, high school, and even college levels. Moreover, I thought that this large group of teachers would service different kinds of students with various learning contexts. This, I thought at the time, would offer a more comprehensive and diverse view of teachers actually implementing HPST in their classrooms. During the defense of my research proposal, it was brought to my attention that this large cross section would definitely accrue data that could be construed as superficial. I decided to focus on those pre and in-service teachers who would afford me the greatest amount of significant and thick data given that my research was qualitative in nature. Moreover, I realized that selecting one participant would be the best way of procuring thick data. Ultimately, to this end, I utilized a case study format.

\section{Case Study}

In order to answer my research questions, I opted to use the case study method. According to Levy (2008), a case study could be seen as an "attempt to understand and interpret a spatially and temporally bounded set of events" (p. 2). This series of events is usually experienced by an individual person or group. A case study can be viewed as a specific body of analysis that might shed light on the experiences of a particular teacher exploring an overarching educational theme or issue. George (1979) reminded us that an individual using the case study method can opt to be historians giving analytic explanations instead of outcome based on variables. Bennett (2005) echoed that 
sentiment by defining a case study as "the detailed examination of an aspect of a historical episode to develop or test historical explanations that may be generalizable to other events" (p. 2). Moreover, Feagin, Orum, and Sjoberg (1991) reminded us that case studies are often used for theory generating, "develop[ing] new theoretical innovations and generalizations" (p. 14).

Within the context of Stake's (2003) instrumental case study definition which reads that an

instrumental case study is examined mainly to provide insight into an issue or to redraw a generalization. The case is of secondary interest, if it plays a supportive role, and if it facilitates our understanding of something else. The case still is looked at in depth, its contexts scrutinized, its ordinary activities detailed, but all because this helps the researcher to pursue the external interest. The case may be seen as typical of other cases or not" (p.137).

three types of methods were predominantly used:

Participant observations. Marshall and Rossman (1989) defined observation as "the systematic description of events, behaviors, and artifacts in the social setting chosen for study" (p.79). Moreover, Kawulich (2005) reminded us that observations permit the researcher to perceive an issue using the five senses and is one of the primary methods for doing field work. For this study, detailed observational field notes were taken at the participant's school during a given implementation of HPST. The actions undertaken by the participant and her students were both noted. These chronicled at least four implementations as well as a personal reflection or commentary on what was observed lasting 50 minutes each.

Interviews. Oltmann (2016) stipulated that interviews were the most direct way a participant and a researcher interact. Moreover, Oltmann also suggested that "the vast majority of writing about interview research methods states that these should be 
conducted face-to-face or simply assumes that they will be done in this mode"

(Oltmann, 2016, p. 2). Raworth (2012) articulated that semi-structured interviews are valuable tools commonly used in qualitative research. At least five pre- and postworkshop and implementation semi structured face-to-face interviews were conducted of the participant at different intervals of this study.

A collection of artifacts and texts. Campbell (1999) categorized the collection of artifacts as an excellent source of data because these try to answer the researcher's questions. Hammersley (2010) articulated that transcriptions were often more rigorous and painted a clearer picture of the evidence gathered than any other method used qualitatively. Within the context of this study, the participant's implementation lesson plans accompanied by student produced handouts, and interview transcriptions were collected and analyzed using the emerging themes process.

\section{Field notes}

Detailed field notes were created pre and post the HPST familiarization workshop, during the participant recruitment interviews and participant interview, and pre/post the various participant implementations. De Clerck, Willems, Timmerman, and Carling (2011) suggested that these "notes include:

1. Observations on the main topics to be observed;

2. Other observations made by the researcher that are not covered by these main topics;

3. Information acquired through conversations with local people, local authorities, key informants; and the

4. Researcher's personal comments" (p. 10)

Based upon their definition, I created field notes that contained the date of the observation, location, the time the observation occurred, a description of the observations 
in detail, and a personal reflection or commentary on what was observed. These were taken manually and then transferred to a Microsoft word document file to my password protected PC (Davidson, 2010).

\section{Phases of the Study}

In an effort to examine the HPST in depth securitizing its contexts and detailing its ordinary activities, the following phases were developed for this study:

1. HPST Training workshop
a. HPST familiarization
b. Lesson plan development with HPST implementation
c. Recruitment of participants for case study observation
d. Recruit selection as case study subject

2. Case study subject interview

3. Case study subject implementation of the HPST Framework in three lesson plans

a. How researcher gauges the implementation (degree to intervention)

4. Lesson plans developed (show outcomes)

5. Researcher's observations

6. Coding

Please refer to Figure 5 below for phases of study flow chart. 
Figure 5. Phases of the study flow chart.

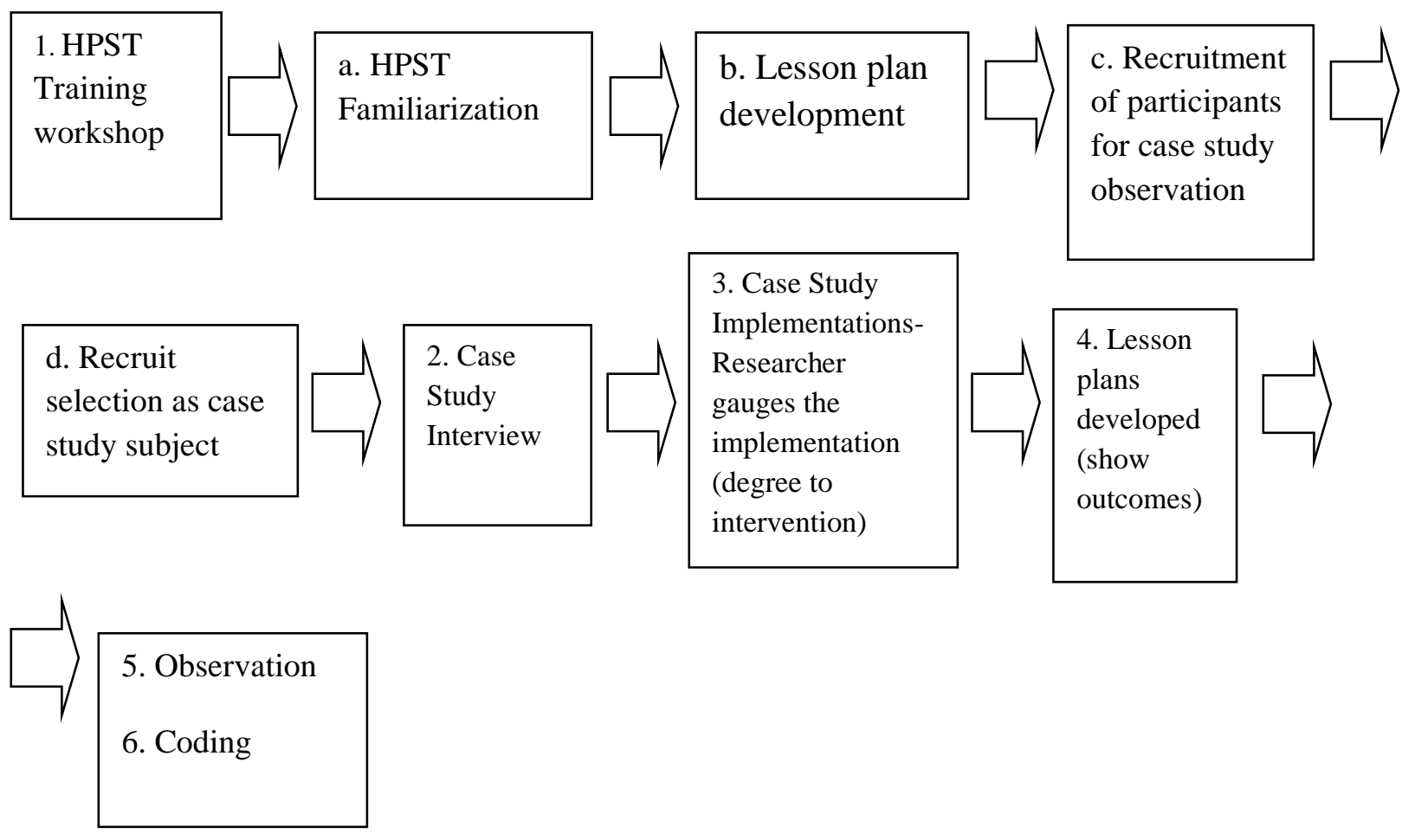




\section{HPST Training workshop}

Before initiating a case study, I had to find a participant. The first procedural step was to ask teachers to take part in a training workshop. I created a Professional Development workshop session that explained the theoretical, conceptual, and implementational aspects of the HPST Framework. Holt et. all (2018) stated that "most workshops have several features in common:

- They're generally small, usually from 6 to 15 participants, allowing everyone some personal attention and the chance to be heard.

- They're often designed for people who are working together, or working in the same field.

- They're conducted by people who have real experience in the subject under discussion" (Community toolbox, 2018, para 3).

The duration of the workshop was either one two-hour session or two one-hour sessions. The two one-hour session workshops were held on consecutive days. These workshops were given in nine undergraduate courses and two graduate courses. The majority of the courses were in Social Studies with the exception of one graduate course focusing on globalization, one undergraduate course in teaching English to speakers of other languages, and a post secondary transitional program's reading course. The workshops occurred periodically over a two year span. These were held in classrooms at Florida International University. I selected classrooms which had smart boards that permitted the use of visuals and audio during the actual workshop presentations.

All the teachers participating in these workshops were either pre or in-service. Moreover, they were also students in undergraduate and graduate courses. I recruited these teachers from courses taught by my professors or me with the exception of the post secondary transitional program's reading course. The instructor of this course was 
a colleague. Since I was part of the grant conducting this class I therefore, had access to the teacher. More than 30 teachers (divided up into small groups of no more than 10 to 12 individuals in total) participated throughout the three years.

\section{HPST familiarization}

The overall purpose of the workshops was to foster familiarization for the teachers who participated. During the actual presentations, teachers learned about the conceptual and theoretical aspects of the HPST framework. Using a PowerPoint presentation (to be included in the next section), I defined what the HPST was, its purpose, and the types of narrative this framework can be used with. Then, an explanation of the two levels of the framework was given to include how each frame was defined and how students would be using them. The student roadmap was discussed to include how assessment would be calibrated followed by examples from selected texts of each frame. Lastly, steps for its implementation were articulated. At the end of the workshops, the participating teachers offered feedback. These teachers' feedback served to further format and refined the HPST with the edits they gave.

\section{Procedures}

\section{Applying the HPST Framework as a Disciplinary Tool}

The following procedures were initially utilized during the teacher familiarization workshop. To model HPST, I used two narratives that examine the First Wave of Cuban Immigration: Firmat's Next Year in Cuba: A Cubano's Coming of Age in America (1995) and Wells, Fernandez, and Ferguson's My Havana: Memories of a Cuban Boyhood 
(2010). These texts included narratives from individuals who immigrated to the United States in their youth. Students could use these texts to examine the similarities and differences between accounts. These narratives were also written at different reading levels and can aid emerging readers and English Language Learners. The overarching goal for the participating teachers was to use this procedure with another topic and implement it with her own students.

\section{Steps for the Interactive Stage:}

1. I demonstrated the interactive phase by explaining how the author, the text itself, and the student reader all played parts in the interpretation of a text.

2. I referred to a visual model that explains the complex interaction of these different layers, namely Lowell's 2011 representation of the Hermeneutic Circle as seen in Figure 2.

3. Then I provided information about the author. Students were also permitted to use the internet to search for this information. The objective of helping students uncover the author's background information was in an effect to help students learn how important it is to determine the author's point-of-view.

a. For example, Gustavo Firmat was born in Havana and, after leaving the island in 1960, was raised in Miami, Florida. Firmat wrote his memoir as part of his academic career.

b. My Havana details the life of architect Secundino "Dino" Fernandez, but it is written and illustrated by Rosemary Wells and Peter Ferguson. The book, describing Dino's childhood, was written from a child's perspective. 


\section{Steps for the Analytic Stage}

The analytic stage evaluated sources using evidence found in the texts. The purpose behind this portion of the workshop was to show teachers how their students would utilize HPST and the type of evidence they would be procuring in the form of direct quotes using the definitions of each frame. During this stage, I:

1. defined what constituted each frame, and

2. offered the participants examples from the selected texts to best model practices for analyzing sources.

The following were good examples of texts selected and were displayed at the workshops:

Historical (Refer to Appendix A)

Havana October 24, 1960. That morning Nena, my mother, woke up earlier than usual. It was a school day, but we were not going to school. In the hallway outside my bedroom the queue of suitcases stretched all the way to the front door. For several years, I had been coming to the States once or twice a year, always taking the City of Havana, the overnight ferry to Key West.

\section{Philosophical}

Fidel's compadre Che Guevara promises that all rents in Cuba will be reduced and all wages will be increased, Papi says... Everything in Cuba will be evenly divided and given to the people... No rich...no poor... everyone the same...Cuba will be like heaven on earth. What nonsense!

\section{Societal}

Fidel is a rich man son Dino... Papi whispers to me... He went to the best private school in Havana, but he's trying to look like a poor peasant... everyone thinks he's Robin Hood sent from heaven to save Cuba... He calls himself El Lider. 


\section{Lesson plan development with HPST implementation}

The teachers (with the exception of the post secondary transitional program's reading course instructor) were asked, as part of their overall course work, to produce a five-day unit plan. This unit plan was created by first selecting a topic and corresponding state and/or national standards. Then the teachers crafted five individual lesson plans based on two criteria: 1) their student's educational needs, 2) the pedagogical knowledge they had acquired in the course. Moreover, the teachers were given an option — namely, that one of their lesson plans be dedicated to document analysis using HPST. The idea behind this was that the group of teachers would later implement the crafted lesson plan in their own classrooms if they choose to participate in the study. (Please refer to Appendix B).

\section{Recruitment of participants for case study observation}

From this group of teachers, several permitted an initial interview with respect to implementing the HPST (Raworth, 2012). Additionally, these teachers gave me hardcopies of the lessons they had created (Campbell, 1999). From these lesson plans three were selected: an in-service university professor who was teaching reading to students with cognitive/physical issues, a pre-service undergraduate instructor teaching third grade Social Studies, and an in-service high school instructor teaching World History. I reviewed all the lesson plans and came to a decision. 


\section{Case study subject selection}

From this sample, the in-service high school instructor teaching World History was selected. The teacher selection was based on the following criteria:

1. The teacher's lesson plan provided curriculum and/or her own teaching that corresponded to HPST.

2. The teacher possessed a background in teaching Social Studies/History that correlated to the researcher.

3. The teacher exhibited intrinsic interest in trying out the framework in her class.

4. The teacher's class was within reasonable proximity of the researcher.

\section{Recruit interview}

I conducted a semi-structured half-hour face-to-face interview to the teacher agreeing to participate in the study that occurred directly after attending the workshop and producing a lesson plan. Raworth (2012) reminded us that

semi-structured interviews focus on specific themes but cover them in a conversational style... they are often the best way for learning about the motivations behind people's choices and behavior, their attitudes and beliefs, and the impacts on their lives of specific policies or events" (p. 1).

This interview was recorded using the Audio Recorder Sony Mobile Communication recording application on my cellular phone (Raworth, 2012) (Campbell, 1999). Then this information was transferred to my PC within a corresponding file. No one else had access to this interview (Davidson, 2010). The interview was held in a student lounge on campus. The participating teacher answered the following set of questions: 
1. Describe your teaching experience. How long have you been teaching and where?

2. How would you describe your experience with narratives?

3. Have you ever utilized narratives in your classroom as part of the content presented within your subject area? If yes, please describe how you used them?

4. What are your perceptions about the HPST Framework (please describe possible strengths and or weaknesses)? Also offer any suggestions for the improvement of this framework.

5. Do you think that you could use the HPST Framework in your classroom?

6. Do you have any other comments concerning the HPST Framework?

\section{Transcription}

Subsequently, I transcribed the recording of this interview. Davidson (2010) "in a study [dealing with] conversations of young children, cited the need for transcription" (p. 260). This transcription was created when I (by means of a Microsoft word document on my PC) slowly and attentively listened to the recording of the interview and typed out everything that the participant (and or I) said (Hammersley, 2012) (Campbell, 1999) (Davidson, 2010). Once the transcription was completed, it was placed into a file on my PC that was password protected. No one else had access to this information (Davidson, 2010).

\section{Case Study Participant}

The description of the semi structured interview revealed the following information. The participant is a Cuban American female and was in her early thirties during the study. She was born in Cuba but came to the U.S. as an infant. The participant possessed a Bachelor's and Master's degree in History and was pursuing her $\mathrm{PhD}$ in Curriculum and Instruction during the time the study took place. She is an in-service 
high school instructor that taught 9 th grade World History. Moreover, she had been teaching for four years at the time of the study. The participant used narrative and narrative analysis in her classroom often. Narrative analysis came in handy she commented with Document Based Questions (DBQ) on end of course exams. The teacher exhibited intrinsic interest in trying out the framework in her class. She had been looking for a quick and easy tool for analysis to give her students. This teacher was definitely excited to use HPST. Additionally, her class was within reasonable proximity of the researcher.

\section{Research site}

The high school used in this study is a private charter school in Doral, Florida and was used as the implementation site. I had written permission from the school's administration to implement HPST there (refer to Appendix C). This school is part of the Miami Dade County school district. Doral is a satellite city orbiting western Miami. This school has received multiple awards for academic excellence, placing it as one of the top school in the South Florida region.

In contrast to many affluent schools featuring similar services, eighty percent of the students in this setting are served by free and reduced lunch, a marker of lower socioeconomic status in the United States. Hispanic students make up the largest population of students in this region, yet there is a meaningful population of Haitian and Jamaican students as well. This means that there are a variety of first or second-generation students and English Language Learners. There are a total of 1305 students attending this school. 
Important extensions the participating teacher's participation in this study were the students in her classes. These students were all in the ninth grade and were taking an Advanced Placement (AP) World History class. There were a minimum of 24 and a maximum of 31 students in a given class. The male to female student ratio for both classes was approximately about 1 to 11/2 (Doral Academy Prep, 2019).

\section{Lesson plans developed}

I asked the participant to create lesson plans based on her students' needs. Moreover, these lesson plans had to incorporate the HPST Framework. She was to select a reading to be used. Ideally, this reading would not be from a traditional textbook, but rather a historical narrative, autobiography, biography, or another literary piece. This teacher commented that she needed to consider the length of the selected reading. It had to align with the block scheduling of her class. This issue was corrected by selecting excerpts of the chosen pieces.

The participating teacher created three lessons. The first two lessons covered the Iranian Revolution using the graphic novel, Persepolis. The third lesson focused on Christopher Columbus's voyages of exploration using his 1492 dairy. The last was on Tsar Peter the Great, using a biography. Students, after a hook (which is an introduction or attention grapping activity) and explanation of the levels of the HPST, by the teacher were grouped. They then read the excerpts of the selected piece and applied the framework to it. It is important to note that during the last implementation the participant's students were familiar with the use of the HPST and thusly the application was individually accomplished as a homework assignment. 


\section{Researcher input on lesson plans or HPST implementation}

I developed the following steps to help the participant craft her lessons using the HPST. Moreover, these procedural steps were also discussed at the end of the workshop sessions and were essential in implementation:

- Step 1: Teacher setting of focus materials. The participant determined the subject area or topic that needed to be covered, as well as, applicable state or national standard(s).

- Step 2: Selection of Narrative. The participant chose a narrative that aligned with subject matter, objectives, and standards.

- Step 3: Hook Activity. For all four lesson plans the participant selected an introduction or attention grapping hook activity, intended to spark student's curiosity about the topic. Students' entered the classroom that was transformed to resemble a museum exhibit. The participant printed out colored images that related to the topic and or content. Then she adhered images on opposing walls of the classroom in such a way that students needed to physically get up and view them. The teacher began this activity by asking students to consider an essential question-For example, why do people migrate? The students walked around examining pictures, captions, artifacts, and information. The gallery walk activity terminated by asking students to reflect on this experience with questions, such as: "What do you think?" Students were also encouraged to write out any questions they had. This exercise was to gain the students' prior knowledge and direct their inquiry on a topic. Appropriate content specific music or sounds 
served as accompaniment to this activity. Finally, the gallery walk activity served as an introduction to the overall lesson (Please refer to Appendix D).

- Step 4: Student's Roadmap. The teacher offered students a literary roadmap used to navigate through the reading that highlighted or referenced the desired content. This roadmap was composed of two elements: a) background on the author (to include an image); and b) vocabulary, concept, essential question (s), and/or terms list. She held a whole class discussion on the background of author, having students look up information on handheld technology. Students dictated their finding and she created a concept map.

- Step 5: Group Assignment. The participant determined which students would be assigned to each frame (i.e. historical, philosophic, and societal) according to her classroom needs. Students were directed into pods--in other words, a sector of the classroom was dedicated specifically to students' representing their corresponding frame. Regardless of what the frame students were assigned to, they were required to address the takeaway frame, thereby giving the students opportunities to address one of the $\mathrm{H}, \mathrm{P}$, or $\mathrm{S}$ frames, as well as the $\mathrm{T}$ frame.

- Step 6: Reading of Text. The teacher assigned excerpts of a text to be read either in the classroom or at home. Even though students were physically sitting in their pods, they read individually.

- Step 7: Application of Frames (i.e. Historical, Philosophic, Societal and the Takeaway). The participant gave an explanation of the frames. The teacher asked students to mark places within the passages that corresponded to each kind of frame, using color pens or pencils to annotation each frame type- red for 
historical, blue for philosophical, and green for societal. (Please refer to Appendix E).

- Step 8: Feedback. The participating teacher went around her classroom visiting each student group during this part of the lesson. She asserted that all the students were on task. Moreover, she made sure that all students in each group participated and contributed equally. By doing this, the teacher assured that the students' levels of engagement were strong. Also, she answered any questions that they had and gave clarifications whenever needed.

- Step 9: The Knowledge Showcase. This was the actual deliverable produced by students. Here was when student groups assigned to a frame shared what they found either orally or in written form. Then, all students engaged in answering their own personal takeaway after going through the HPST process.

\section{Lesson plans in action}

\section{Researcher/subject interviews}

After each implementation, I interviewed the participant. These interviews were conducted after completion of the actual implementation or 24 hours after the day of the implementation. This was part of a debriefing session I and the participant had. The interviews took place at the implementation site. These interviews were recorded using the Audio Recorder Sony Mobile Communication recording application on my cellular phone. Then this information was transferred to my PC within a corresponding password protected file. No one else had access to these interviews. The following questions were used: 
1) How did you use the HPST Framework in your classroom?

2) What are your perceptions of this framework now?

3) What are your suggestions for improvement, modifications, or accommodations of this Framework after using it?

4) To what extent has the use of the HPST changed your thinking about curriculum and or your teaching?

5) Do you have any other comments concerning the HPST Framework?

\section{Observations}

As mentioned previously, I had written permission from the High School's administration, to observe the classroom dynamic during all the implementations. During observations, I hand wrote field notes. I later typed my notes into Microsoft word documents that included: date of the observation, location, the time the observation occurred, a description of the observations in detail, and a personal reflection or commentary on what was observed (De Clerck, Willems, Timmerman, Carling 2011). Then this information too was kept in a corresponding password protected file. No one else had access to these field notes. During each of the implementation, an observation transpired which produced detailed field notes. A total of four different observations occurred. There was also a collection of artifacts gathered. This included the participant's implementation lesson plans, interview transcriptions, and handouts produced by her students which were analyzed using the emerging themes process.

\section{Coding Emerging Themes}

Bogdan and Biklen, (2003) suggested that an effective way to code would be first to read through the data collected, and paying close attention to what could be identified, labeled, and classified into overarching concepts. This back and forth comparison 
between categories trying to make connections was critical. They remind us that whether in the field making observations or conducting interviews, qualitative data analysts use many different types of coding categories, including those connected to context, situation, ways of thinking, perspectives, processes, activities, events, strategies, and relationships, among others. Resultantly, to achieve, Bogdan and Biklen's objectives, I applied Lichtman's (2013) qualitative analysis approach to evaluate the participant's lesson plans and interviews, my field notes, and students' handouts:

Step 1: Initial coding. Going from responses to summarizing ideas of the responses,

Step 2: Revisiting initial coding,

Step 3: Developing an initial list of categories,

Step 4: Modifying initial list based on additional rereading,

Step 5: Revisiting your categories and subcategories, and

Step 6: Moving from categories to concepts" (Lichtman, 2013, p. 253).

Using the above mentioned format, I coded the data, identifying common and uncommon emerging themes. Then I compared both sets of codes, narrowing and grouping codes as themes.

The participating teacher's students were referred to anonymously. While the participant discussed student experiences, their names are not included in this study.

\section{Believability}

Ryan, Coughlan and Cronin (2007) suggested that "the critique of qualitative research requires an appraisal of the rigor in documentation, procedural rigor, and ethical rigor" (pp. 6-7). Moreover, Tracy (2010) offered the "Eight Big Tent Criteria model for quality in qualitative research that were: worthy topic, rich rigor, sincerity, credibility, resonance, significant contribution, ethics, and meaningful coherence" (p. 1). Following 
these stipulations, I asserted that the participating teacher's lesson plans had worthy topics and were sincere, credible and meaningfully to her and her students (Tracy 2010, Ryan Coughlan and Cronin 2007). Additionally, the transcriptions of interviews were ethically done, and the rich and detailed field notes were thoroughly analyzed using the coding process of emerging themes (Lichtman 2013, Tracy 2010). Procedural rigor was insured by use of the lesson plans crafted by the teacher (which were given to me by participant), the two face to face post workshop(s) and implementation interviews, and chronicling the observed classroom dynamic when consenting teacher implemented the HPST in her classrooms with detailed field notes.

\section{The researcher and the study}

Throughout this piece, glimpses have been given of who I am as a person and a professional. Pinar (1975) reminded us that "formal studies, like literary study, can be utilized to illuminate the myriad of surface ways...we evolve through time (and as a subset of this set, so to speak) how our intellectual interests evolve through time" (p. 5). Personally, I am a first generation Cuban American born to immigrant parents and raised in Miami. Professionally, I hold a B.A. Degree in history, a Master's of Science in Curriculum and Instruction with an area of specialization in Social Studies education. At the time of this study, I was a fourth year Doctoral Candidate also in Curriculum and Instruction (language, culture, and literacy track) with a special interest in historical narrative.

This study came about because of many reasons. Chief among them was the Common Core State Standards Initiative (NCSS, 2010), which espoused literacy competencies to be met. These standards are based on reading material that is to be 
analyzed by students so that greater understanding of content can be achieved. The second reason two was that in high school, I was mainly taught how to understand the content of a particular text by summarizing it. This entailed the basic reading of the piece and regurgitating all its particulars. In college, however, this all changed. I was expected, by my professors, not only to summarize a text, but also to achieve some sort of understanding of it through the use of analysis. Moreover, university professor expect their students to have of what analysis is and how to implement it.

Sadly, I remember thinking to myself at the time "what exactly is analysis and how do I use it?" Hence, there was my challenge and in retrospect my inspiration (Pinar, Currere Method, 1975). As my career progressed and I transitioned into teaching, the issues that I had experienced not knowing how to analyze appeared in the high school and undergraduate students I taught. The last (and most important reason) behind this study was my desire to equip students with an organizational tool that could be used for document analysis. This tool will perhaps serve to empower students so that they would not face the challenges I did with narrative analysis.

\section{Synopsis of research methodology}

The following chart serves as a recap of the methodology used in this study to answer the research questions. Please refer to Figure 6. 
Figure 6. Recap of the methodology.

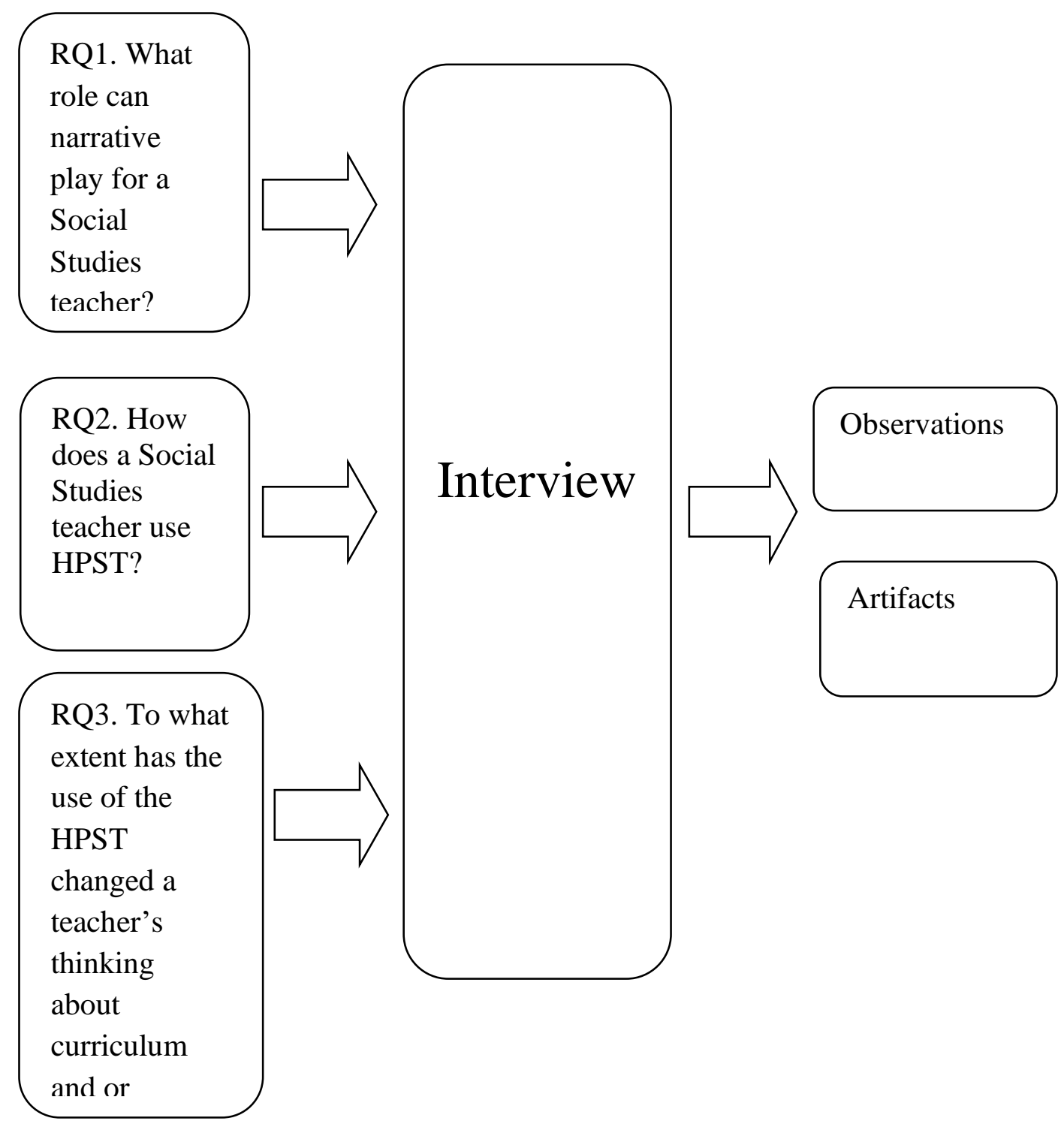




\section{Possible limitations}

A possible limitation to this study was that I did not have direct access to actual students in the Miami Dade County Public Schools system. Because of this, I never implemented the HPST in high schools directly. Implementation was conducted by the participant in a case study format. Additionally, implementations occurred with a finite number of students at same grade level and with the same academic ability. The students were all in the ninth grade Advanced Placement (AP) World History classes. Students were mainly from middle to upper middle class families. The training workshops were not offered to the general public. These were only offered to pre- and in-service teachers which were taking courses with the $\mathrm{Pi}$ or $\mathrm{CoPi}$ at the university where research was conducted. The case study method can also be limiting because it targets only a small segments of the population the study is exploring. It only chronicles one participant experiences and not a wider range of individuals from differing backgrounds that could possibly take part in the study and change its outcome. 


\section{CHAPTER FOUR}

\section{PRESENTATION OF DATA AND RESULTS OF THE ANALYSIS}

\section{RQ1: How does a Social Studies teacher use HPST?}

\section{Implementation Protocol}

The following implementations chronicled below were in response to RQ\#1 that reads, how does a Social Studies teacher use HPST? Moreover, these implementations were the results of the application of the HPST Framework in two of the participant's ninth grade Advanced Placement (AP) World History classes. She explored how her students utilized the framework to examine historical narratives. Additionally, she was "interested in seeing if they could use HPST to possibly disrupt stereotypes or generalizations of marginalized communities." There were four implementations in total, utilizing several different topics and occurred over a two- year span. After each individual implementation was completed, this teacher reported all her findings to me. Moreover, data was also extracted from interviews, observations, and artifacts of the participant. Also, she gave me access to all student work. It is important to mention, however, that student work here will not be exhibited in accordance to the IRB and Miami-Dade County Public Schools permission parameters.

In each session, the participant followed the following procedures:

1. The teacher prepared by crafting lesson plans (utilizing the desired topics, state and nation standards, hook activity, assessment etc.) and selected literary pieces that were to be read by students. 
2. Students engaged in a gallery walk, entailing having students enter the classroom that was transformed to resemble a museum exhibit. She printed out colored images that related to the topic and content. Then, she adhered images on opposing walls of the classroom in such a way that students needed to physically get up and view them. The teacher began this activity by asking students to consider essential questions. The students walked around examining pictures, captions, artifacts, and information. The gallery walk activity terminated by asking students to reflect on this experience again referring to the essential questions. This activity helped to solicit students' preconceived ideas about the topic. Content related music or sounds accompanied this activity. It is important to note that, an abridged version of the gallery walk activity was also used. This version still utilized images that were not adhered to classroom walls, but were exhibited on the smart board of her classroom by the participant to elicit student discussion.

3. Following this, participant described the HPST to her students by first explaining each frame. She defined what constituted each frame:

- Historical $(\mathrm{H})$. The identification of the historical event or phenomena itself; the time, dates, or timeline the history occurred; the changes (if any) of this event or phenomena over time, and the geographic location the historical event transpired.

- Philosophic (P). This frame is made up of the belief (s) associated with the historical event or occurrence, school (s) of thought, public opinion, the 
psychological paradigm or ramification this belief incurred, and the "isms" of the period.

- Societal (S). Within this frame people were chronicled and examined. Also, the underpinnings and nuances of culture were explored; such as: food, entertainment, religion, and tradition celebrations.

- The Takeaway (T) is where students critically reflect on what they have learned after using the framework in relation to the lesson's content. It was intended to give students an active and participatory voice or platform for classroom discussions.

4. The teacher presented her class with excerpts of the literary piece which was individually read by students.

5. Afterwards, the participant grouped the class into three pods, namely: an $\mathrm{H}$ group, a P group, and an S group.

6. Then as a group, students identified evidence of their assigned frame within specific portions of the text.

7. The teacher went around her classroom visiting each student group during this part of the lesson. She asserted that all the students were on task. Moreover, she made sure that all students in each group participated and contributed equally. By doing this, the teacher assured that the students' levels of engagement were strong. Moreover, the participant answered any questions that they had and gave clarifications whenever needed.

8. After all the student groups had finished, the teacher reconvened them and then debriefed the session by asking students to tell her what evidence they 
had found. This evidence was then written on the smart board by her and students were asked to copy this information for future use.

9. For the takeaway frame, she instructed students to write out their own perspectives after going through the HPS process and/or to answer the essential question (s) posed at the beginning/end of the lesson.

10. Once the implementation was terminated, this teacher reported to me comments from students.

\section{Implementation One}

HPST was first implemented utilizing the topic of the Iranian Revolution. The participating teacher mentioned, during both interviews and observations, that there was an imperative need for this topic because students were studying a unit on revolutions. She began the lesson, using a gallery walk, soliciting students' preconceived ideas about this revolution, Islam, and gender roles in an Iranian context. Then, she described HPST to her students by explaining each frame and presenting the class with excerpts of Marjane Satrapi’s (2003) graphic novel Persepolis. Persepolis is an autobiography chronicling Satrapi and her experience as a young Iranian woman during the 1979 revolution. As a group, the students identified evidence of the various frames within specific portions of the text. For the takeaway, students were asked to write out their own perspectives on Islam after reading this graphic novel and going through the HPS process. 


\section{Implementation Two}

The topic of the Iranian Revolution was again utilized for implementation two. The participant mentioned, during the interview after implementation one, that she wanted to re-implement using this topic because some students, in the first session, did not really understand the Philosophical Frame. This teacher applied the same implementation protocol as in the first session. Specifically, she: 1) used a gallery walk to solicit students' ideas about the revolution, Islam, and Iranian gender roles, 2) gave a description of the HPST by explaining what constituted each frame, 3) presented the same excerpts of the graphic novel Persepolis to the class, 4) students identified evidence of the various frames within specific portions of the text, and 5) students wrote out their own perspectives on Islam after reading this graphic novel and going through the HPS process.

\section{Implementation Three}

The third implementation utilized Christopher Columbus as the topic and focused on the essential question: "Was Columbus a friend or foe of history?" During this session, students first partook in an abridged gallery walk which was debriefed by the participating teacher. She reminded students how to use HPST. Then, the students analyzed excerpts of Christopher Columbus's 1492 diary in small groups. As the final takeaway, students determined if Columbus was a friend or foe based on the evidence they procured from the text. 


\section{Implementation Four}

The topic of Peter the Great was used for the last implementation. This implementation related to the question: "What perceptions did students have about Peter the Great's reign?" At this advanced stage, since students were very familiar with HPST, they were asked to analyze excerpts from Robert K. Massie's piece entitled, Peter the Great: His Life and World (1981), Vasili Klyuchevsky's Peter the Great (1958) and Alexander Chubarov's The Fragile Empire: A History of Imperial Russia (1999). These three works discussed how Peter the Great's reign introduced new administrative and territorial divisions to Russia that impacted immigrants and used them to improve the Russian economy. Moreover, these changes caused social-cultural and political upheavals which ultimately led to the modernization of Russia

\section{HPST in Action}

\section{Implementation One: Persepolis}

The topic for implementation one was the Iranian Revolution utilizing the graphic novel, Persepolis. The participant said that she "wanted to evaluate student's perceptions of Islam and Iranian culture... and possibly interrupt stereotypes and give voice to marginalized communities." First, students engaged in a gallery walk. Content related music or sounds served as accompaniment to this activity. For example, the song "Rock the Casbah" by the musical group The Clash played during the Persepolis implementations. The following images were utilized for the gallery walk. Please refer to Figure 7-11 below. 
Figure 7. Gallery walk image.

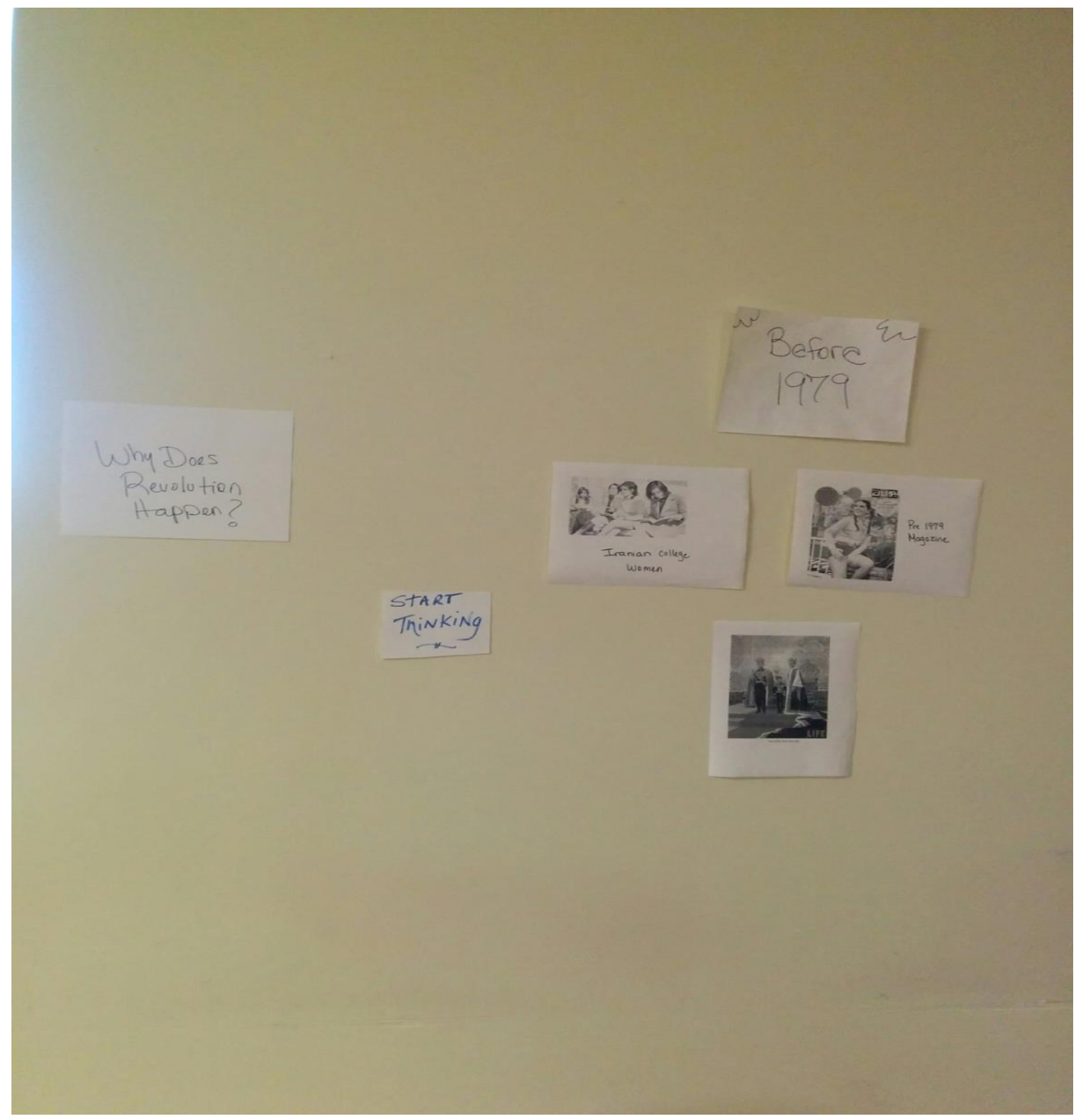


Figure 8. Gallery Walk Image.

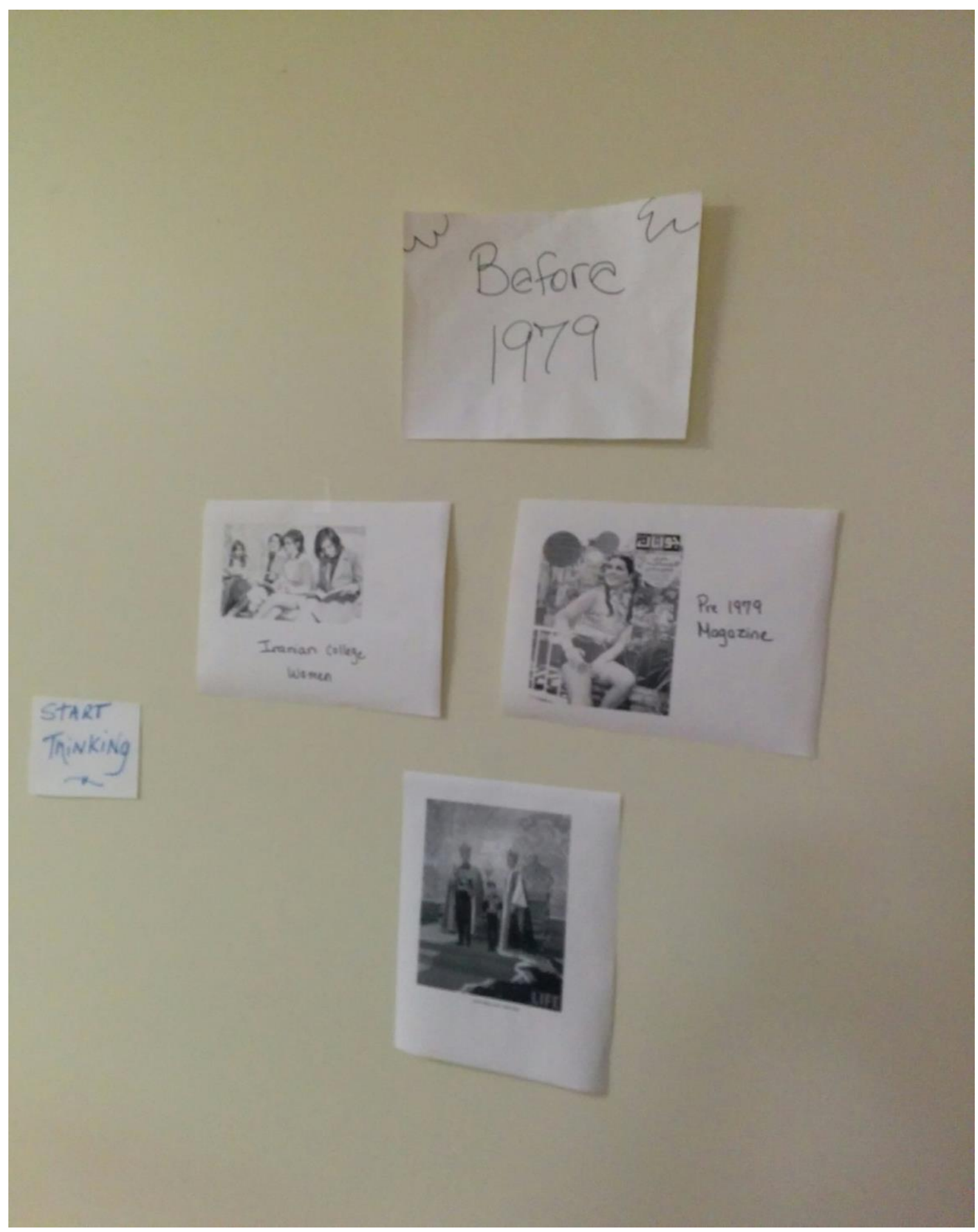


Figure 9. Gallery Walk Image.

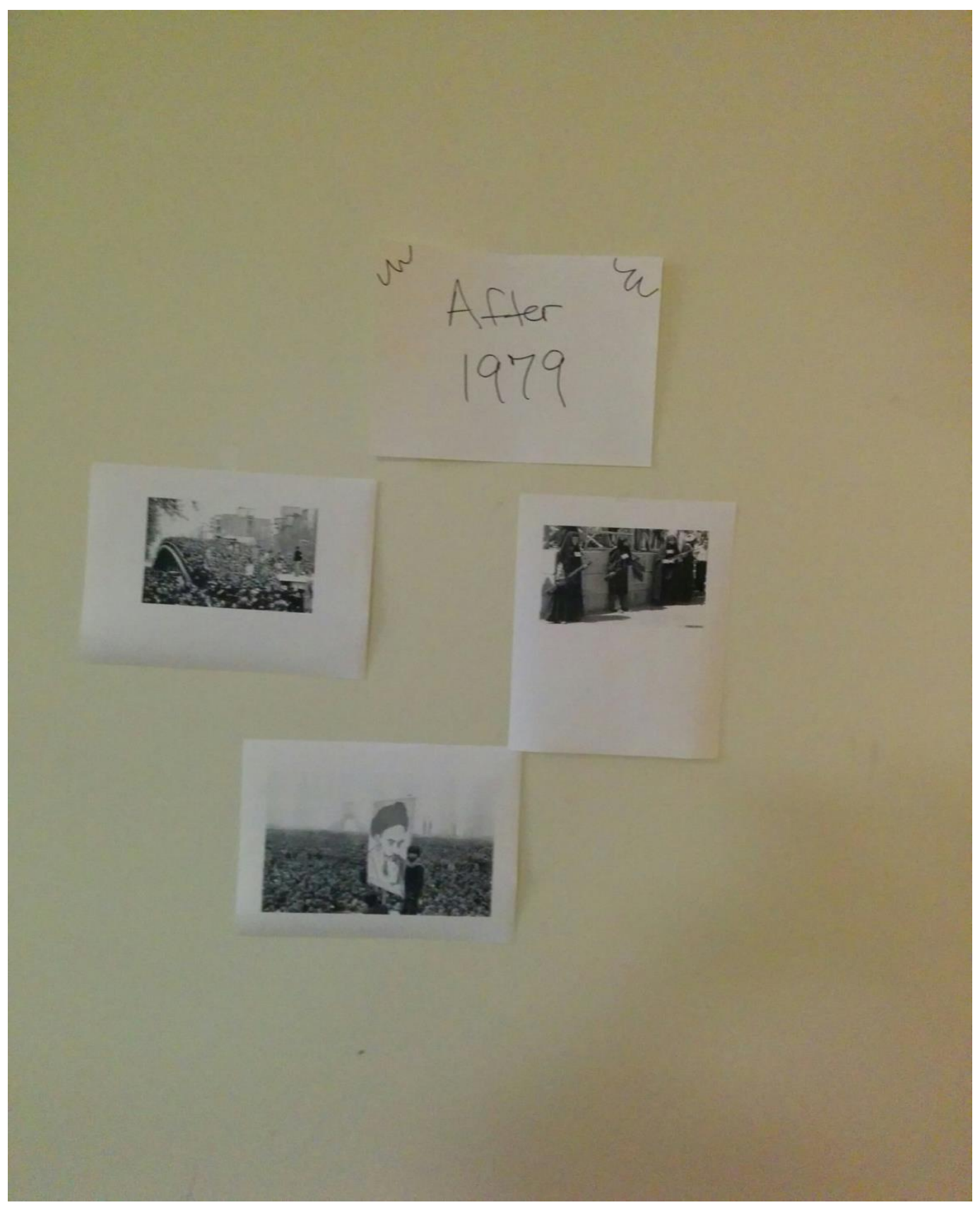


Figure 10. Gallery Walk Image.

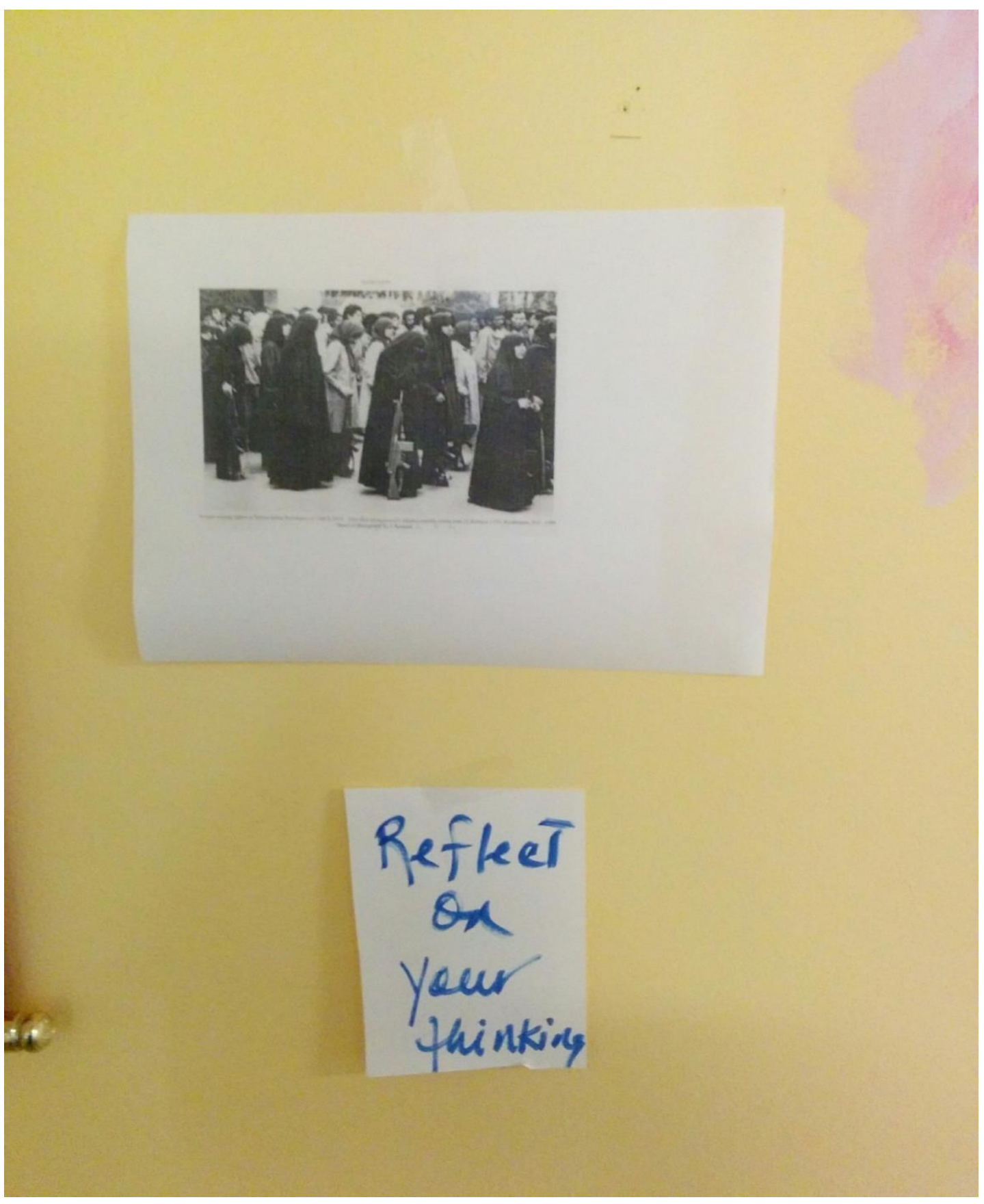


Figure 11. Gallery Walk Image.

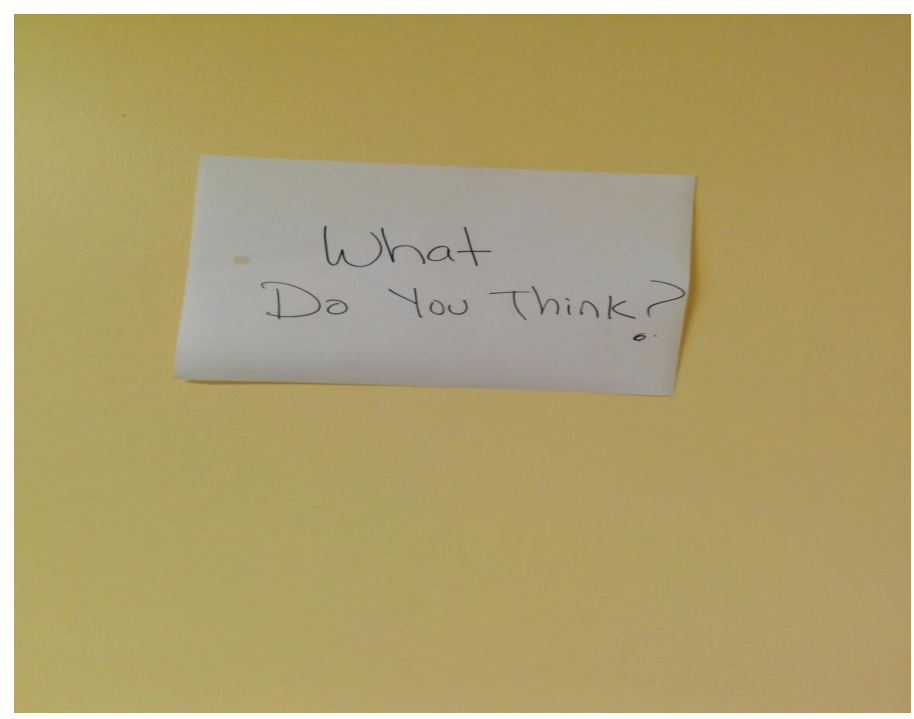

After students completed the gallery walk, she debriefed this activity by soliciting students' preconceived ideas about the Iranian Revolution, Islam, and gender roles in an Iranian context. The teacher, previous to this implementation, had shown these students the film, Argo. The purpose of showing this film was so that students could have a better understanding of both sides of the Iranian conflict. Then, during the implementation, to refresh students' memories, she showed a clip of the first five minutes of this movie. Afterwards, the participant discussed Sharia Law and modesty for women in countries like Iran, which tended to honor more traditional practices. The teacher then showed a YouTube video on how fashions have changed for Iranian women from the 1900s to the present entitled, One Hundred Years of Beauty series. Please refer to Figure 12 below. 
Figure 12. One Hundred Years of Beauty [YouTube Video]. (Iran-Sabrina, 2015)
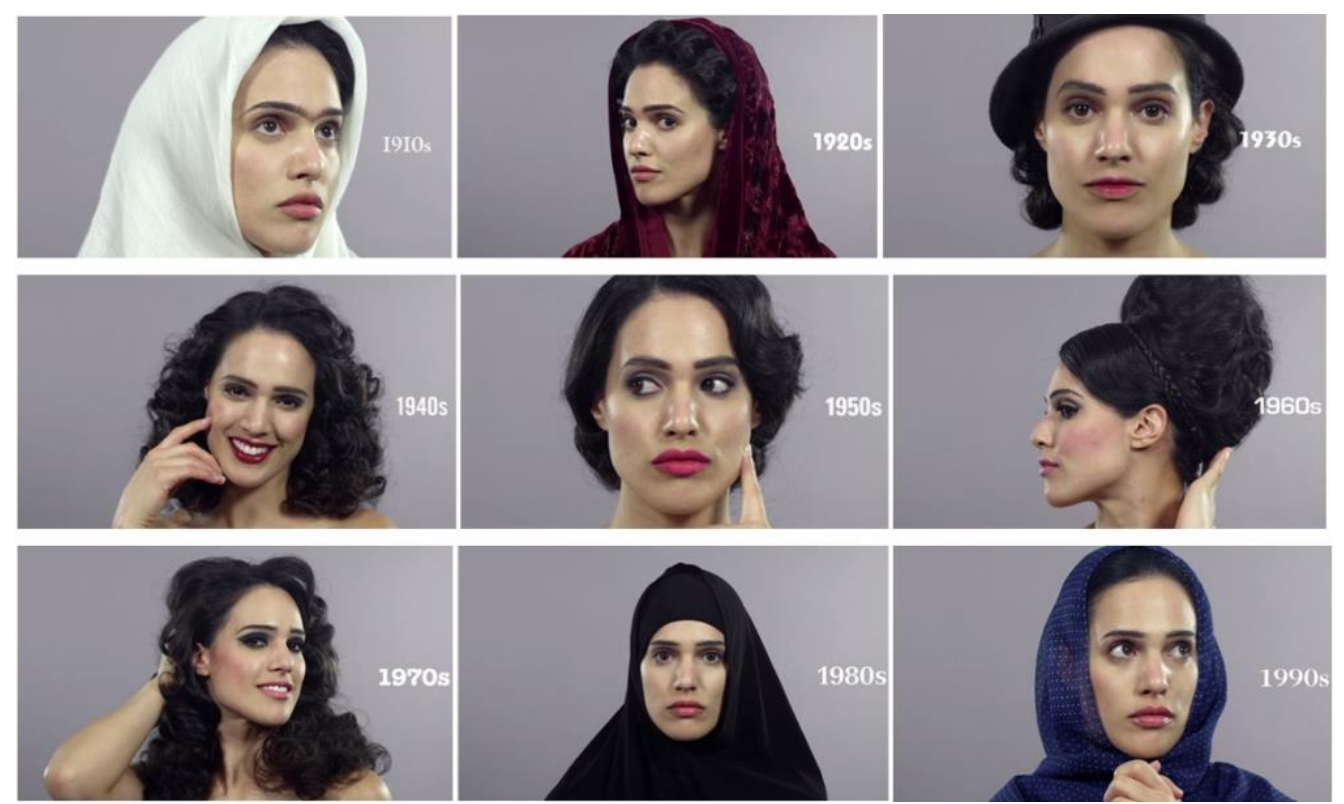

The participant commented during her content discussion on the background of the Iranian Revolution that

the revolution had brought back traditional dress for women who had become more westernized under the Shah Mohammad Reza Palavi. This was emblematic of and reinforced the philosophical frame since society wanted an ideological shift towards conservatism seen through the acceptance of Sharia Law and the covering of women through dress.

In response to her, the teacher said a student commented that "covering up is stupid." The participant responded that "modesty in dress for women was an intrinsic part of Islamic culture and it should be respected."

After this discussion, the teacher had students research on tablets, laptops, or other handheld devices, Marjane Satrapi, the author of the text that was read. Please refer to Figure 13 below. 
Figure 13. Marjane Satrapi. [Photograph]. (Byrd, 2016).

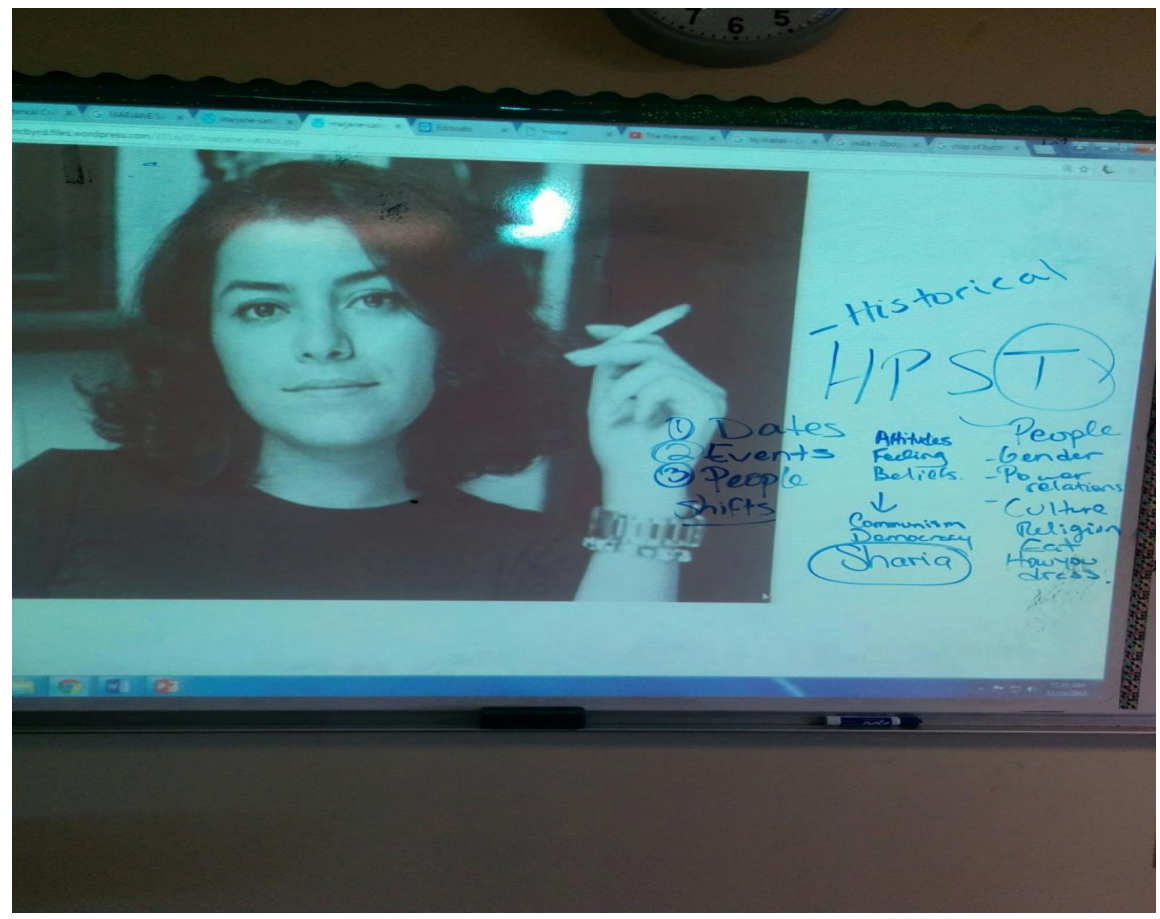

The participating teacher reminded the class that the intent behind having students research the author's background information to include an image was multifaceted: 1) to make a direct connect with the text, 2) to make the reading of the text more relevant, and 3) so that students can understand that an author's background influences his/her writing. In this implementation, the teacher explained that

Satrapi was against the revolution. She was a Shahist. Shahists were individuals siding politically with Mohammad Reza Pahlavi (the last Shah of Iran). Marjane did not side with the coup launched by the Ayatollah Khomeini. At an early age, Satrapi immigrated to Europe with her family and received a Western education.

The teacher commented that a student said "that understanding [Satrapi's] background will help because it influences what she writes"-an explanation of the author's background that seemed crucial in aiding in the students' overall understanding of the text. 
She continued the classroom discussion by explaining the Interactive Level of the framework. She articulated during observations that this level constituted

the dynamic between the author (Satrapi), the text (Persepolis), and the student reader (you)...this is referred to officially as a Hermeneutic Circle.... which means that these three aspects do not stand alone....they engage, effect, and interact with each other....this is what you all will be doing once you read the text.

This teacher further explained that "a text has a voice, and it can speak to you, but that the author of that text has bias and a point of view that needs to be identified."

Afterwards, she explained the Analytic Level (or second level of the framework). Here, the teacher discussed how each frame was defined and what constituted the H, P, S, and T. This was the initial orientation for students with respect to HPST. Hence, the participant instructed students to

refer back to the definition of each frame as you read the text, then you will find evidence in the form of direct quotes or paraphrasing that aligns best with the definition offered by the frame...then highlight what you find.

The teacher did this to help students understand the actual HPS process better. Following this explanation, she distributed the excerpts from the text. The students read the excerpts of Persepolis that the teacher distributed individually. Please refer to Figure 14-16 below.

Figure 14. Satrapi (2003) Persepolis text excerpt. 

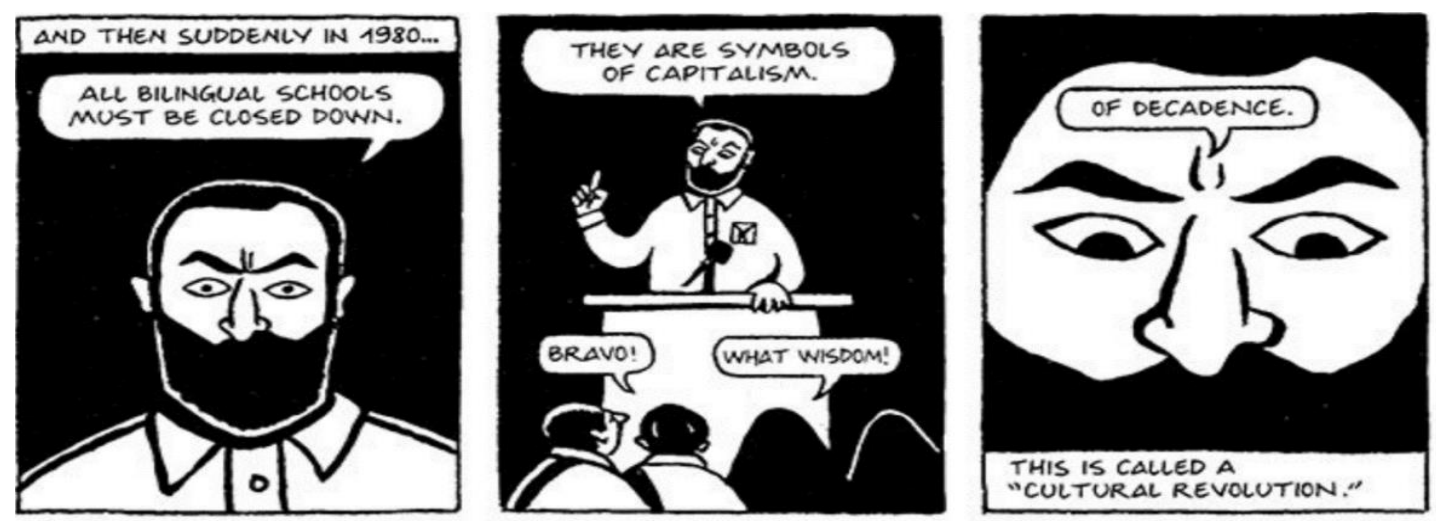

Figure 15. Satrapi (2003) Persepolis text excerpt. 


\section{- THE VEIL}
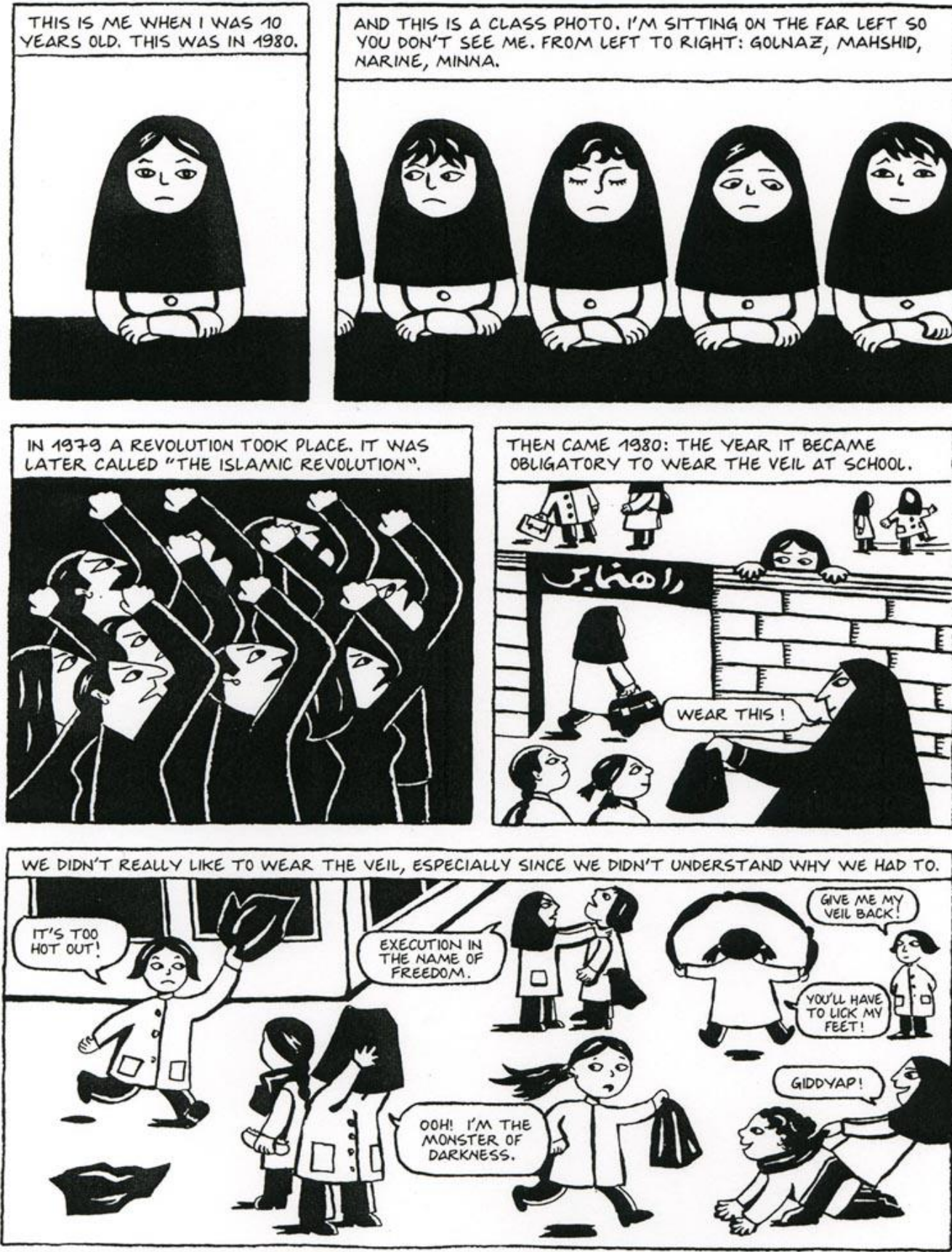
Figure 16. Satrapi (2003) Persepolis text excerpt.
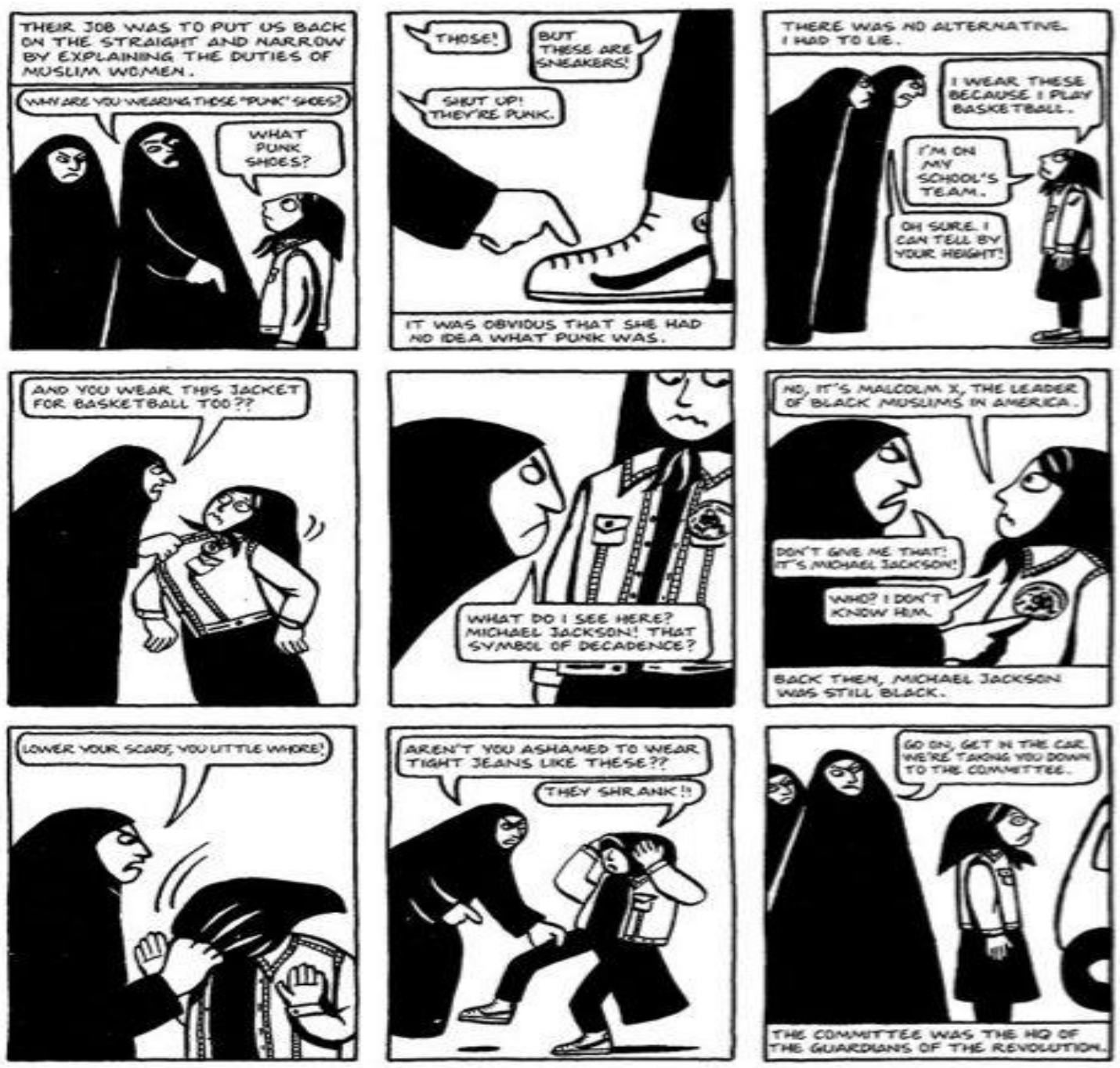
Next, the students were randomly placed into $\mathrm{H}, \mathrm{P}$, and $\mathrm{S}$ groups and they begin to procure evidence from the text. The participating teacher went around her classroom visiting each student group during this part of the lesson. She asserted via observation notes and her reflections that all the students were on task. The teacher made sure that all students in each group participated and contributed equally. By doing this, the participant assured that the students' levels of engagement were strong. Moreover, the teacher answered any questions that they had and gave clarifications whenever needed.

Finally, she reconvened the students groups and asked each to present their findings. These students groups identify evidence in the form of direct quotes or paraphrases from the text which was exemplary of their assigned frame. The student procured evidence was then written on the SMART Board by this teacher. Lastly, once the implementation was terminated, the teacher reported to me comments from students, as displayed in Table 1.

Table 1. Implementation One Findings.

\begin{tabular}{|c|c|}
\hline Frames & Student quotes relayed by teacher \\
\hline $\begin{array}{l}\text { Historical } \\
\text { (H) }\end{array}$ & $\begin{array}{l}\text { "In } 1979 \text { a revolution took place. It was called the Islamic Revolution." } \\
\text { "A lot of things changed when the new Shah was elected. This is how } \\
\text { the revolution of } 1979 \text { started.... that's when everything changed." }\end{array}$ \\
\hline $\begin{array}{l}\text { Philosophic } \\
\text { (P) }\end{array}$ & $\begin{array}{l}\text { "The author of this text stated that we didn't really like to wear the veil, } \\
\text { especially since we didn't understand why we had to." } \\
\text { "The veil is a philosophic ideal because Sharia Law requires or forces } \\
\text { women to hide their upper bodies." }\end{array}$ \\
\hline Societal (S) & $\begin{array}{l}\text { "Satrapi said why are you wearing punk shoes...but they are (Nike) } \\
\text { sneakers...it was obvious that she had no idea what punk was." }\end{array}$ \\
\hline
\end{tabular}




\begin{tabular}{|l|l|}
\hline $\begin{array}{l}\text { The } \\
\text { Takeaway } \\
(\mathrm{T})\end{array}$ & $\begin{array}{l}\text { "Islam changed; not everyone was for it. Not everyone has the same } \\
\text { ideal and beliefs. Historical, social and philosophical views can be } \\
\text { observed from this." } \\
\text { "My views on Islam have altered after hearing Marjane's story because }\end{array}$ \\
& $\begin{array}{l}\text { I didn't understand their culture or religion. But I do a little better now. } \\
\text { the same as those like ISIS." }\end{array}$ \\
\hline
\end{tabular}

The participant articulated that the following passage was offered by several students as evidence for the $\mathrm{H}$ frame, "In 1979 a revolution took place. It was called the Islamic Revolution." This reference recognized dates and events/occurrences within the piece. When reflecting on the text, another student continued by saying that a lot of things changed when the new Shah was elected. This is how the revolution of 1979 started.... that's when everything changed.

Here, the teacher suggested that "the student had identified the context of the text and had unpacked the ideas of contextualizing periodization and change over time."

The participating teacher told me that students identified the following excerpts as exemplary of the P frame, "the author of this text stated that we didn't really like to wear the veil, especially since we didn't understand why we had to." She then recalled that a student remarked that "the veil is a philosophic ideal because Sharia Law requires or forces women to hide their upper bodies." In testament to this, the teacher said some students were able to recognize the imposition of wearing the veil as a philosophical concept grounded in religious beliefs. Generally students understood how cultural values were implemented into law and how these affect the populace. The participant remarked that 
while most students grasped this concept, a few students in the class struggled connecting how a belief system, prompted changes.... or the preservation of laws, religious practices, and accepted social norms aided in this... and citizens with differencing beliefs opposed these same practices in Iran [sic].

Moreover, she said that "students can understand social structure but did not fully grasp the abstract philosophical concepts of values and how they seep into cultural traits practiced in everyday life." At this point, this teacher commented that there might be a need to have a second implementation using this same topic to reinforce that students understand $\mathrm{P}$.

Lastly, the participant articulated that students were able to identify the following excerpts as exemplary of the S Frame, "Satrapi said why are you wearing punk shoes...but they are (Nike) sneakers...it was obvious that she had no idea what punk was." The evidence described by the teacher suggested that students seemed to be extracting content knowledge from the application of frames to the actual text they read. This teacher remarked that "students used many excerpts from the two previous frames interchangeably such as cultural practices with cultural values because they grasped the complexity of document analysis and categorized themes within a text." Generally, she remarked that the S frame "was the easiest for students to understand because it dealt with humans and the social constructs we create."

For the T frame, a Think-Pair-Share handout was then distributed by the teacher. The handout was intended for students to think individually and then share with classmates, creating a platform for discussion. Students were asked to write out their own perspectives on Islam after reading the excerpts provided of this graphic novel and going through the HPS process. The participant said that a student extrapolated 
that Islam changed; not everyone was for it. Not everyone has the same ideal and beliefs. Historical, societal and philosophical views can be observed from this.

Moreover, the teacher uncovered that other students commented that

my views on Islam have altered after hearing Marjane's story because I didn't understand their culture or religion. But I do a little better now.

The participant also unpacked that other students commented that "they still feel that some Muslims are radical, but I know not all feel or think the same as those belonging to ISIS.” These comments suggested that students' perceptions of Islam and Iranian gender roles had possibly changed.

\section{Follow-up interview on Implementation One}

After Implementation One, a follow up interview occurred with the participant. The collected data suggested that students in participanting teacher's class utilizing the HPST Framework with Satrapi's graphic novel Persepolis, challenged notions of gender roles in Islamic nations. For example, students were shocked that the author embodied a free-thinking, Western woman because she was raised in a traditionalist part of the world, Iran. When they observed an image of the author in class, this teacher said that students responded that "she looks sexy and confident." These students were shocked to see a "Westernized" Muslim woman. This reaction indicates that the image of an uncovered woman smoking a cigarette challenged their stereotype of Muslim women.

After applying the HPST process to this text, many students possibly changed their views about the revolution. They realized that perceptions of one group within a nation are not representative of the entire group. Finally, the teacher realized that students identified Satrapi as a dissident and were surprised to see that some Iranian "women were 
more militant... and they supported the revolution... and they had more of a role after the Revolution." Additionally, this teacher found students were displaying geographical context which allowed her to infuse geography into the class. Regional bias and stereotypes surfaced during the class conversation. The participant remarked that "the students felt they understood the notion of being a Muslim woman until the teacher challenged these ideas with Marjane's picture." The teacher stated the geographic and gender bias held by students produced multifaceted class discussion by first meeting the author in a role not shown in the book or in the students' conceptualization of a Muslim woman, much less any woman in the region known as the Middle East.

By the end of this interview, the participant and I decided, that there was a definite need to plan out a second implementation session using the same topic to assure that students understood the P frame.

\section{Implementation Two: Persepolis Again}

Implementation Two mirrored Implementation One. The teacher utilized the same implementation protocol. She began the lesson, using a gallery walk, soliciting students' preconceived ideas about this revolution, Islam, and gender roles in an Iranian context. She then debriefed this session by answering any student questions and reminding students that they would answer an essential question at the end of the lesson. Following this, the teacher showed a five minute clip of the film, Argo (a movie summarizing the Iranian Revolution) and the One Hundred Years of Beauty (a YouTube video depicting how Iranian women's fashions have changed in 100 years). The participant, on her classroom's SMART Board, displayed the same image of Marjane Satrapi (as in implementation one) author of the text Persepolis which students read. She articulated 
that students upon seeing this image "were again amazed to see an unconventional Muslim women with short hairy, looking sexy and smoking." Afterwards, she reminded students that "Satrapi was a Shahist and had left Iran for Europe at a very young age and received a Western education." The teacher then engaged students in a brief discussion on Sharia Law.

Afterwards, the participant described the Interactive Level. Here, she reminded the class that

the intention behind giving you background information on this author was: to make a direct connect with the text, to hopefully make the reading of the text more relevant for you, and so that you can understand that an author's background influences his/her writing.

Following this, she described the Analytic Level to her students by explaining each frame. During this portion of the lesson, the teacher discussed how each frame was defined and what constituted $\mathrm{H}, \mathrm{P}, \mathrm{S}$, and T. The participant unpacked that since $\mathrm{P}$ was hard for students to fully understand, she made it a point to clearly and slowly explain this frame to students. She discussed its definition carefully and applied what constituted $\mathrm{P}$ back to the text students read. For example, the teacher commented that this frame is made up of the beliefs associated with the historical event itself...in the graphic novel, Persepolis, this would be the philosophical factors behind the 1979 Iranian Revolution......also, the P frame is interested in schools of thought, public opinion and the '-isms' of the period....keep in mind what we discussed about Sharia Law and how these religious ideals made Iran change and how these issues affected Iranians....especially women's dress and overall role.

The teacher then grouped students into pods, namely an $\mathrm{H}$ group, a $\mathrm{P}$ group, and an $\mathrm{S}$ group. The participant then presented the class with the same excerpts of Persepolis, as in Implementation One, which students read individually. Within their assigned groups, the students identified evidence of the various frames (namely: the $\mathrm{H}, \mathrm{P}$, and $\mathrm{S}$ ) within 
specific portions of the text. The teacher went around her classroom visiting each student group during this part of the lesson. She asserted that all the students were on task. Moreover, she made sure that all students in each group participated and contributed equally. By doing this, she assured that the students' levels of engagement were strong. Moreover, this teacher answered any questions that they had and gave clarifications whenever needed. For the takeaway, students were asked to write out their own perspectives on Islam after reading this graphic novel and going through the HPS process using a Think-Pair-Share handout. "This is a worksheet for student note-taking during partnered classroom discussions. The teacher typically sets forth the questions for discussion and each student takes notes on his/her answers, as well as his/her partner's answers. The pair of students then decides what will be shared with the rest of the class." Please refer to appendix F for the Think-Pair-Share Worksheet. Finally, she reconvened the student groups and asked each to present their findings. These students groups identified evidence in the form of direct quotes (or paraphrasing) from the texts which were exemplary of their assigned frames. The student procured evidence was then written on the SMART Board by her. Lastly, once this second implementation was completed, the participating teacher reported to me comments students had made. 
Table 2. Implementation Two Findings.

\begin{tabular}{|l|l|}
\hline Frames & Student quotes relayed by teacher \\
\hline $\begin{array}{l}\text { Historical } \\
(\mathrm{H})\end{array}$ & $\begin{array}{l}\text { "In } 1979 \text { a revolution took place...then came 1980, the year it became } \\
\text { obligatory to wear the veil at school." }\end{array}$ \\
\hline $\begin{array}{l}\text { Philosophic } \\
(\mathrm{P})\end{array}$ & $\begin{array}{l}\text { "Wearing modernized clothing is highly frowned upon by the Muslim } \\
\text { community. The philosophical ideas of girls are changed and other } \\
\text { ideologies (such as wearing the veil) are imposed on them." }\end{array}$ \\
\hline Societal (S) & $\begin{array}{l}\text { "That when Sharia Law was imposed that there was a change of } \\
\text { culture that occurred.... Western Culture was frowned upon by Islamic } \\
\text { Culture." }\end{array}$ \\
\hline $\begin{array}{l}\text { The } \\
\text { Takeaway (T) }\end{array}$ & $\begin{array}{l}\text { "Our cultures are very much alike until it comes to religion. That's } \\
\text { why I think it's wrong to stereotype Islam/Iran as we wouldn't' like it } \\
\text { done to us." }\end{array}$ \\
\hline
\end{tabular}

The participant cited that the following passage was offered by students as evidence for the H frame, "In 1979 a revolution took place...then came 1980, the year it became obligatory to wear the veil at school." This reference made by students not only recognize dates and events within the piece, but also the idea of needing a before, during, and after period to conceptualize historical periodization. She told me that students identified the following excerpts as exemplary of the P frame,

wearing modernized clothing is highly frowned upon by the Muslim community. The

philosophical ideas of girls are changed and other ideologies (such as wearing the veil) are imposed on them.

This teacher remarked that students

started to understand how cultural values were implemented and eventually became law...moreover, students connected how a belief system prompted changes in religious practices, and how the philosophy behind Sharia Law affects social norms and political legislation in traditional countries like Iran.

Moreover, she commented that "students now understood social structure and the abstract concepts of values and philosophical cultural traits." Lastly, the participant articulated that student were able to identify the S frame easily. She cited that one student remarked 
that "when Sharia Law was imposed that there was a change of culture that occurred.... Western Culture was frowned upon by Islamic Culture.” The evidence described by her here too suggested that students seemed to be extracting content knowledge from the application of frames to the actual text they read. The teacher remarked that "students used many excerpts from the two previous frames interchangeably again."

As the physical embodiment of the T frame, a Think-Pair-Share handout (please refer to appendix G) was then distributed by the participating teacher. The handout was intended for students to think individually and then share with classmates, creating a platform for discussion. Students were asked to write out their own perspectives on Islam after reading this graphic novel and going through the HPS process. The teacher said that a student group stated "our cultures are very much alike until it comes to religion. That's why I think it's wrong to stereotype Islam/Iran as we wouldn't' like it done to us." This activity revealed that perhaps students' opinions had changed after this lesson.

\section{Discussion on Implementations One and Two}

These implementations were effective in creating a relationship between students and the author, having them recognize Satrapi as a marginalized voice within the larger context of gender relations. The participant commented that "the dominate Western Perspective is that Middle Eastern women are relegated to passive roles in society." The first step in the HPST Framework was to look up the author's biography, including an image, so that students could understand there was a relationship between the author, text, and reader (referred to officially as a Hermeneutic Circle). She ascertained that "having students inquire about and learn information on the author's background created 
a deeper connection to the reading of the text." The inception of the Hermeneutic Circle was evident in these implementations when the students saw an image of the author and mentioned how she looked Western; in this case the author was smoking a cigarette, smiling, and looking casual. The students knew Satrapi was Iranian, but the teacher said they respond to the image by saying "She looks sexy and confident." With this comment, the students were possibly inferring about the author's life and were seemly trying to make connections even before they were engaged with the reading of this graphic novel. Moreover, by learning about the author, students were already trying to possibly explain what they would find in the text.

Also, the participant alluded that students instead of pointing out Satrapi as being a possible terrorist, based on their preconceptions about Iran, Islam, and what they had previously seen in the media, students felt a sense of compassion for this woman who might be stereotyped. She articulated that

The Hermeneutic Circle established a relationship between reader and author through the use of biography in narrative. Students looked at the individual (Satrapi) and how the Iranian Revolution affected her rather than a religious group or the entire country.

The teacher said that students wanted to know more about Satrapi and were interested in her background and point of view, constantly mentioning during the implementations that "she, Marjane" was feeling one way or another. Moreover, students were able to identify the tone and language in some of the excerpts, explaining that there was a "loss of identity" that young Marjane experienced in the excerpt from "The Veil" based on her facial expression seen graphically as well as the few words printed on the excerpt. In addition, they recognized how what was said in this excerpt aligned with the dynamics behind the forces of the Hermeneutic Circle. The participant commented that 
the students were able to understand that reading the text Persepolis which is authored by Satrapi, who is a modern, short haired, Muslim woman with a Western education that smokes, was sexy, confident, and not necessarily looked any different than themselves.

Finally, the participating teacher commented that she felt that "students made personal connections with the author and achieved the first step of the framework which is the identification of Hermeneutic Circle."

The participant unpacked that students apparently understood the $\mathrm{H}$ frame easily. She was convinced that students were able to identify the historical occurrence itself (a revolution), multiple dates associated with this history (e.g. 1979), geographical locations (e.g. Iran), and the notion of change over time (e.g. issues that transpired pre and post the 1979 revolution that changed Iran). She said that students found this frame to "jumped out at them as they read." However, it is important to mention again, that the teacher said that students had the most trouble understanding the Philosophical frame. The teacher reaffirmed that the

students understood that Muslim women, even young girls, actively protested the new implementation of wearing the veil, different from the images of support for the revolution and its traditional ideas such as the wearing of the veil...Moreover, students recognized that women were taking a less passive role...that they are protesting against an idea that they don't have, meaning that the girls at Marjane's school were unhappy with the new dress code.

Nonetheless, students possibly understood the philosophical connection between the imposition of Sharia Law and the wearing of veil by Iranian women. The participating teacher said that "many students came to this realization after Implementation Two."

With the societal frame, the participant commented that students wrote that "the different restrictions, like the veil, show that there are problems in the society." Moreover, she felt that students understood Muslim women are not all the same and they 
themselves had a conflict with their government because of this. The teacher commented that "the HPST seemly allowed controversial topics such as the wearing of the veil to be seen by students as a problem and an imposed societal construct." The students using a Think-Pair-Share activity (which asked them to think about an essential question or concept, write down their thoughts, and then share these with a classmate) at the end of the implementations were asked if their thoughts on Iran/Islam had changed. She articulated that students shared

I got to see a much harsher lifestyle and how the shift in the leader Ayatollah Khomeini can make such a big impact in someone's life.

Again, here she mentioned that perhaps student's thinking had possibly changed.

\section{Implementation Three: 1492 Diary of Christopher Columbus}

The third implementation utilized the topic of Christopher Columbus and loosely mirrored implementations One and Two. The participating teacher began this implementation with a hook activity. She showed her students an image of the painting by Dioscoro Teofilo Puebla, The First Landing of Christopher Columbus in America, on the classroom's SMART Board. Please refer to Figure 17. 
Figure 17. Tolin (1862). The First Landing of Christopher Columbus in America.

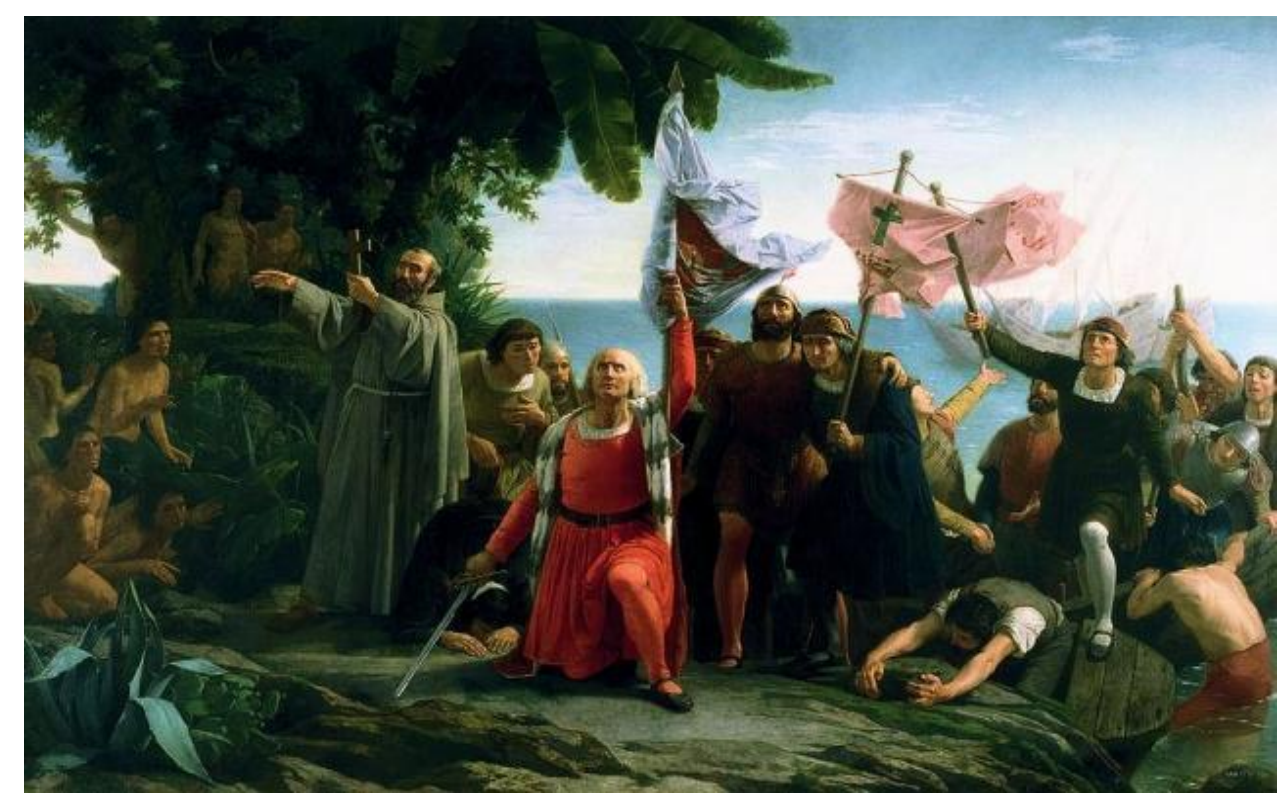

This was an abridged version of the gallery walk activity used in previous implementations. This teacher mentioned that because students were being dismissed early that day, she did not have the class time to have them participate in a standard gallery walk. The gallery walks used in Implementations One and Two entailed having students enter the classroom that was transformed to resemble a museum exhibit by adhering images on opposing walls of the room in such a way that students needed to physically get up and view them.

The participant, afterwards, had students ponder on the essential question: Was Christopher Columbus a friend or foe of history? She told me that she instructed students "to keep this question in mind as [they] go through the lesson.....and that [the students] would be answering this question at the end." Also, the teacher shared with me during an interview, that "she wanted students to keep in mind the terms: conquered, conqueror, Catholicism, colonialism and nationalism (which they had discussed previously) and 
what dynamic these created." With that said, the participant felt that "the students were already familiar with Columbus being portrayed as in the painting: glorious and triumphant." However, the participating teacher explained to students that

[Columbus] was appointed by the Spanish government of the time as Admiral... Unfortunately, for him, the Admiral was eventually put on trial by the end of his tenure for inequities that he was accused of.

Additionally, the teacher commented that "when she was young Columbus was seen as a great hero and was celebrated. Now, however, some challenge this notion."

The participating teacher mentioned to me that she

believed that the more students understood Columbus's background; the more students would understand the reading and their comprehension would hopefully be stronger.

The discussion that ensued as the teacher debriefed Tolin's painting not only explained and conceptualized Columbus's background, but also exposed students again to the dynamics of the Hermeneutical Circle. The teacher told me that she expressed to students that

there are forces existing between the author (Columbus), the readers (you guys), and the actual text itself (his diary). The more you understand this dynamic; hopefully the stronger your comprehension will be [sic]."

Then, she asked students to look up more facts online about Columbus on handheld devices, such as: cellular phones, tablets and laptops. Afterwards, the participant debriefed this activity by asked students to share what they found. Finally, the teacher showed a YouTube video on Columbus to continue familiarizing students with the topic called, Christopher Columbus - Explorer | Mini Bio published by Biography.com. The participating teacher articulated to me that she wanted students to pay close attention to this video because it discussed the main themes and issues surrounding Columbus' first voyage. It used heroic/dramatic 
music and imagery effectively, with many flags for example, which ultimately dealt with the ideas of nationalism, empire, and religion (Catholicism). This video also depicted Columbus traditionally falling to his knees upon reaching the shores of the New World and kissing the ground while holding up a crucifix which mirrored the painting I showed students in the first part of the lesson.

Another debriefing session occurred after the students watched this video which further explained the topic and gave students more background context and details on Columbus. The teacher then grouped the class into three pods, namely: an $\mathrm{H}$ group, a $\mathrm{P}$ group, and an S group. Preceding this, she gave each student group a sheet of blank paper that was used to write the passages from the text — in either direct quotes or paraphrases - which students selected as exemplary of their assigned frames. Afterwards, the teacher distributed excerpts of text which were individually read by students. These excerpts were selected from the 1492 Diary of Christopher Columbus from the historyguide.org which were divided chronologically by dates and included actual numerical days of the week, month, and year. Please refer to Figures 18-19 below. 
Figure 18. Diary of Christopher Columbus (1492) excerpt.

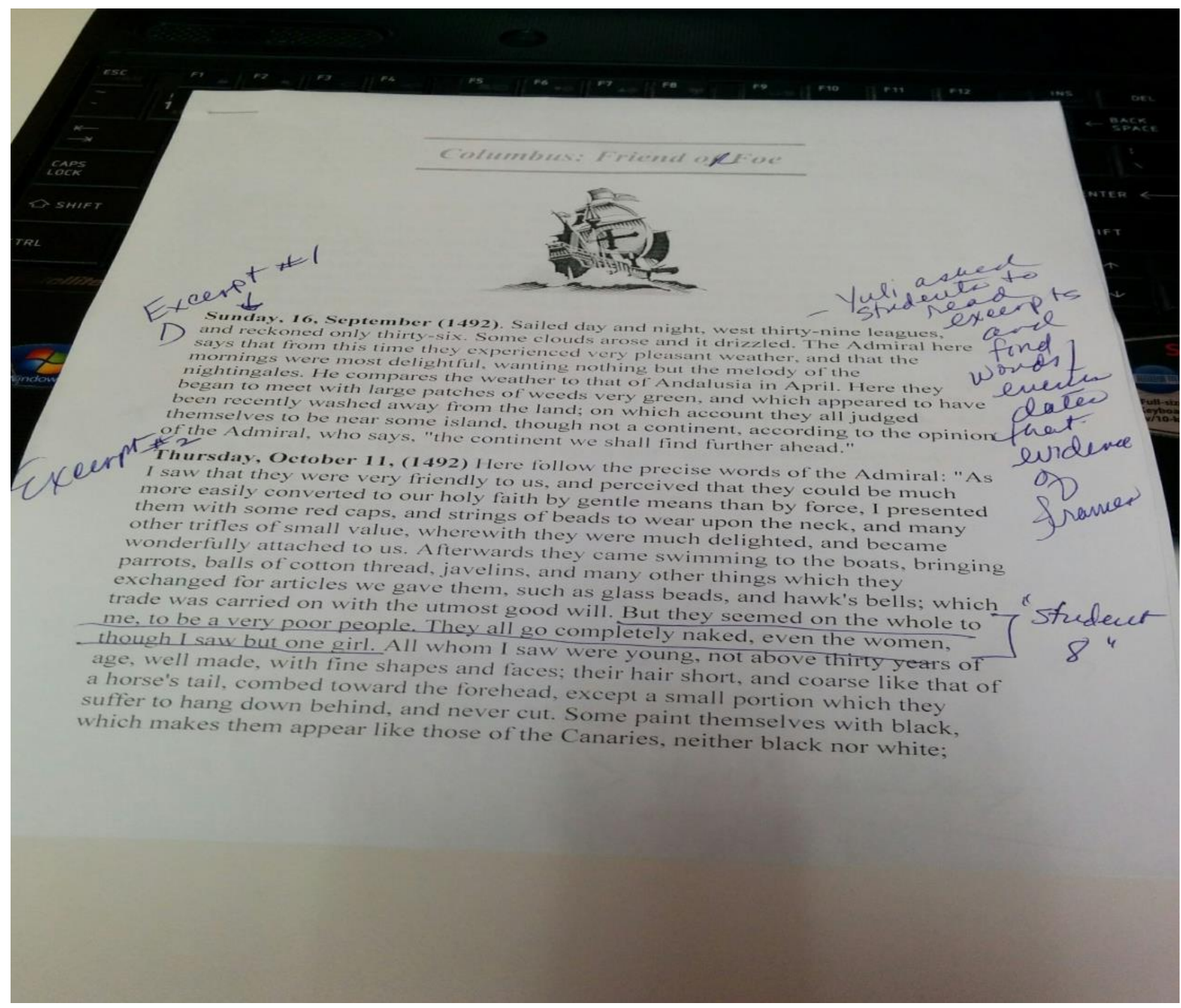


Figure 19. Diary of Christopher Columbus (1492) excerpt.

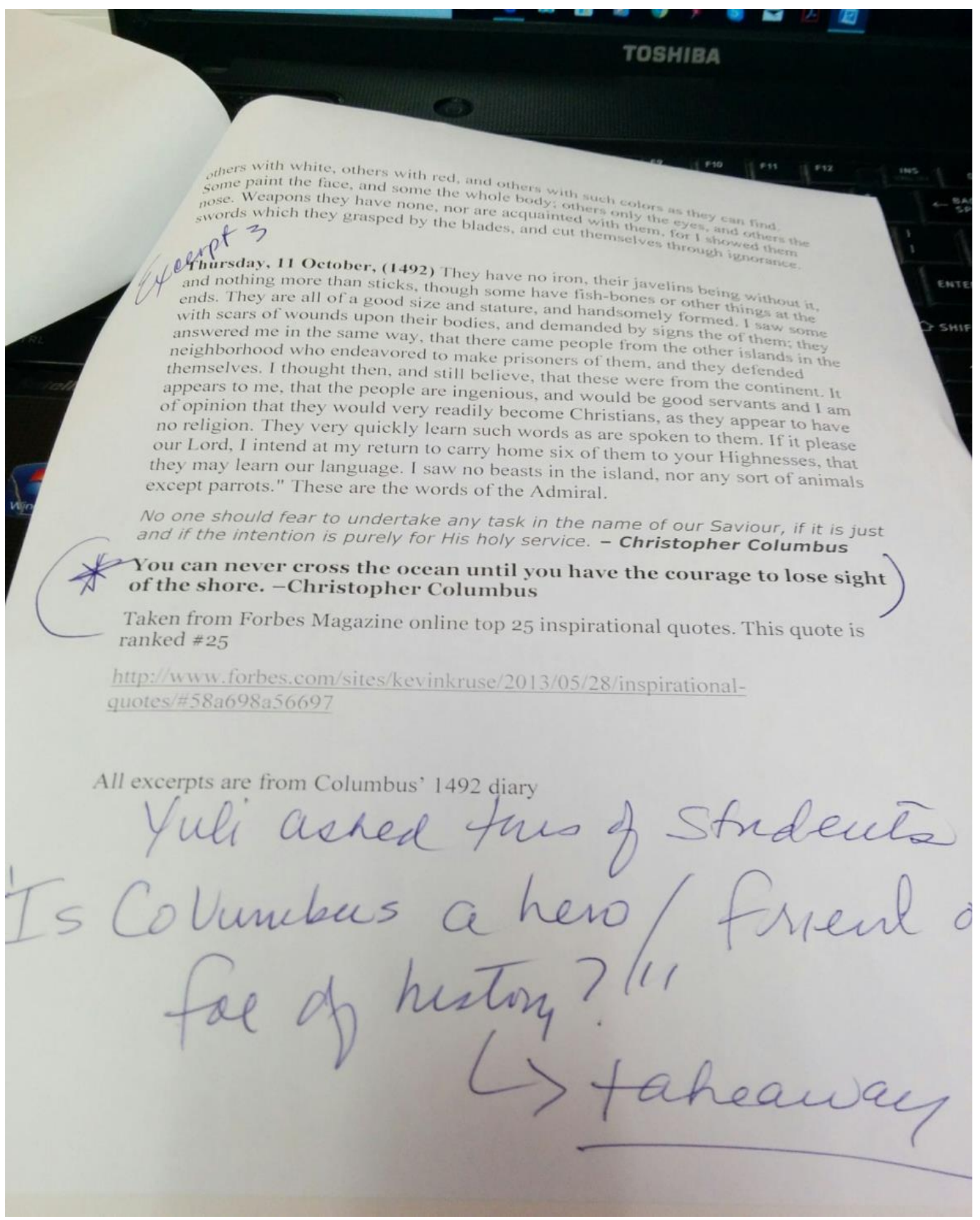

111 
The teacher then proceeded to explain the frames because these students were already familiar with the HPST and its usage. Nonetheless, she reminded students what constituted the H, P, and S and what these frames meant. First, the participant asked the students to read the excerpts of the text individually. Second, the teacher instructed the students to find passages --either direct quotes or paraphrases--that were exemplary of the each frame's definition. Each student group wrote the evidence they procured on the blank sheet of paper distributed at the beginning of the lesson. For the Takeaway frame, she then asked each student to answer the essential questions: was Christopher Columbus a friend or foe of history? This teacher went around her classroom visiting each student group during this part of the lesson. She asserted that all the students were on task. The participant made sure that all students in each group participated contributed equally. Lastly, she assured that the students' levels of engagement were strong. Moreover, this teacher answered any questions that they had and gave clarifications whenever needed. Finally, she reconvened the session and asked student groups to present the evidence that they had procured. The teacher then wrote student findings on the SMART Board.

Table 3. Implementation Three Findings.

\begin{tabular}{|l|l|}
\hline Frames & $\begin{array}{l}\text { Student quotes relayed by teacher } \\
\text { Historical } \\
\text { (H) }\end{array}$ \\
$\begin{array}{l}\text { "9/16/1492: the crew believes they're near land due to weed patches } \\
\text { floating on the water." } \\
\text { "1492-They finally arrived after sailing days and nights." } \\
\text { "Was written on the 16th of September of 1492...they are near to a } \\
\text { continent or an island." } \\
\text { "That the second except was written on October 11th of 1492." }\end{array}$ \\
\hline
\end{tabular}




\begin{tabular}{|c|c|}
\hline $\begin{array}{l}\text { Philosophic } \\
\text { (P) }\end{array}$ & $\begin{array}{l}\text { "Christopher Columbus believes that he will find a continent further } \\
\text { ahead...finding faith in a new land." } \\
\text { "Columbus believes the best way to control the indigenous peoples was } \\
\text { by being nice...also, he believes people from the continent (Europe) are } \\
\text { attracted to those of the island, and it makes them vulnerable to follow } \\
\text { his religion...they hold on to hope of finding a new land because how } \\
\text { much Columbus values Nationalism." } \\
\text { "the indigenous population did not place much value on materials } \\
\text { possessions...they had no set religion and therefore, have no set } \\
\text { values...the women of the natives were naked as opposed to the } \\
\text { European women who were kept to a high standard of modesty." } \\
\text { "To the natives, nudity of women was a sin (beliefs)...it was believed } \\
\text { that the natives did not have a religion...the native believed that the } \\
\text { Explorer Columbus would enslave them as other island visitors would } \\
\text { have tried to do...the natives valued the following resources: parrots, } \\
\text { balls of cotton \& thread, and javelins (values). Europeans were } \\
\text { Christians, but islanders had no religion...and Native Americans saw } \\
\text { Columbus as a God...Columbus perceived them to be easier to convert } \\
\text { to Christianity.". }\end{array}$ \\
\hline Societal (S) & $\begin{array}{l}\text { "Columbus witnesses a different civilization and notes their unique } \\
\text { lifestyles...their way of life is completely different from how he and his } \\
\text { men were...the people on the island do not dress and they are } \\
\text { completely naked...The indigenous people had various customs that } \\
\text { were considered strange to the Europeans. Also, the two parties traded } \\
\text { amongst themselves to create an amicable bond. They also had no } \\
\text { weapons due to their lack of need for defending against other } \\
\text { groups...They would convert to Christianity if they were taught to do } \\
\text { so. He planned to use them as servants." } \\
\text { "Natives had no iron, were poor, and severely undeveloped...Hardly any } \\
\text { animals and the Admiral wants to take women and plunder. Natives } \\
\text { never cut their hair and had no weapons. The other island attempted to } \\
\text { make prisoners out of natives Columbus found out... Columbus' troops } \\
\text { exert higher power; superiority over the natives (emphasis added)." } \\
\text { "the indigenous peoples came swimming to Columbus's boats with } \\
\text { tribute showing a power hierarchy...Natives painted themselves with } \\
\text { colors as a custom among their society or culture...Both men and } \\
\text { women were naked in contrast to the people of Europe who were } \\
\text { always covered. This shows more gender equality..." }\end{array}$ \\
\hline
\end{tabular}




\begin{tabular}{|c|c|}
\hline & $\begin{array}{l}\text { "Weapons of advanced technology did not exist in their culture. This } \\
\text { culture never used weapons...they wanted to bring six islanders back to } \\
\text { Europe. Islanders are quick learners." }\end{array}$ \\
\hline $\begin{array}{l}\text { The } \\
\text { Takeaway } \\
\text { (T) }\end{array}$ & $\begin{array}{l}\text { "Viewed Columbus as a foe of history because his wrong-doings } \\
\text { overshadowed his accomplishments. Towards the end of his life, even } \\
\text { his own people turned on him because of his lack of respect for human } \\
\text { life. He used God to justify his greed and genocidal tendencies. While } \\
\text { others may argue that he was a product of his time, does not change } \\
\text { the fact that his actions were wrong." } \\
\text { "Columbus was neither a friend nor foe of history...he was both because } \\
\text { to Europeans, he discovered a 'New World,' but to the indigenous } \\
\text { people of the island he was a foe that pillaged and enslaved the people } \\
\text { of the island." }\end{array}$ \\
\hline
\end{tabular}

The participant cited that the following passages were offered by students as evidence for the $\mathrm{H}$ frame, “9/16/1492: the crew believes they're near land due to weed patches floating on the water." Another group said, "1492-They finally arrived after sailing days and nights." Yet other students commented that the first excerpt "was written on the 16th of September of $1492 . . . t h e y$ are near to a continent or an island." The last student group said "that the second except was written on October 11th of 1492."The teacher affirmed, in the post implementation interview, that overall

many student groups seemly understood the Historical frame because they demonstrated accuracy labeling the excerpts of this narrative with dates (specifically months, days, and years) and subsequent historiographical elements, such as: periodization, change over time, and geographic locations which exemplary of $\mathrm{H}$.

This teacher cited that the following passages were offered by students as evidence for the P frame, "Christopher Columbus believes that he will find a continent further ahead...finding faith in a new land." Another student group commented that Columbus believes the best way to control the indigenous peoples was by being nice....also, he believes people from the continent (Europe) are attracted to those of the island, and it makes them vulnerable to follow his religion...they hold 
on to hope of finding a new land because how much Columbus values nationalism.

The last student group articulated that, "the indigenous population did not place much value on materials possessions...they had no set religion and therefore, have no set values...the women of the natives were naked as opposed to the European women who were kept to a high standard of modesty." Moreover, this same group said,

To the natives, nudity of women was a sin (beliefs)...it was believed that the natives did not have a religion...the native believed that the Explorer Columbus would enslave them as other island visitors would have tried to do...the natives valued the following resources: parrots, balls of cotton \& thread, and javelins (values). Europeans were Christians, but islanders had no religion... and Native Americans saw Columbus as a God...Columbus perceived them to be easier to convert to Christianity.

The participant confessed to me, that at the beginning of this implementation, she felt a bit of trepidation about her students not fully understanding the Philosophical frame. This coupled by the fact that $\mathrm{P}$ previously served to be more challenging for students unnerved her. To be quite frank, this unnerved me as well. She and I were both surprised to see that religion and the treatment of the indigenous peoples by Columbus were major themes that emerged in students' responses. Religion, which for Columbus was Roman Catholicism, and the ideals of nationalism that he (and more importantly the Spanish Crown at the time) espoused aligned directly with Ps definition that constituted identification of the schools of thought and the -isms of the period. The teacher eluded that she, "felt that students, during this implementation, apparently understood these philosophical precepts better...they were starting to get it!"

The participating teacher shared that the following passages were offered by students as evidence for the $\mathrm{S}$ frame, they articulated that 
Columbus witnesses a different civilization and notes their unique lifestyles...their way of life is completely different from how he and his men were...the people on the island don't dress and they are completely naked...The indigenous people had various customs that were considered strange to the Europeans. Also, the two parties traded amongst themselves to create an amicable bond. They also had no weapons due to their lack of need for defending against other groups...They would convert to Christianity if they were taught to do so. He planned to use them as servants.

This student found that

natives had no iron, were poor, and severely undeveloped...Hardly any animals and the Admiral wants to take women and plunder. Natives never cut their hair and had no weapons. The other island attempted to make prisoners out of natives Columbus found out... Columbus's troops exert higher power; superiority over the natives (emphasis added).

Nevertheless, yet other students unpacked that the indigenous peoples

came swimming to Columbus's boats with tribute showing a power hierarchy...Natives painted themselves with colors as a custom among their society or culture...Both men and women were naked in contrast to the people of Europe who were always covered. This shows more gender equality.

These students voiced that "weapons of advanced technology did not exist in their culture. This culture never used weapons...they wanted to bring six islanders back to Europe. Islanders are quick learners.” The teacher felt that the $\mathrm{S}$ was fairly straightforward for students to understand. In her opinion, she commented to me, that the student groups successfully identified how this narrative not only chronicled Columbus's experiences, but also how the indigenous peoples were possibly perceived and the nuances of their culture unpacked.

For the $\mathrm{T}$ frame, the participating teacher asked students to answer the following question: was Christopher Columbus a friend or foe of history? She reported that of the eight student groups participating, four felt Columbus was a foe and four articulated he 
was both. For example, this teacher assured that the following student viewed Columbus

as a foe of history because

life,

his wrong-doings overshadowed his accomplishments. Towards the end of his

even his own people turned on him because of his lack of respect for human life.

He used God to justify his greed and genocidal tendencies. While others may argue that he was a product of his time, that does not change the fact that his actions were wrong.

Other students commented that

Columbus was neither a friend nor foe of history...he was both because to Europeans, he discovered a 'New World,' but to the indigenous people of the island he was a foe that pillaged and enslaved the people of the island.

None of the student groups categorized him solely as a friend of history. The teacher, during the post implementation interview, thought that these results possibly "disrupted the established stereotypes about Columbus and that her students were given some resources to continue discussing this polemic topic in the future."

\section{Implementation Four: Peter the Great}

The topic for the last implementation was Peter the Great of Russia. Here, the HPST Framework was applied to excerpts of three different readings that the participant's students had to complete for homework. The teacher disclosed to me, in a pre-implementation interview, that she "felt her students were familiarized enough with the HPST process to work on this assignment independently at home." Moreover, she continued this discussion by articulating that

the basic premise of this implementation is the same as the others... Namely, that students will hopefully be identifying the historical, philosophical, and societal components of texts... but the main difference is that students are not working in groups. 
Moreover, the teacher added that this implementation was significant because

we are covering the subject of enlightened despots in class and more specifically how Peter the Great attempted to Westernize Russia...it would challenge these students.... and hopefully charge them with the understanding that the HPST could be used universally and had real world applications...this is a tool that they could take with them on to the upper grades in high school and beyond.

The participating teacher began this lesson with a hook activity. Mena showed her students an image of Paul Delarouche (1838) painting of Peter on her classroom's SMART Board. Please refer to Figure 20 below.

Figure 20. Paul Delarouche (1838) Peter the Great Image.

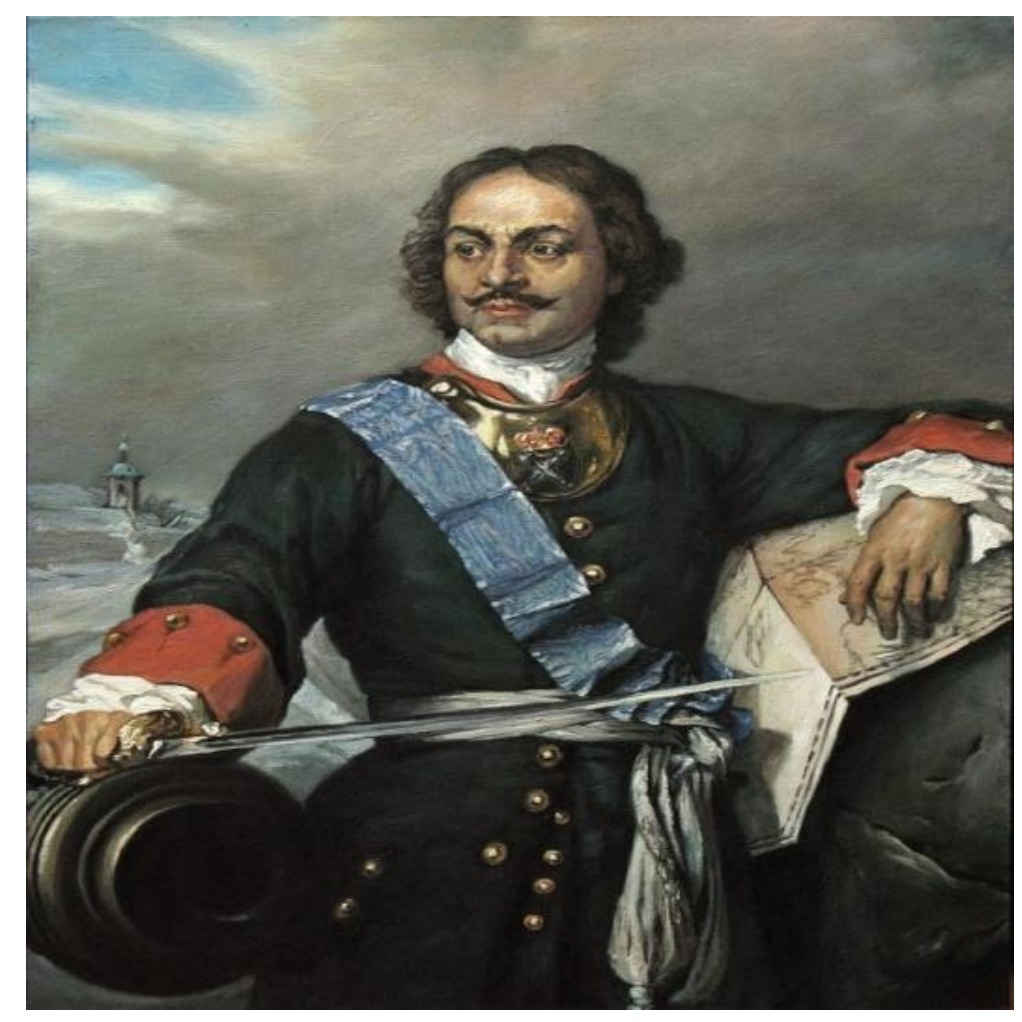

This was an abridged version of the gallery walk activity used in previous

implementations. A standard gallery walk entailed having students enter the classroom that was transformed to resemble a museum exhibit by adhering images on opposing walls of the room in such a way that students needed to physically get up and view them. 
At this point, a short discussion ensued when the teacher unpacked how Peter the Great was depicted in this painting, the images' provenance, and who painted it. Moreover, she reminded students that at the end of this lesson "at home...for homework....they were to answer the Takeaway frame by offering their perceptions of what they had learned about Peter's reign after going through the HPS process." The participant then showed students a YouTube video on the life of this monarch called Peter the Great: A Biography published by Biography.com.

After the video was viewed, this teacher asked students to look up background information on the three authors of texts they read, namely: Robert K. Massie, Vasili Klyuchevsky, and Alexander Chubarov online via the use of laptops, cellular phones, and other handheld devices. Then, a short discussion ensued when she asked students to share what they found. The participating teacher commented to me that the reason she had students inquire about the author's background online was "to reacquaint them with the forces behind the Hermeneutic Circle — which are the text, author, and reader." A subsequent discussion emerged when Yuliese explained the first or Interactive Level of the framework to her students which reinforced that "texts, authors, and readers are connected and all of these forces affect one another."

Following this, the participating teacher lectured students about the context of Peter's life, including his violent childhood and fascination with the technology of the period. She assured me that student learned how Peter created powerful Russian armed forces .... and how he treated immigrants and how his legislation changed how Russian citizens of the period viewed immigration... and how he provoked an upheaval of the old order of Russian politics and societal norms. 
Moreover, the participant connected the above mentioned historical issues to contemporary ones found in U.S society today. The teacher said that "immigration is still a very hot topic in today's world and leaders are still determining who or who does not have access to legally immigrate." A student commented, "Nothing has really changed from the time of Peter the Great till now....how sad." Other students commented that "at least we don't have serfs today." The participant shared that she joked with her students by retorting that, "We don't... are you sure about that?" Nonetheless, the teacher urged students to take notes of all these historical events discussed throughout the lecture and to refer to these notes as needed later. Following this part of the lesson, she then distributed the texts the students read. Please refer to Figures 21-23 below. 
Figure 21. Massie (1981) Peter the Great excerpt.

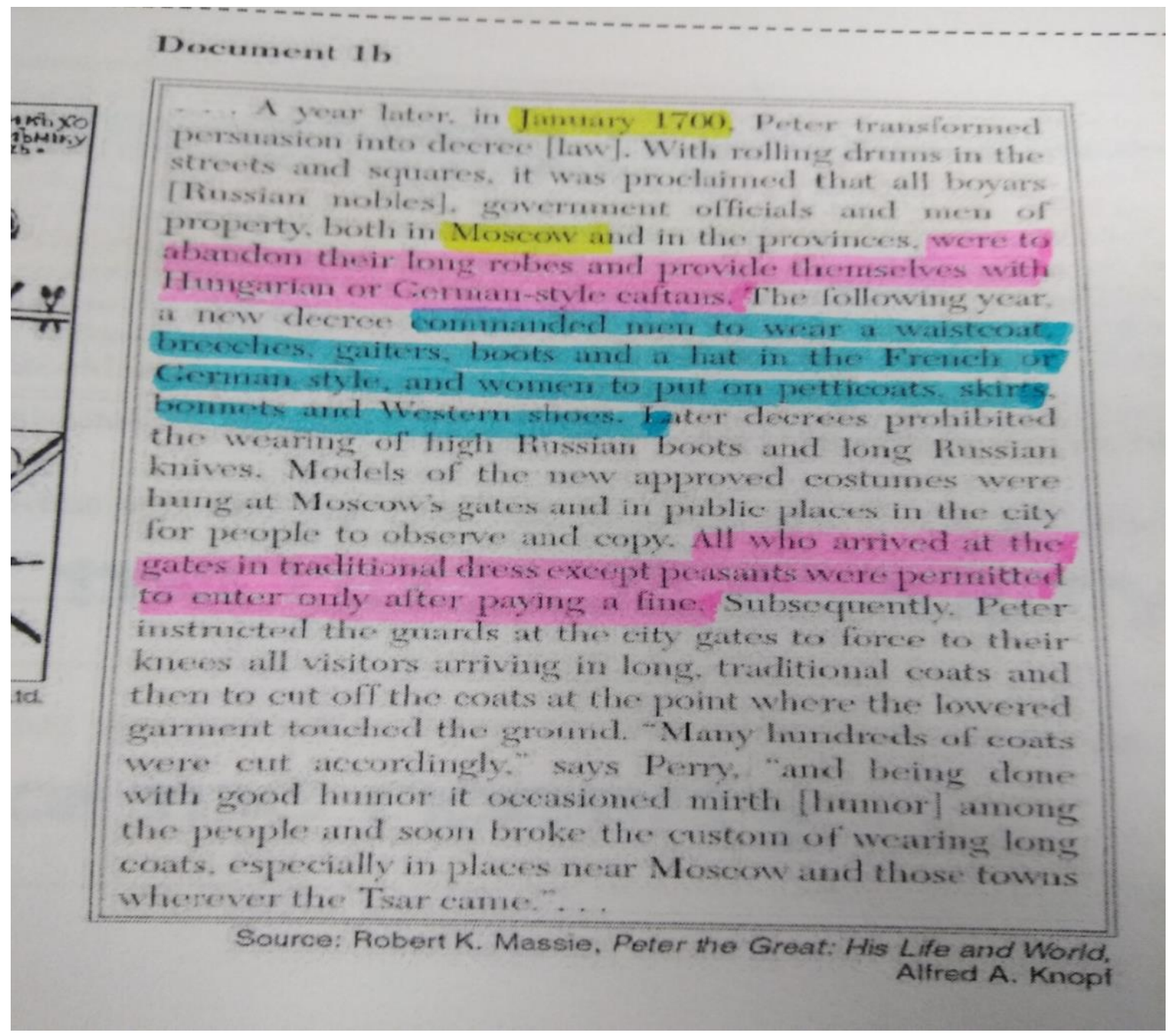


Figure 22. Klyuchevsky (1958) Peter the Great excerpt.

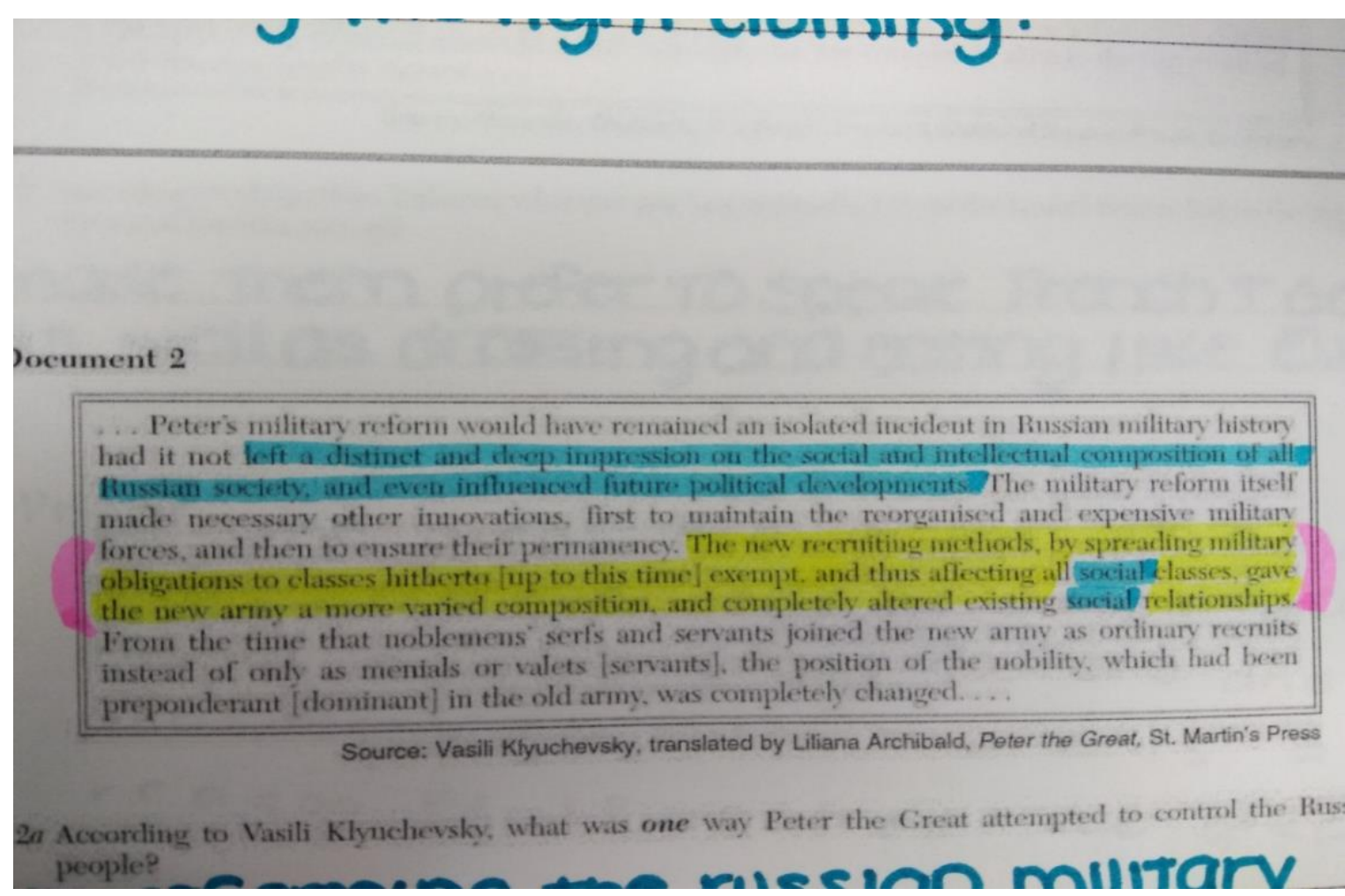

Figure 23. Chubarov (1999) The Fragile Empire: A History of Imperial Russia excerpt.

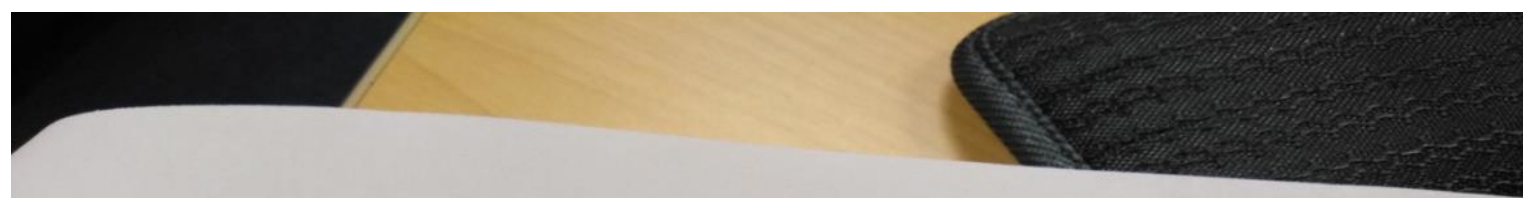

PETER THE GREAT DBQ ANALYSIS

\section{Document 3}

The Petrine [Peter's] Refonergence of "Dual Russia"

irfevocable [umalterable Reform is often seen as the main cause and the starting point of the

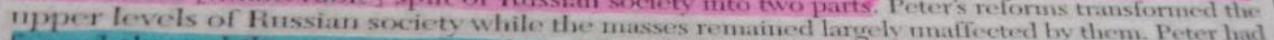
forced the nobility to acyuire tectmical knowedge of Western Erometed by them. Peter had styles of dress and mammers. Fh increasingly Europeanized edncation of the upper classes brought with it a faubiliarity with the philosophies and theories of the Enlightenment. Soon many Russian nobles even preferred to speak the languages of Western Europe (particulantie French and C:erman) to Rassian? By the nineteenth century their world was European in dress? manmers. food, education, attitudes, and language, and was completely alien to the way of life of the Russian popular masses. ..

Source: Alexander Chubarov, The Fragile Empire: A History of Imperial Russia, Continuum

According to Alecander Chubarov; what was one long-term effect Peter the Creat's reform had on the up 
The teacher then proceeded to quickly explain the second or Analytic Level of framework because these students were already familiar with the HPST and its usage. Nonetheless, the participant reminded students what constituted the $\mathrm{H}, \mathrm{P}$, and $\mathrm{S}$ and what these frames meant. She then asked the students to create a color-coded key for the historical, philosophic, and societal frames. This teacher articulated that this part of the lesson directed "students to highlight the evidence found in the texts of the $\mathrm{H}$ in yellow, of the $\mathrm{P}$ in red, and of the $\mathrm{S}$ in blue." Then students were charged, by the participating teacher, to write a paragraph to describe their "take-away" after engaging with the material that answered the essential questions posed at the beginning of the lesson which was: What are your perceptions of Peter the Great reign? Lastly, she then mentioned to students that

first please read the texts, then using the definitions I gave you of each frame... apply them to the text by using your colored markers... code the evidence that you find according to each frame ... and then provide an answer to the $\mathrm{T}$ frame on the back of the sheet.

The participant gave these instructions verbally in class and also wrote them on the online student portal for the students who might have forgotten her directives. This edict issued by this teacher was followed by students and they returned the completed assignment by a future date. 
Table 4. Implementation Four Findings.

\begin{tabular}{|l|l|}
\hline Frames & $\begin{array}{l}\text { Student quotes relayed by teacher } \\
\text { "A year later, in January 1700, Peter transformed persuasion into } \\
\text { decreed law." } \\
\text { "By the nineteenth century [the Russian] world was European in dress, } \\
\text { food, education etc..." }\end{array}$ \\
\hline $\begin{array}{l}\text { Philosophic } \\
\text { (P) }\end{array}$ & $\begin{array}{l}\text { "An increasingly Europeanized education brought with it a familiarity } \\
\text { with the philosophies and theories of the Enlightenment." } \\
\text { "Peter's military reform...left a distinct and deep impression on the } \\
\text { intellectual composition of Russian society and even influenced future } \\
\text { political developments." }\end{array}$ \\
\hline Societal (S) & $\begin{array}{l}\text { "a new decree commanded men to wear a waistcoat, breeches, gaiters, } \\
\text { and a hat in the French or Germany style, and women to put shirts, } \\
\text { petticoats, bonnets, and western shoes." } \\
\text { "affected all social and gave the army a more varies composition...this } \\
\text { completely altered social relationships." }\end{array}$ \\
\hline $\begin{array}{l}\text { The } \\
\text { Takeaway } \\
\text { (T) }\end{array}$ & $\begin{array}{l}\text { "I believe that Peter was good for Russia in that he expanded his empire } \\
\text { and did much for his people. However, based on the texts I read, Peter } \\
\text { also caused a lot of unnecessary Europeanization in Russia. He forced } \\
\text { his people to eat, dress, speak, and be educated in a certain way. In the } \\
\text { end, I believe that he did more harm than good because of the societal } \\
\text { split he caused by his reforms." } \\
\text { "Peter the Great was not good because under his rule, he did not treat } \\
\text { people the right way. He did not let his people be free and express } \\
\text { themselves as they would want. Peter forced the men to cut off their } \\
\text { beards and made women dress in a more Western fashion. He changed } \\
\text { their foods, language, and education system to be more like that in the } \\
\text { rest of Europe...how unfair." }\end{array}$ \\
\hline
\end{tabular}

The participant cited that the following passages were offered by students as evidence for the $\mathrm{H}$ frame, "a year later, in January 1700, Peter transformed persuasion into decreed law." Other students said, "By the nineteenth century [the Russian] world was European in dress, food, education etc." She affirmed, in the post implementation 
interview, that overall "students possibly grasped $\mathrm{H}$ correctly by identifying dates, years, and historical concepts like periodization and Westernization.”

The following student articulated passages were offered by the teacher as evidence for the P frame, "An increasingly Europeanized education brought with it a familiarity with the philosophies and theories of the Enlightenment." Other students unpacked that "Peter's military reform...left a distinct and deep impression on the intellectual composition of Russian society and even influenced future political developments." The teacher commented that the Philosophical frame "was possibly understood by students, but it needed reinforcement." The participating teacher mentioned, in the post implementation interview, that she

re-explained to students how an ideology seen through a value system is expressed in public opinion, the intelligentsia of a nation, or by the legislative policies created by governmental bodies....After scaffolding these concepts, via a post implementation class discussion (before they turned in their work), the students correctly identified the cutting of the beards of the boyars [mentioned in the text] as the physical representation of new ideological shift from tradition to modern Westernization implemented through Peter the Great's reforms.

The teacher shared that the following passages were offered by students as evidence for the $\mathrm{S}$ frame. She indicated that they articulated that "a new decree commanded men to wear a waistcoat, breeches, gaiters, and a hat in the French or Germany style, and women to put on skirts, petticoats, bonnets, and western shoes." Other students found that Peter's new army recruiting methods "affected Russian society and gave the army a more varied composition...these completely altered societal relationships." This teacher then commented to me after this implementation that the societal frame saw few students struggle, since most understood the frame meaning human relations, practices, and traditions that were part of a culture. They identified the social hierarchies that existed in Russian society of the period and the authority Peter had over the Boyars, Russia's noble ruling class. 
For the $\mathrm{T}$ frame, she asked students to answer the following question: What are your perceptions on Peter the Great s reign? One student said,

I believe that Peter was good for Russia in that he expanded his empire and did much for his people. However, based on the texts I read, Peter also caused a lot of unnecessary Europeanization in Russia. He forced his people to eat, dress, speak, and be educated in a certain way. In the end, I believe that he did more harm than good because of the societal split he caused by his reforms.

Yet, another student commented that

Peter the Great was not good because under his rule, he did not treat people the right way. He did not let his people be free and express themselves as they would want. Peter forced the men to cut off their beards and made women dress in a more Western fashion. He changed their foods, language, and education system to be more like that in the rest of Europe...how unfair.

In testament to the above mentioned responses, the teacher felt that some

students possibly understood that although Peter has been acclaimed by history as being a great reformer and 'enlightened despot'...his techniques to achieve those reforms, in today's world, would still be seen as nationalist, Euro-centric, emasculating and integrationist.

The participating teacher then added that "student seemed to have disrupted the stereotypical view [of a strong autocratic absolute ruler] of Peter and possibly given voice to the groups that he tried to marginalize." Lastly, the participant assured me that "students were very successfully in identifying the various frames using the color-coded system that [she] assigned.” 


\section{RQ2: What role can narrative play for a Social Studies teacher?}

The following chronicled an interview of the participant of this case study; in response to Research Question \#2 that reads what role can narrative play for a Social Studies teacher? The teacher began this interview by stating that she "always loved history and education." Moreover, she felt that "Social Studies are a very big part of [her] professional life which is ultimately is an extension of who she is personally." There were two key factors that drove the participant's approach to the usage of narrative in her Social Studies teaching, namely: provocation, and restory.

\section{Provocation}

This teacher articulated that her answer to this question could be conceptualized within two spheres: first, as a student, she enjoyed reading biographies and narratives housed in history textbooks whenever available. The participating teacher remembered that when she was in school,

Reading a whole historical narrative was not done...it was more for leisure at home usually...However, my teachers would assign short stories or pieces, in class, that would grab our attention or be provocative. (emphasis added)

Second, as a teacher, she drew from this experience and utilized short narratives that "were fun, provocative, controversial, and peeked students' interest in some way." As an example, the participant paraphrased a story about Catherine the Great of Russia having sex with her favorite horse,

which obviously is a rumor or conspiracy theory spread by her enemies. The reality is that we do not really know if this story is true or false. It is just a narrative that is interesting to consider, fun and, above all, thought provoking. 
These types of narratives she assured 'would hopefully peek students' interest to the point that they would ask more important overarching questions dealing with topics such as propaganda, power, and influence, etc."

An artifact in this case study specifically used by her that provoked or elicited a response from students was the picture of Marjane Satrapi displayed in Implementations One and Two. During these lessons, she made it very clear to students that Satrapi was a Muslim woman before they actually saw her image. However, when the participant displayed the picture, students viewed a short-haired, modern, casually acting young woman that smoked. This picture of Satrapi lies in direct opposition to images of Muslim women wearing the hijab. The aim behind this provocation, this teacher said, "was to possibly disrupt the stereotypical views students had of Muslim women mainly generated by social media and some new sources."

Another example of provocation used by the participant when teaching occurred during Implementation Four. During that lesson the participant commented to me that, via content lecture, she explained to students not only Peter the Great's treatment of immigrants, but how his legislation changed Russian citizen views on immigration. These new policies created a political and social upheaval of the Old Russian order. In response to this discussion a student commented that "at least we don't have serfs today." This teacher shared that she joked with her students by retorting, "We don't... are you sure about that?" This rhetorical question issued by this teacher to her student was definitely thought provoking and possibly challenged the view the student possessed. 


\section{Restory}

The participant commented that the more she has learned about and taught with narrative the more she realized that this genre was not just about a story. "Narrative has a definite structure," this teacher said. Moreover, the teacher unpacked that professionally as she researched oral histories for her own dissertation, she came to understand the process behind this form of discourse. Additionally, she became aware of the different schools of thought that accompany this genre. The participant realized that "we as humans have an imperious need to recreate our own shared history... and that human beings reconstruct their memories using narratives." She commented that scholars referred to this as Restory, and that "humanity has the need to make meaning of their shared past and create narratives to chronicle this."

In Implementation Three, this teacher utilized Christopher Columbus's 1492 Diary as a narrative that her class restored. The restoration began when the teacher assigned excerpts of this text which her class read. Next, she guided her students through the HPST process. This process offered the participant's students a multidimensional approach that helped them not only break down this narrative into its subsequent themes (or parts) using the $\mathrm{H}, \mathrm{P}$, and $\mathrm{S}$ frames, but ultimately restory the narrative by answering the $\mathrm{T}$ frame which was tied to the essential question: Was Columbus a friend or foe of history? The answer students gave to T offered them the ability to add their own personal insight, based on the guided inquiry generated by HPS, to their overall discourse on Columbus's voyage. Simply put, the perspective that students offered restored this text. Please refer to Figure 24 below. 
Figure 24. Implementation Three student restory.

"Both. Due to the fact that he along with other brave men discovered the New

World. He brought back land and riches to his nation, Spain. But he also enslaved a whole race. He brought famine to this New World. During this time Columbus was doing what he thought was right. It was a time where technology was not advanced and people could not communicate their thoughts. Columbus was doing what he thought was right. "

The Restory of the assigned texts which students wrote also occurred in Implementation One, Two, and Four. Please refer to Figures 25-27 below.

Figure 25. Example of student restory in Implementation One.

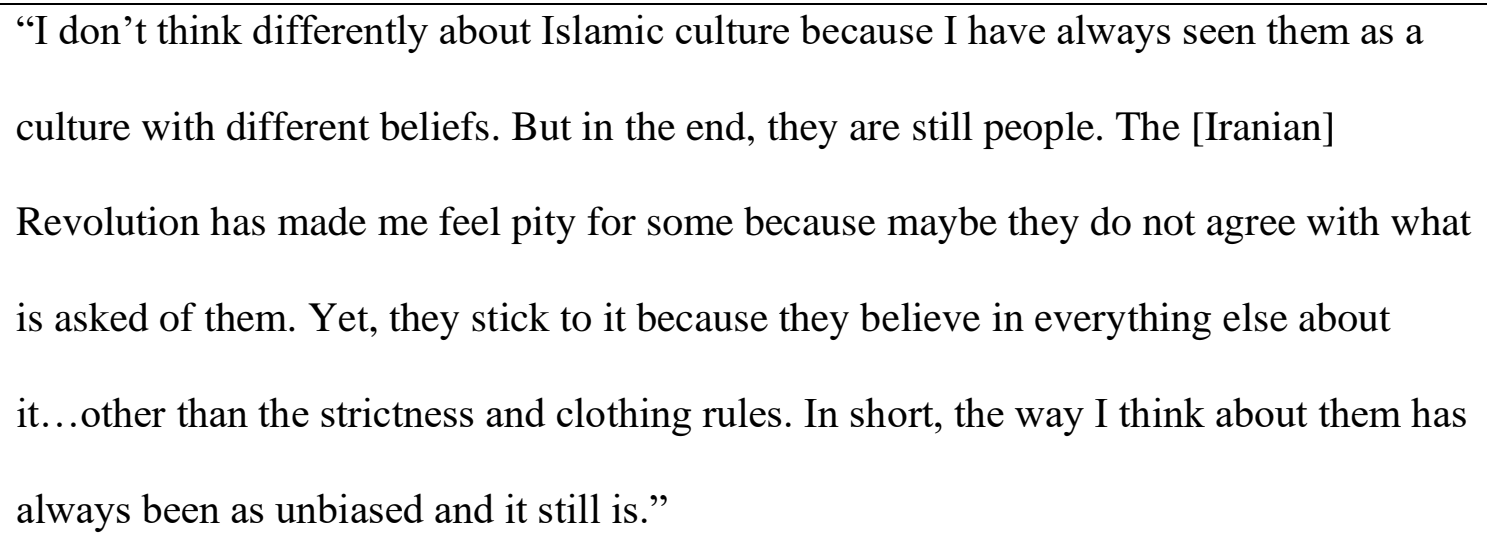

Figure 26. Example of student restory in Implementation Two.

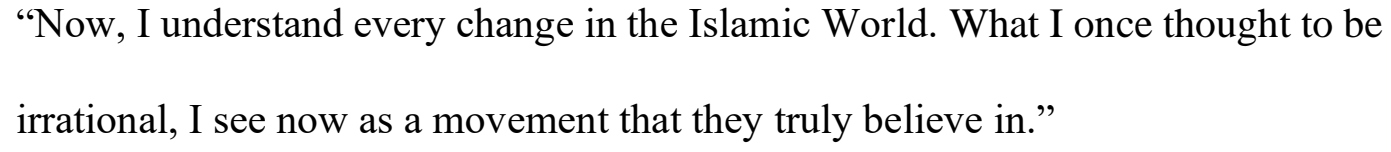


Figure 27. Example of student restory in Implementation Four.

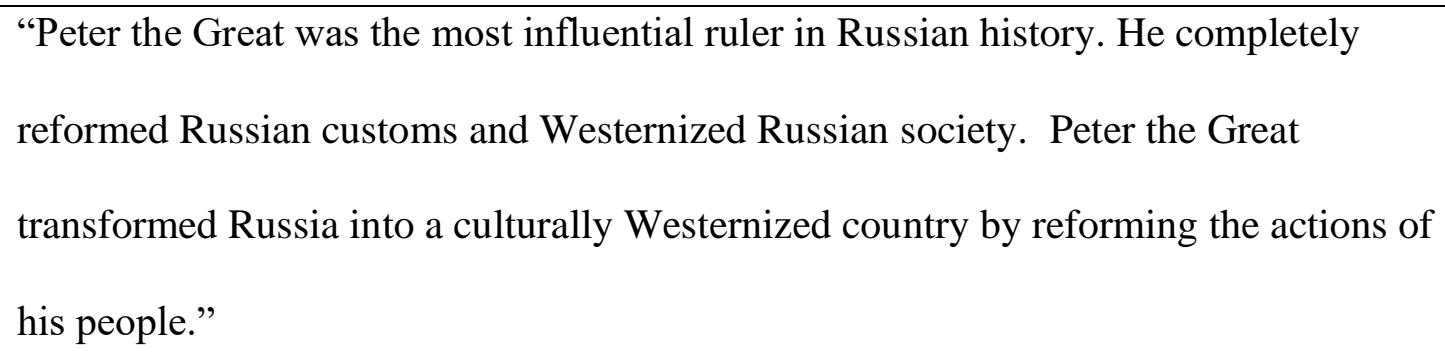

The participating teacher articulated that she

found that narratives are intentional and can often be positively or negatively biased...but when it comes down to it...they are stories... and I use these because they can be fun and engaging for students... because the kids don't necessarily know that they are learning when using them.

This teacher categorized narrative as a powerful tool because it is intricate, well designed, and "the human brain loves this genre without even knowing it." Finally, the participant assured that "the more you study and use narrative...the more one is impressed with what it can accomplish."

\section{RQ3: To what extent has the use of the HPST changed the teacher's thinking about curriculum and/or her teaching?}

The following chronicled an interview of the participating teacher in response to research question \#3 that reads to what extent has the use of the HPST changed the teacher's thinking about curriculum and/or her teaching? The participant commented that she always used narrative in her teaching whenever possible. When preparing for her lessons, "narrative was [her] go-to favorite." The teacher stated that her teaching style and how she conceptualized curriculum was based on her and her students' lived experience. When the participant reflected on her way of teaching and curricular views 
she said that "William Pinar's (1975) Currere Method instantly comes into mind.” The participant categorized herself as having an experiential approach to her teaching methods that was "organic and grassroots-like...that is why narrative is the perfect vehicle to deliver this." For this teacher, curriculum

is like life: possessing different levels (much like what Pinar alludes to in Currere) ....and of course, aligns with the reconstruction of human memory precept

echoing Clandinin and Connelly's theories that narrative possesses a beginning, middle, and an end.

With that said, the teacher assured that for her "curriculum is a grand narrative" and that "she teaches students to view history through this lens coupled with elements of cause and effect and periodization."

\section{Periodization}

Periodization could be viewed as an historian categorizing history into its historiographic elements such as: dates and geographical locations to be able to analyze and/or study these to determine certain outcomes. The participant students' identification of the $\mathrm{H}$ frame within the assigned texts, in the various implementations, was exemplary of periodization because they possibly understood that historical phenomenon occurs within a certain timeframe or era. Please refer to Figures 28-29 below. 
Figure 28. Example of Periodization in Implementation Three.

\author{
"Historical: \\ *Sunday, September 16, 1492 \\ *Thursday, October 11, 1492 \\ *Thursday, October 11, 1492”
}

Figure 29. Example of Periodization in Implementation One.

\begin{abstract}
"Historical:
In 1979, a revolution took place. Then came 1980 the year it became obligatory to wear the veil at school. She [Marjane Satrapi] was 10 years old in 1980."
\end{abstract}

\title{
Cause and Effect
}

Cause and effect could be described as "noting a relationship between actions or events such that one or more are the result of the other or others" (Dictionary.com, 2019). Within the HPST process, the P frame would be most exemplary of a cause and effect relationship. Throughout the various implementations, the participants's students uncovered the $\mathrm{P}$ frame in the assigned readings which determined what school (s) of thought, psychological paradigm and/or -isms caused the historical phenomena to occur and what effect did this have on history of the actual period itself. Please refer to the Figure 30 below. 
Figure 30. Example of Cause and Effect in Implementation Two.

"Philosophical:

The view is a philosophical ideal because due to Sharia Law they were forced to hide their upper body. They are protesting against an idea that they do not have."

\section{HPST, Document Based Questions and End-of Course Exams}

"I am one of those weird teachers that do not really like teaching to a test...even though I have to sometimes," this teacher commented. Furthermore, she articulated that "the end of course exam requirements make me prepare students to be able to pass this test." Prior to utilizing HPST, the participant tried "thematic or rhetorical analysis and others, but the students did not completely understand them." The teacher said she "would flounder trying to teach students to be comprehensive with their analysis." Moreover, she struggled to find teaching strategies or other tools to offer her students that when coupled with narrative could make analysis of these easier and more meaningful.

Moreover, she worried that her students would not be adequately prepared to tackle Document Based Questions (DBQ), which was part and parcel of their required coursework. DBQs are questions students must answer at the end of an exam based on the reading of a text. Student responses to these are either in essay or short answer formats. In their responses, students must use literary and/or contextual evidence from the text which is anchored by an overarching essential question or prompt.

In Implementation Four, the participant selected three text excerpts purposely to prepare her group of students to answer the DBQs on their end-of-course exam. The preparation process began when she assigned the excerpts which her class read. Next, she 
guided her students through the H, P, and S frames. This process offered the teacher's students a multidimensional approach that helped them not only break down these texts into their subsequent parts using the HPS, but also restory them by answering the T frame which was tied to the essential question: What are your perceptions about Peter the Great's reign? Then the participant had students answer the actual DBQs based on the guided inquiry generated by HPST process. Please refer to Figures 31 and 32 for DBQs.

Figure 31. DBQ 1.

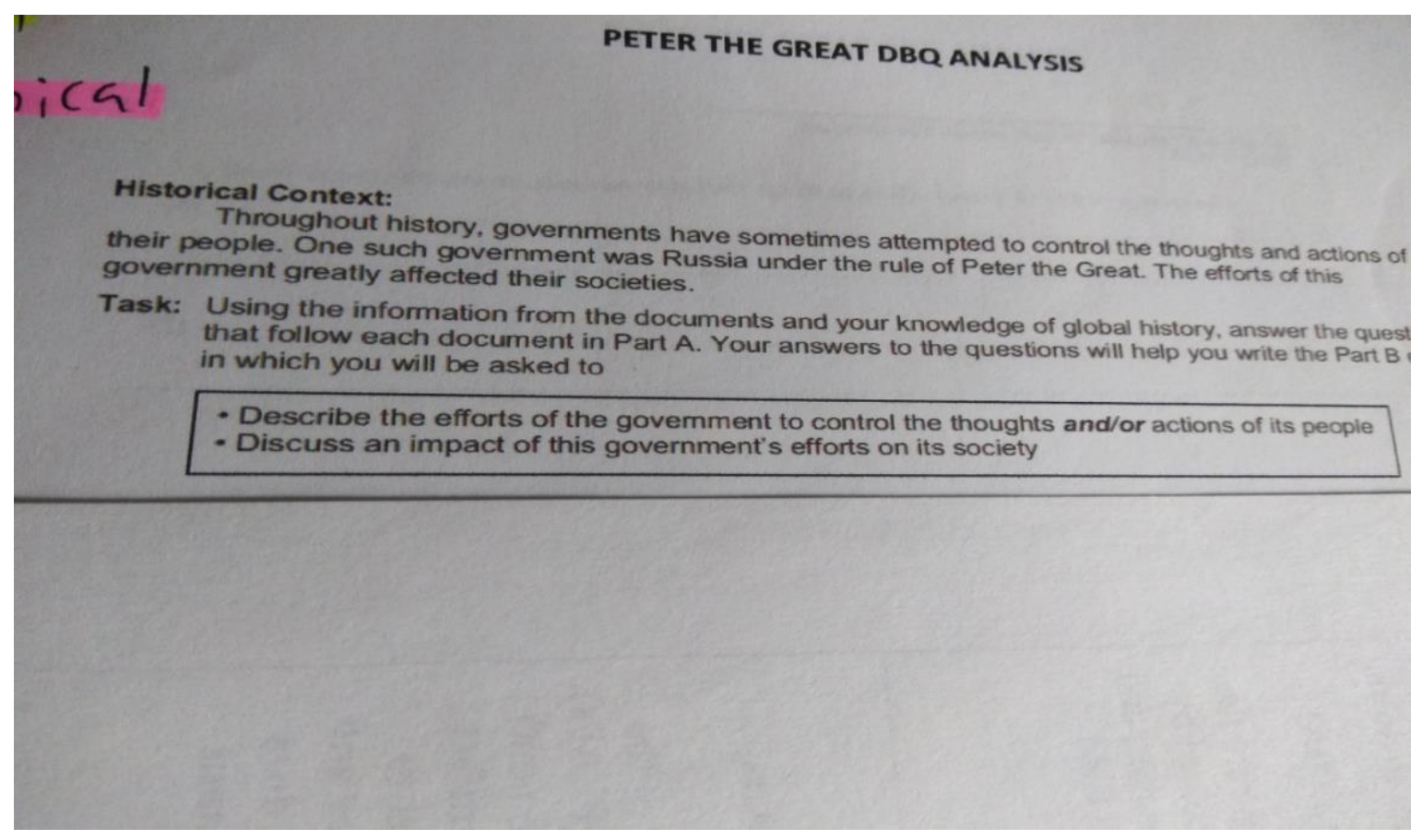


Figure 32. DBQ 2.

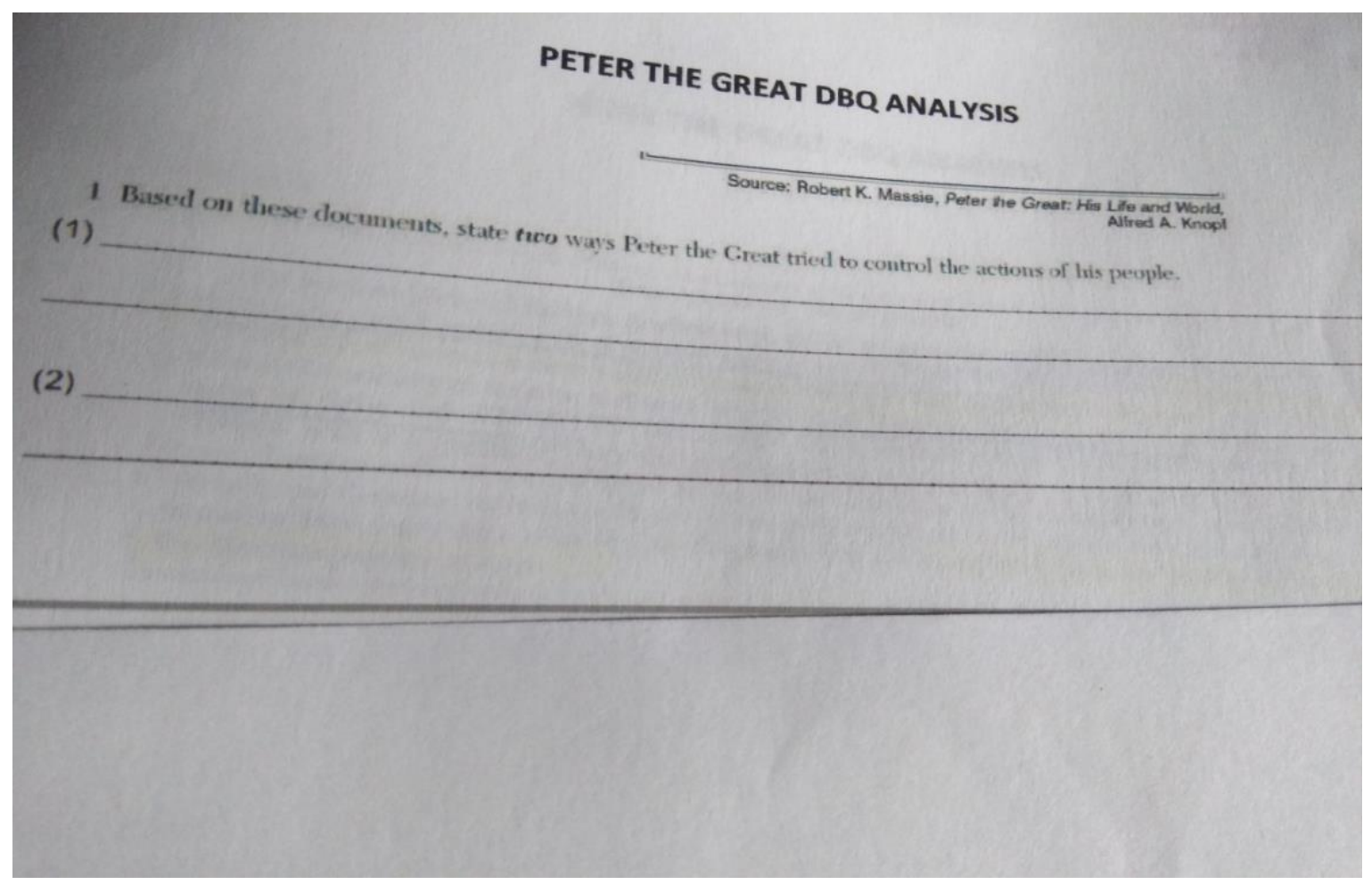

Lastly, this teacher commented to me that she used previous end-of-course exams text excerpts and questions as practice for students during this implementation.

The participant "loves the HPST because it employs the use of narrative and is an organized way to teach history, that is easy and user friendly." The teacher assured that

this framework teaches the skills necessary to understand history based on document analysis...challenging students to interpret a narrative utilizing both the interactive level (or Hermeneutic Circle of author, text, and student reader) and analytic (namely the $\mathrm{H}, \mathrm{P}, \mathrm{S}$, and T) frames to compartmentalize the piece... weaving together all those elements in such a way that the content knowledge possibly acquired by students is hopefully transferable to any historical phenomena.

The participating teacher articulated that when she witnessed the weaving of HPST components happening in her classroom with her students "personally, this was when my own teaching changed." She continued by mentioning that the "HPST made me a better 
teacher because I felt more organized... and hoped that my students felt the same and ultimately would be better prepared to answer the DBQs on their end-of-course exams." Finally, this teacher felt that the "HPST can now be viewed not as solely being a localized teaching strategy, but in time José, you will hopefully develop this idea to become the next Maria Montessori." 


\section{CHAPTER FIVE}

\section{DISCUSSION OF DATA AND ANALYSIS OF THE RESULTS}

\section{Overview}

This chapter begins by discussing how the participant used the HPST Framework, what role narrative played for her and to what extent this teacher's use of the HPST changed her thinking about curriculum and/or her own teaching. Moreover, this chapter unpacks the particulars behind narrative and the use of the Hermeneutic Circle. Additionally, commentary on restory, provocation, and the significance of Advanced Placement (AP) courses in a high school setting were given. Also, the contributions made by HPST are highlighted as well as the possible benefits and limitations of this study. Finally, the future research line for HPST is discussed.

\section{RQ1: How does a teacher use the HPST?}

It is important to note that all the emerging codes discussed throughout the dissertation came directly out of the conversations with the participating teacher. This process was crucial because I understood not only the method behind her teaching, but also how her use of historical narrative coupled with the HPST Framework coalesced and created a new educational perspective for her and her students. Moreover, HPST went beyond the standard use of Social Studies textbook, classroom lectures, tests, and pacing guides (Nokes 2013, Bruner 1990).

The use of historical narrative was an integral part of the HPST process. Moreover, the narratives utilized in this study chronicled not only historical phenomena, but students learned about the individuals making this history by reading these stories. This echoed Pinar's (1975) Currere Method that utilized one's own experience as a data 
source. By reading these narratives, students engaged in Pinar's process which urged them to regress, progress and analyze the lived historical experience of the author or the historical person making the history. The participant said that this was "significant for students because it not only deepened their connection with history, but it helped [students] formulate their own opinions about it."

As I have said previously, the Hermeneutic Circle was best described as the forces that exist between the author of a text, the text itself, and the students that read this text. Please refer to Howe's (2011) representation of the Hermeneutic Circle Osborne (1991) below.

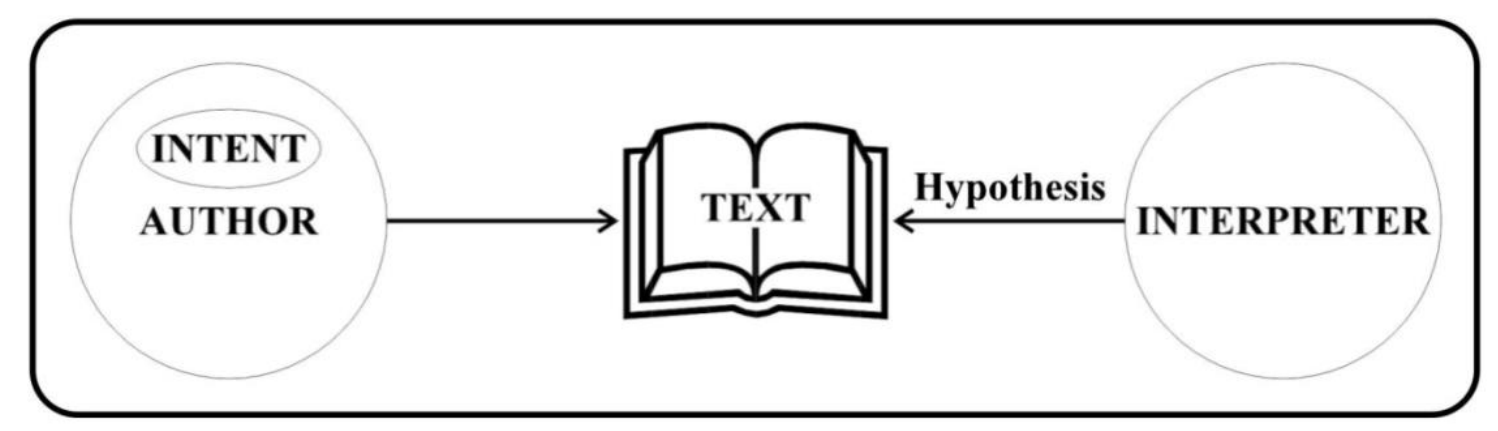

The teacher commented to me that it was of paramount importance to her students that "they understand the significance of this dynamic." Moreover, she assured that “comprehension of a text could not be achieved if my students didn't understand that an author has bias and that those are based on his or her lived experiences." The interaction between an author, a text, and the reader possibly gave this teacher's students the ability to unpack deeper connections to the assigned reading that made comprehension seemly easier.

The participant commented to me that the "discussions and conversations elicited by the use of the HPST heightened a meta-cognitive disposition in her classroom." This 
meta-cognitive disposition, or the act of critical thinking on the part of her students, seemingly intensified the participant's critical teaching. Instead of introducing new points throughout the various implementation sessions, she "now elaborated on a more critical thinking stance, since [her] students were apparently engaging with a text more deeply." Moreover, this created a dual platform whereby the more her students would inquire via questions or evidence gather about the text; the more this teacher followed up with other essential question prompts to deepen the critical discourse. This process fostered more critical teaching in the mind of the participant. The teacher commented that "the engagement experienced by [her] students, via the use of HPST, could be viewed as document analysis." Moreover, she wholeheartedly endorsed HPST and categorized it as

an inquiry-based strategy which allows students to think critically and layer information to see beyond the social, political and economic views a text would have.... and incorporate issues of class, race, politics, and their subcategories into these larger frames.

\section{Questions Pondered}

It is important to note that after I had analyzed all the research materials gathered from the participating teacher and written the chapter's results, I decided to share these results with her. Moreover, I asked this teacher to comment on what was found. In this post-hoc interview, the participant unpacked what these finding meant to her, and discussed their significance. The following were some questions pondered:

\section{Could HPST be used by other kinds of teachers?}

This teacher described HPST as "very user friendly that could be used by both novice and professional teachers because it can be customized to the teachers' classroom 
needs." The HPST familiarization workshops were created to address these issues. The purpose behind these workshops was to guide pre- or in-service teachers on how to implement the HPST with a step-by-step process. This process delineated the phases a teacher would need to craft a lesson incorporating the framework. Moreover, the process also left room to modify or accommodate HPST to the teachers' and the students' needs. The following were examples of the participating teacher's modification of HPST process occurring in

a) Implementations Three and Four. At the beginning of these sessions, the participant utilized abridged gallery walks instead of the standard one. The abridged version of this activity consisted of only showing one image on her classroom's Smart Board instead a series of pictures adhered to the classroom's walls and having students physically getting up to view them. The teacher commented to me that this modification occurred mainly because of time constraints. It is important to note that a teacher can opt not to use a gallery walk as anticipatory set. He or she can utilize another type of hook activity because technically the gallery walk activity is not part of the HPST Framework;

b) Implementation Four. By this point, this teacher's class was familiar with HPST because her students had used it several times. During this session, she used HPST as homework instead of an in-class assignment. Again, here this decision was taken primarily because of time constraints. Moreover, the teacher also mentioned that she wanted to challenge her students because this assignment would be done individually instead of working in groups. 
HPST can be implemented, with students at varying learning contexts, if a teacher: a) participates in the HPST familiarization workshops and resonates with the framework. The participant not only partook in the familiarization workshop, but she also understood and resonated with HPST because of her background in Social Studies; b) selects a historical narrative which is of interest to students and that relates to the overall content of the course being taught. She selected excerpts from Satrapi (2003) Persepolis, the 1492 Diary of Christopher Columbus, Chubarov (1999) Fragile Empire: A History of Imperial Russia, Klyuchevsky (1958) Peter the Great and Massie (1981) Peter the Great because those narratives aligned with the content needed to be covered in her class, and this teacher felt that her students would enjoy reading them. Moreover, elements of provocation, restory, periodization, and cause and effect were found in these texts; c) crafts a lesson which follows the step-by-step procedure offered by the HPST familiarization workshops. The participant followed this protocol to craft the four lessons that were implemented; and d) adequately allots classroom time for implementation. The teacher commented to me that setting aside enough class time was of paramount importance. If these criteria are met, I feel that HPST could be implemented with a variety of different types of students.

Would HPST implementation require seasoned teachers and schools with well-funded resources?

Overall, the answer to this question seems to be yes. In an ideal world, highly trained teachers would 
- Be aware that narrative could be used as a teaching tool,

- Be seasoned enough to easily craft lessons that utilized narratives incorporating HPST, and

- Have all the economic resources available to them given by their school (for incidentals such as: printing of both the gallery walk images (if the teacher selects to use this as anticipatory set or hook activity) and the assigned text (s) students would read), and there would be ample class time allotted for the implementation to occur.

\section{Could HPST be tackled by novice teachers, but in less funded sites?}

To comprehensively answer this question, it must be broken into two parts. First, let us address if HPST could be tackled by novice teachers? HPST can be utilized by this group given that these teachers were made aware of their ability to use narrative as a teaching tool. Moreover, the awareness of this availability is paramount because it adds to the battery of resources that novice teachers have access to and can employ. As Czarniawska (2004) and Bogdan and Biklen (1998) reminded us in Chapter One, narratives are full of enriching elements, that when harnessed, bring Social Studies alive. Moreover, novice teachers would be exposed to narrative as a teaching tool by taking the HPST familiarization workshops themselves. Within these workshops, excerpts from a biography and an autobiography were used as examples of texts students would be reading when explaining the $\mathrm{H}, \mathrm{P}$, and $\mathrm{S}$ frames. Workshop facilitators leading the sessions could make novice teacher aware of the use of narrative by exposing them to these excerpts, and articulating to them their importance, significance and usability. 
Colby (2008) unpacked that the "integration of primary source documents into the curriculum...teaches history through an authentic intellectual process characterized by inquiry, contextual reading, resource gathering, text analysis, historical reconstruction and argument formation" (p. 60). Nonetheless, HPST familiarization workshops may give session attendees' opportunities to become aware of the usage of historical narrative in their teaching.

Now, let us address the second part of this question. Funding can vary from school to school. The level to which schools have access to funds for printing — for example - also varies. Fortunately, teachers in some schools have access to these funds and can provide printing for their students. Other schools' teachers can offer limited printing. Unfortunately, schools, especially in very rural areas, have teachers which cannot provide anything for their students (Elias, 2010). These degradations could definitely be very frustrating to teachers, particularly novice ones. (Hilburn and Fitchett, 2012).

A possible solution to avoid printing issues would involve teachers creating a virtual gallery walk using either the Microsoft PowerPoint or Prezi applications. Then, the teacher could display this online version of the activity in class (using a SMART Board, overhead projector, or a laptop) instead of adhering printed images to the classroom walls and having students physically getting up and walking around to view the selected images and engaging with the artifacts. Moreover, students may be given access to the assigned texts online or by posting the texts on the school's student portal website or on a social media platform, such as Schoology, Edmodo, Facebook or Instagram. If the teacher does not have access to an online student portal website or social 
media platforms, he or she could also opt to email the text to students directly. Of course, the above mentioned, would be contingent on the school acquiring the funding to: have a Smart Board or overhead projector, purchase a web address and online school portal, buy internet connectivity and have teachers and students ascribe to social media platforms. If the school and or teacher does not have this accessibility the above mentioned could not happen. Lastly, class time used for an implementation could be reduced by having students go through the HPST process as a homework assignment much like what this teacher did in Implementation Four.

What would happen with HPST if a teacher were under the constraints of pacing guides?

Pacing guides were best described as curricular literature that teachers were strongly suggested to use by school administrators that determine the flow, speed and fluidity of content disseminated to students on a certain week during the academic year (Brazofsky, 2019). Please refer to Figure 33 as an example below. 
Table 5. Brazofsky (2019). Miami-Dade County Public Schools Social Studies Pacing Guide: Summer Week \#1 (course code 2109010)

\section{First Week: July 1-3 \& 5 Instructional Resources}

\section{\begin{tabular}{l|l} 
July 1: HISTORY & NGSSS-SS Benchmarks Addressed:
\end{tabular}}

- What is History?

- Studying the Past

- Role of Historians

July 2: GEOGRAPHY

- Maps and Globes

- The Six Essential Elements of Geography

- Geographic Terms and Tools

- Graphs and Charts
SS.6.W.1.1 Use timelines to identify chronological order of historical events.

SS.6.W.1.2 Identify terms (decade, century, epoch, era, millennium, $\mathrm{BC} / \mathrm{BCE}, \mathrm{AD} / \mathrm{CE}$ ) and designations of time periods.

SS.6.W.1.3 Interpret primary and secondary sources.

SS.6.W.1.4 Describe the methods of historical inquiry and how history relates to the other social sciences.

SS.6.W.1.5 Describe the roles of historians and recognize varying historical interpretations (historiography).

SS.6.W.1.6 Describe how history transmits culture and heritage and provides models of human character.

\section{NGSSS-SS Benchmarks Addressed:}

SS.6.G.1.1 Use latitude and longitude coordinates to understand the relationship between people and places on the Earth.

SS.6.G.1.2 Analyze the purposes of map projections (political, physical, special purpose) and explain the applications of various types of maps.

SS.6.G.1.5 Use scale, cardinal, and intermediate directions, and estimation of distances between places on current and ancient maps of the world.

SS.6.G.2.1 Explain how major physical characteristics, natural resources, climate, and absolute and relative locations have influenced settlement, interactions, and the economies of ancient civilizations of the world. 


\begin{tabular}{|c|c|}
\hline 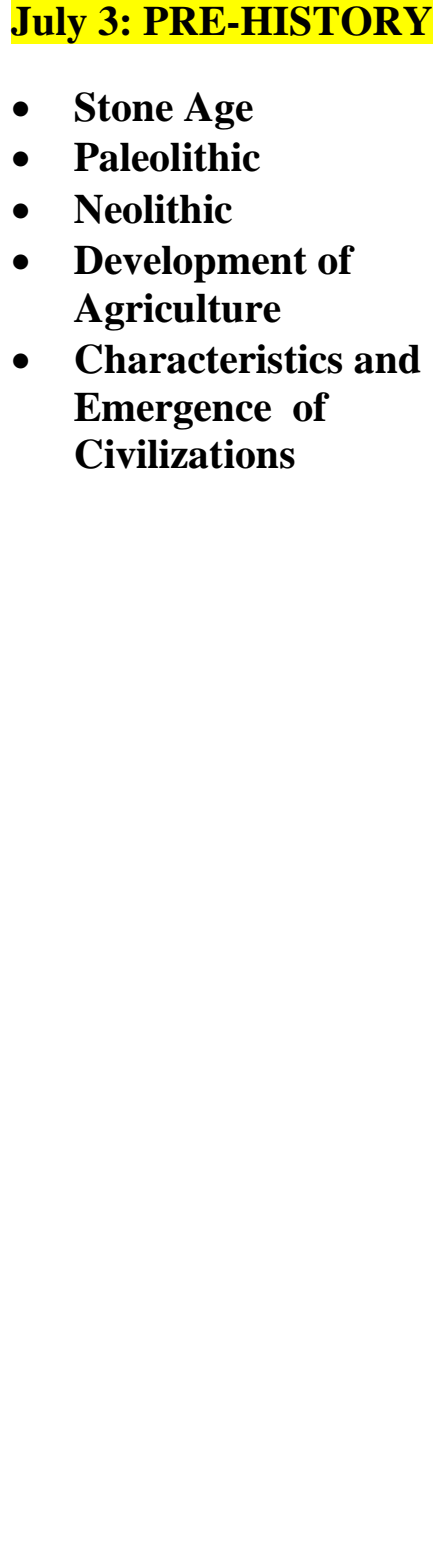 & 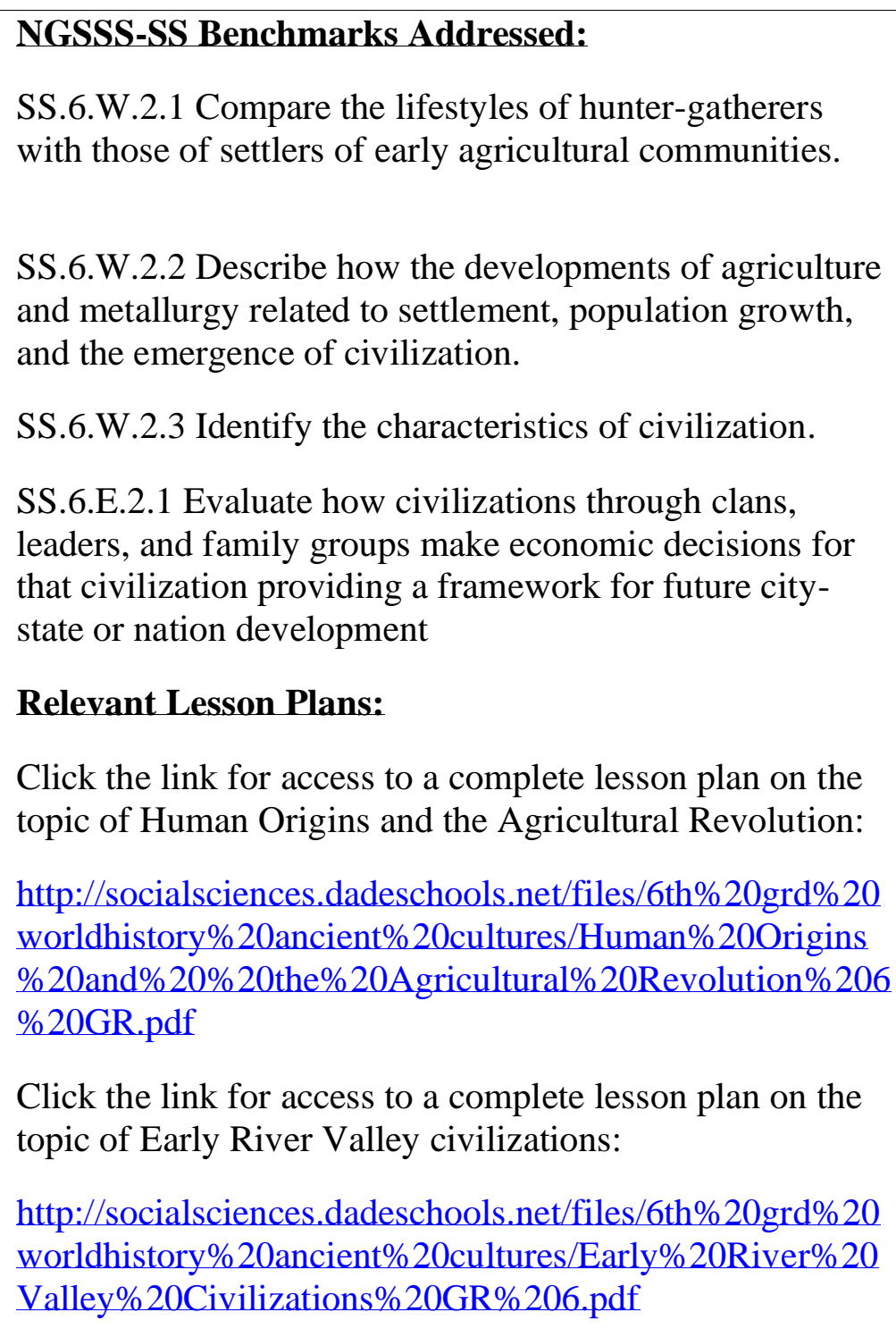 \\
\hline
\end{tabular}




\begin{tabular}{|c|c|}
\hline $\begin{array}{l}\text { July 5: MESOPOTAMIA } \\
\begin{array}{ll}\text { - } & \text { Early River Valley } \\
\text { Civilizations } \\
\text { - } & \text { Sumerians } \\
- & \text { Mesopotamian } \\
\text { Empires }\end{array}\end{array}$ & $\begin{array}{l}\text { SS.6.W.2.4 Compare the economic, political, social, and } \\
\text { religious institutions of ancient river civilizations. } \\
\text { SS.6.W.2.7 Summarize the important achievements of } \\
\text { Mesopotamian civilization. } \\
\text { Relevant Lesson Plans: } \\
\text { Click the link for access to a complete lesson plan on the } \\
\text { topic of Early River Valley civilizations: } \\
\text { http://socialsciences.dadeschools.net/files/6th\%20grd\%20 } \\
\text { worldhistory\%20ancient\%20cultures/Early\%20River\%20 } \\
\text { Valley\%20Civilizations\%20GR\%206.pdf } \\
\text { Click the link for access to a complete lesson plan on the } \\
\text { topic of the Ancient Middle East: } \\
\text { http://socialsciences.dadeschools.net/files/6th\%20grd\%20 } \\
\text { worldhistory\%20ancient } \% 20 \text { cultures/The\%20Ancient } \% 20 \\
\text { Middle\% } 20 \text { East } \% 20 \mathrm{GR} \% 206 . p d f \\
\text { See History Channel link below for related articles and } \\
\text { videos for this topic: } \\
\text { www.history.com: (use the history channel's search } \\
\text { engine, using the topics on the left, to find related } \\
\text { articles and video clips) }\end{array}$ \\
\hline
\end{tabular}




\begin{tabular}{|c|c|}
\hline $\begin{array}{l}\text { July 5: ANCIENT } \\
\text { EGYPTIAN AND } \\
\text { AFRICAN } \\
\text { CIVILIZATIONS } \\
\text { The Nile River } \\
\text { - Life in Ancient Egypt } \\
\text { - Egypt's Empire } \\
\text { - The Nubians } \\
\text { - The Kushite } \\
\text { Kingdom/Axum }\end{array}$ & $\begin{array}{l}\text { NGSSS-SS Benchmarks Addressed/Lessons Plan } \\
\text { Options/Links: } \\
\text { SS.6.W.2.4 Compare the economic, political, social, and } \\
\text { religious institutions of ancient river civilizations. } \\
\text { SS.6.W.2.5 Summarize important achievements of } \\
\text { Egyptian civilization. } \\
\text { SS.6.W.2.6 Determine the contributions of key figures } \\
\text { from ancient Egypt. } \\
\text { Relevant Lesson Plans: } \\
\text { Click the link for access to a complete lesson plan on the } \\
\text { topic of Early River Valley civilizations: } \\
\text { http://socialsciences.dadeschools.net/files/6th\%20grd\%20 } \\
\text { worldhistory\%20ancient\%20cultures/Early\%20River\%20 } \\
\text { Valley\%20Civilizations\%20GR\%206.pdf } \\
\text { See History Channel link below for related articles and } \\
\text { videos for this topic: } \\
\text { www.history.com: (use the history channel's search } \\
\text { engine, using the topics on the left, to find related } \\
\text { articles and video clips) }\end{array}$ \\
\hline
\end{tabular}

Teachers in MDCPS use Pacing Guides to teacher Social Studies. During an interview, the participant disclosed that she had to follow pacing guides in her teaching. For several implementations, she allotted a whole class period and veered from the pacing set by the guide. However, when the teacher had timing issues, she used time at the end of a week, when the load of lesson benchmarks went from four that needed to be covered to three. She assured that with one less benchmark to cover there was a time gap available "to teach skills." She used this slot of time to implement HPST if needed. 


\section{RQ2: What role does narrative play for a teacher?}

\section{Restory and Provocation}

There were two important themes that emerged from my discussions with the participant as to the role that narrative played for her: restory and provocation. The “process of 'restorying' data compiled from participants is performed by breaking down definable aspects of a narrative into themes or designated content (such as characters, plot, etc.) and then reforming the story and presenting it in text" (Anapilotis, 2016). In retrospect, based upon Anapilotis's definition of restory, the participant assured me that her students were able to use the HPS process to deconstructing a historical narrative into its subsequent thematic parts. Then, they answered the essential question, which was attached to the $\mathrm{T}$ frame, to restory it and add their input or perspective to the overall piece. The restorying of an assigned text was important for the teachers's students because she said that "this act was part and parcel to document analysis."

Provocations was defined as “experiences set up in response to children's interests and ideas...providing hands-on exploration for them to practice, test, construct and deconstruct their ideas and theories...A provocation will provoke thinking" (Sally, 2016, para. 2). Based upon this definition, this teacher constructed several experiences that could be viewed as student provocation. The gallery walks, for example, used in all of the participant's lessons, were most emblematic as to how she provided first hand explorations for her students to practice, test, construct, and deconstruct their ideas and theories. This coupled by this teacher's debriefing of this activity after it occurred which highlighted the lesson's essential questions was also paramount in provoking student 
thought. Novice or seasoned teachers would benefit from being given the opportunity to become aware of historical narrative, restory, and provocation and be able to use it in their teaching. She reminded us that

narrative functions as a tool to teach. It is like having a second teacher in the classroom especially when the narrative is a biography. It is vital for student comprehension through the sequence of a story.

\section{Implications for Future Research}

The usage of narrative incorporating HPST including themes of provocation and restory could possibly be implemented in other realms of content-area teaching, not only Social Studies. I would suggest incorporating provocation and restory into other genres, such as: language arts and reading classes, Teaching English to Speakers of Other Languages (TESOL) courses, and first year writing courses (ENC 1101/1102). It would be of great interest to me if a colleague specializing in Science, Technology, Engineering and Math (STEM) would evaluate the HPST to see its feasibility in that field. Please refer to Figure 33 below. 
Figure 33. Provocation and restory in other disciplines.

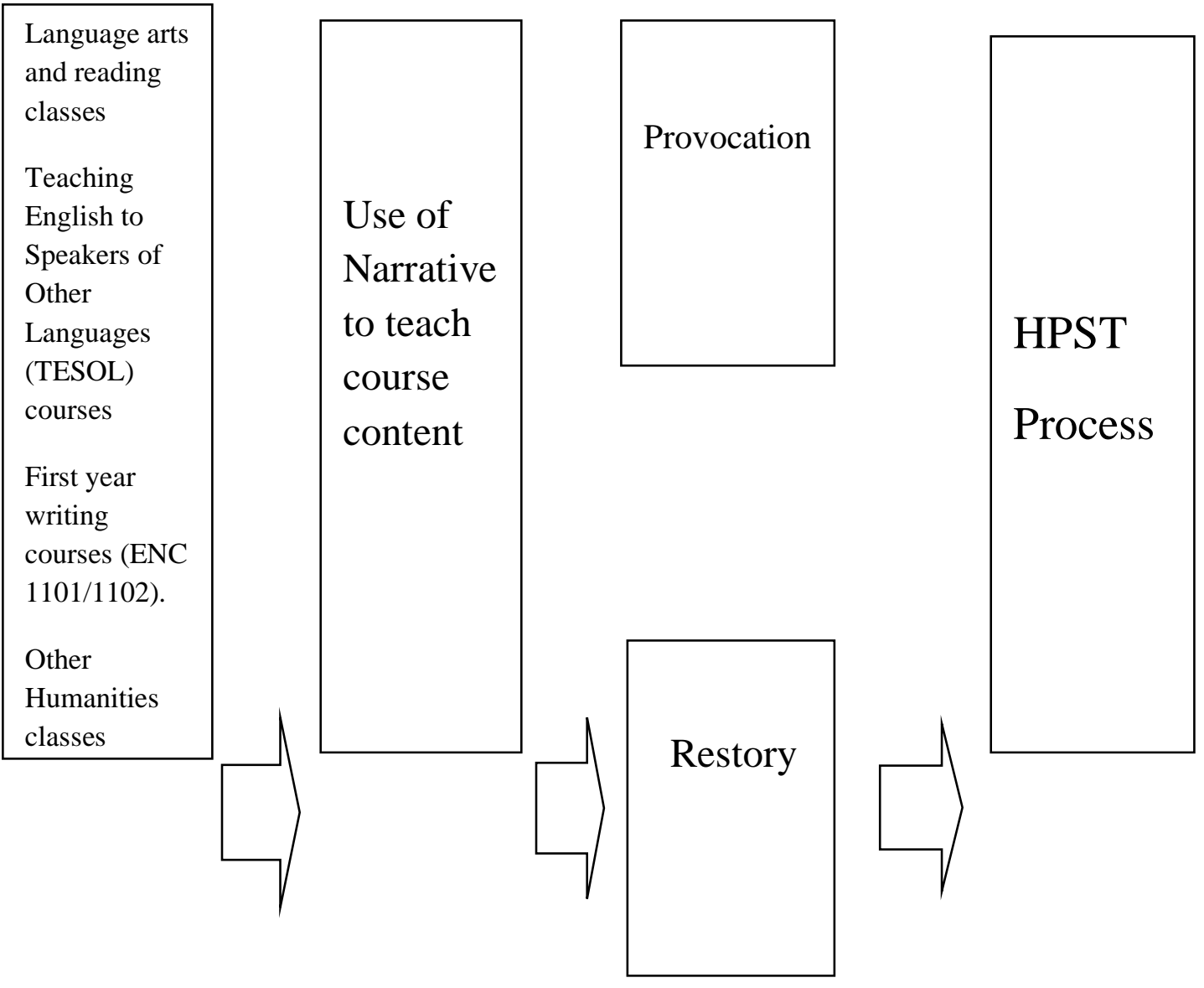

RQ3: To what extent has the use of the HPST changed the teachers thinking about curriculum and or her teaching?

Overview

The participant articulated to me in one of our discussions that

HPST has changed [her] thinking in that it challenges [her] to step back and do more in-depth teaching even though the clock is running to complete the pacing guide. This is reflected in the benefits of HPST which include a deeper understanding of document analysis by categorizing events into more than one category. This is a skill that students transfer to other lessons with varying historical concepts making the HPST a valuable tool to teach skills. Additionally, it allows more classroom interaction between students and students with the text which would not otherwise exist in the traditional lecture-based classroom. 
As this case study possibly demonstrated, this teacher found that HPST Framework offered a flexible method of teaching history because it was used in multiple classroom settings and was tailored to teacher's and student's needs. Moreover, HPST took on distinct functions and forms according to the content the participant's students needed to learn. For example, in Implementation One and Two, the teacher's students read the graphic novel Persepolis and through the HPST process unpacked and examined themes associated with the Iranian Revolution. In particular the teacher's students “recognized the complexity of gender roles and of human actions during historical events." Subsequently, in Implementations Three and Four, HPST was utilized to cover other complicated themes that she said were harder for students to grasp, like colonization, immigration, or revolution. Teachers could possibly use historical narrative coupled with the HPST process to teach the required content instead of recurring to a traditional textbook and lecture. Understanding the limitations set up by the pacing guides, in Implementation Four, this teacher decided "to test the flexibility and effectiveness of the framework for independent student work" by assigning HPST as a take-home assignment.

\section{What's left is the T, and "that's me!"}

What's left is the T, and "that's me!" is a humorously contrived and easy-to-recall comment that may help teachers understand the position of students within the construct of the HPST approach. As I have mentioned previously, HPST is an organizational tool which students could possibly use for document analysis. This framework worked on the

principle that a student utilized the $\mathrm{H}, \mathrm{P}$, and $\mathrm{S}$ and applied them to a provocative (Sally, 
2016) historical narrative via a process whereby they actively searched for evidence of the frames' definitions within an assigned text (Ramberg \& Gjesdal, 2005) (Dilthey, 1982) (Howe, 2011) (Heidegger, 1927) (Gadamer, 1975). Simply put, the HPS are the essential components of the approach, while the $\mathrm{T}$ ultimately represented the role of the student. The $\mathrm{T}$ is the most important frame because it gives the student a voice and allows a space for him or her to discus. As Anapilotis et.al stated, restory not only calls forth what the student has learned from the HPS process, but allows the student to add his or her perspective to the overall conversational discourse. In fact, a student's experience, just as my own chronicled in the preface and the incorporation of personalized narratives (Bruner, 1990) (Pinar, 1975) juxtaposed with academic and sometimes sterile representations of historical elements (Colby, 2008), were not just part of the framework, but also became an outcome that helped students learn history and generate their own connections to it.

\section{Advanced Placement (AP) Courses in a High School Setting}

The students who participated in this case study were all in a World History Advanced Placement (AP) course. The participant mentioned to me that an AP classroom is one where students and teachers are pressed for time due to content requirements. The students are required to complete comprehensive tests over the material and those tests then designates whether students receive college credit. In some school districts schools are also rewarded or penalized based on students' pass rates. These constraints leave little room for deviating from the curriculum and engaging in group work.

However, she opted to circumvent from the above mentioned AP constraints, and allowed her students a space to use what she called, "a new and innovative pedagogical strategies and that engages students to go beyond just learning something to simply pass the test." 
Nonetheless, she added that "HPST will definitely help my students answer the DBQs...so it is a win-win for everyone."

\section{HPST Contributions}

Again here, it is important to note that after I had analyzed all the research materials gathered from the participant and wrote this chapter, I decided to share these results with her in a post-hoc interview. Then, the teacher the shared with me the following contributions with me:

1) “HPST added to literature by prioritizing historical narratives to convey information through stories which humanize the people involved in significant world events." For example, in Implementation One, the history behind the Iranian Revolution came to life for this teacher's class through the eyes of Marjane Satrapi author of the assigned text students read, Persepolis. By reading excerpts of this piece and going through the HPST process, the participant's students possibly better understood not only the particulars behind this historical event, but also interacted directly with Satrapi's immigration story. These interactions humanized the Iranian Revolution for students. Moreover, hopefully this story offered students a glimpse into a real life event that is part and parcel of a larger historical phenomenon.

2) "HPST helped students extract content knowledge from the texts they read." The teacher defined content knowledge "as those elements, discussions, skills, pedagogical tools and/or teaching strategies needed by students to understand historical phenomena." The HPST process allowed the participant's students 
to not only comprehend the text they were reading, but also possibly gave them an opportunity to apply the frames to inquire about the historical event they learned about. It is important to note again, that throughout this study, the participant chronicled her students' perceptions to me.

3) "Historical narratives allow students to sympathize with the other... Students discover the impact of events through narratives that familiarize students with diverse groups in the society." The participant's students partook in discussions that possibly led to deeper understandings on what it would be like to be an Iranian female during the Ayatollah Khomeini's administration, in Implementation One, or an indigenous person coming in contact for the first time with the White European Christopher Columbus, in Implementation Two. The teacher's students unpacking these types of issues hopefully familiarized them with the other in diverse societies.

4) "HPST served as a platform for student discussion because it takes the existing classroom discourse about philosophy, politics, and society and power - for example — and cognitively arranges it in two levels for students to engage with the text and the author followed by an analytical layer to enhance comprehension and critical thinking. " In the various implementations, during the Interactive Level, this teacher offered students an introduction to each lesson by having them participate in a gallery walk that included an image of the assigned text's author. The aforementioned activity led to discussions about his or her background that were anchored by essential questions. Moreover, these discussions served to help place students within 
the general historical context being studied and prepared them for going through the HPST process by initially helping them organize their thoughts. With the Analytic Level, students applied H, P, S, and T to an assigned text. This inquiry not only procured evidence of these frames in the reading, but also unpacked discussions that possibly deepened their comprehension of the piece and shed light on further questions or other points of interest that could be thought of critically.

5) "HPST is significant for the teaching profession because it expands the arsenal of teaching tools available to educators." By going through the HPST process, the participant and her students possibly understood the different levels of human experience and thought embedded in narrative sources by highlighting the historical, philosophical, and societal implications of historical accounts. Moreover, students were also exposed to the historical causation which exists within the various actors of an historical event having opposing views, governments which do not reflect their people, and stereotypes that risk erroneous misconceptions.

6) "It allows students to engage in discovery learning instead of prescribed analysis by the teacher." Throughout the various implementations, HPST gave the participating teacher's students a tool to seemly unpack the complexities found in a narrative. However, Mena commented to me that she made it very clear to students that there really was not a wrong or right answer. There was simply their own perspective that was justified by the evidence of the frames found in the assigned text. Nonetheless, this discovery 
learning also engaged students in inquiring about controversial topics by dissecting and breaking the assigned texts into their subsequent themes or parts.

\section{Benefits of HPST}

The following chart offers a synopsis of the possible benefits of the HPST. Please refer to Figure 45 below.

Figure 34. Benefits of HPST.

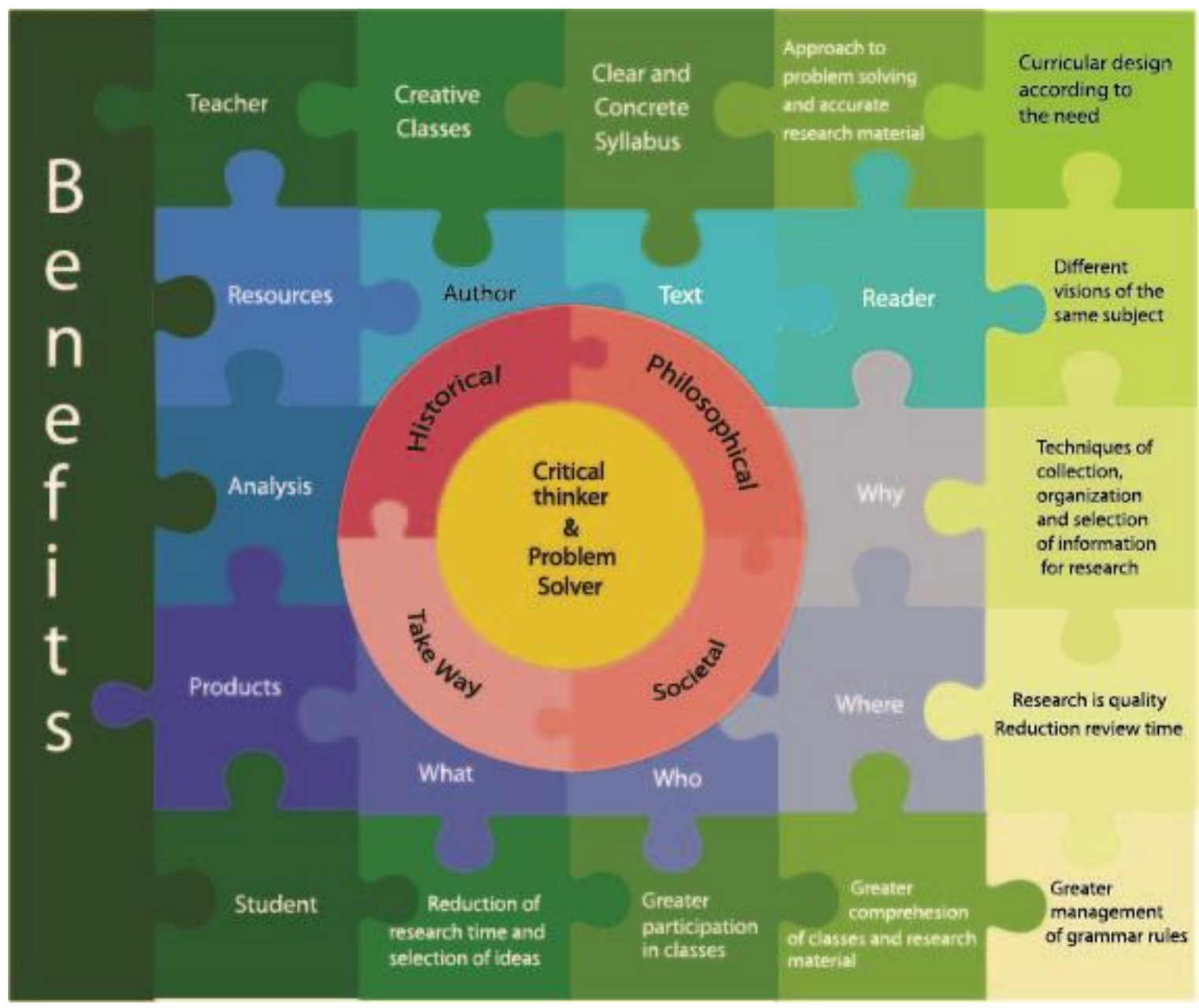




\section{Drawbacks of the Study}

There were several drawbacks that this study possessed, namely:

1) I did not have direct access to students in the Miami Dade County Public Schools (MDPS) District. Because of this, I did not implement the HPST directly to students in that area. Implementation was done by a second party who was a MDPS teacher;

2) HPST was only implemented with students in a ninth grade World History Advanced Placement (AP) course. It would be advantageous to present the HPST to traditional students that were not considered AP, in different grade levels, and within other subject areas;

3) $98 \%$ percent of students in the participant's course were minorities. In the future, a boarder spectrum of students from different ethnicities should be used;

4) Doral Academy was an elite and privileged chart school;

5) The participating teacher was a highly educated historian that possessed much teaching experience and understood the utility of HPST from the beginning;

6) The city of Doral, where the participant's high school is located, is considered an affluent upper middle class city;

7) The HPST Framework offered a superficial level of contextual analysis to students; 
8) HPST needed at least two full 50 minute class periods to fully implement coupled by teacher facilitation and reinforcement of the Interactive and Analytic levels of the framework post implementation.

9) The participating teacher allocated the time used for implementing HPST in reference to and aligned with the rhythm of her pacing guide.

\section{Limitations of the study}

There were several limitations this study possessed. First, I was not able to observe the natural tendencies of the participant's teaching practices ahead of time before actually implementing HPST. I would have advised the participant better if I had observed her previously to the actual implementation. This would have possibly aided her with lesson planning incorporating HPST more efficiently. Second, this research was conducted in AP classes. It would beneficial to see if HPST could be used with other age groups, in younger grades and in mainstream settings. Third, the setting of this study was in a well-funded charter school in an affluent city. Lastly, that this research was a study case. It would be interesting to see a broader sample size of teachers and or students implementing HPST.

\section{Future for HPST}

The following chart delineates the future for the HPST in the coming years. Please refer to Figure 35 below: 
Figure 35. Future for HPST.

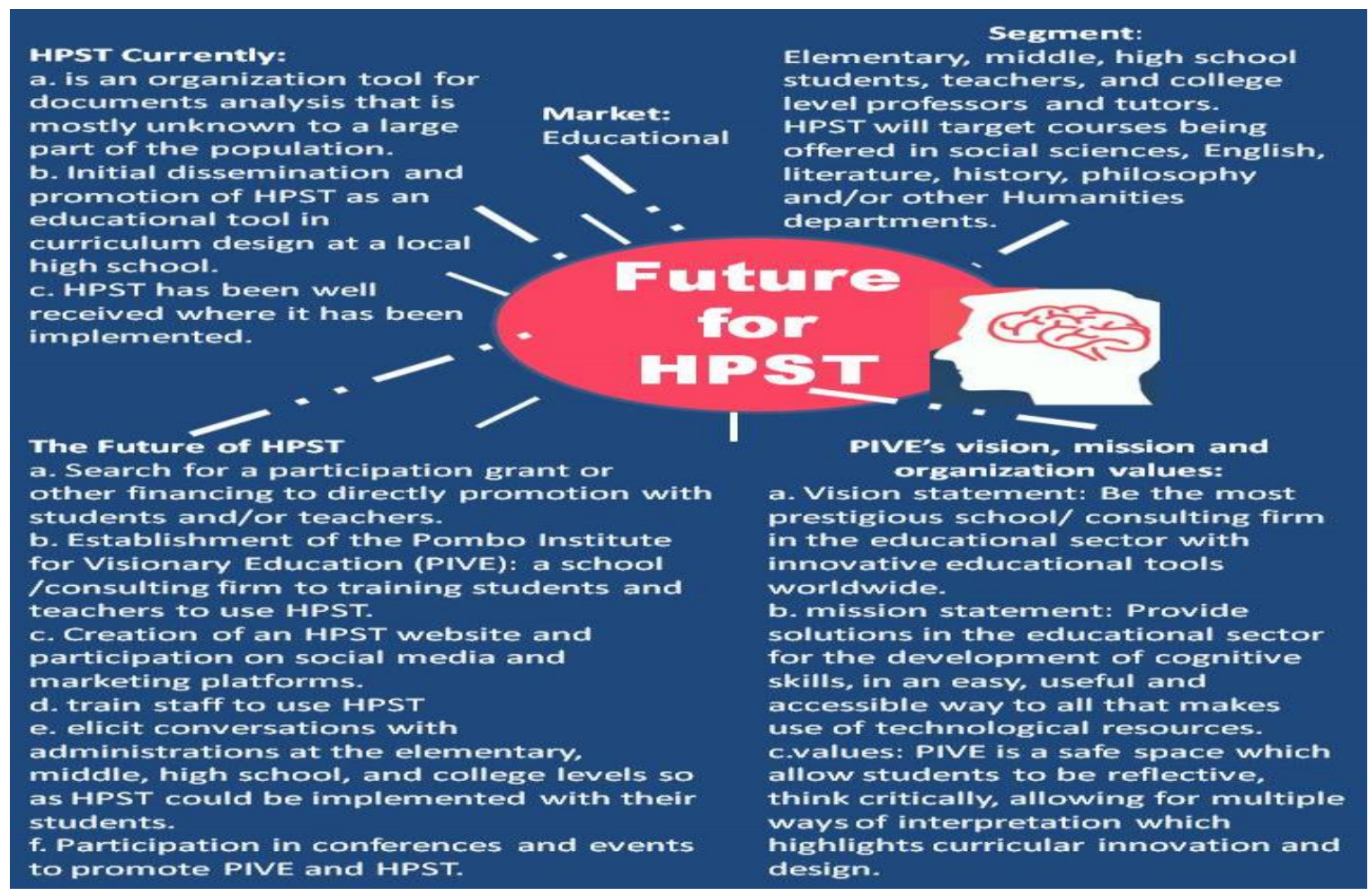

In the future, I would like to continue sharing the HPST Framework with elementary, middle, and high school teachers and their students. Moreover, I would also want the HPST process to be taught at college level and with tutors at university's writing centers. More specifically, HPST could be part of first year writing programs that utilize document and/or contextual analysis as part of their coursework. Moreover, I would want HPST used in social sciences, English, History, literature, Philosophy, and in other humanities courses.

Ideally, I would solicit grants that could allow the HPST to grow as above mentioned. Moreover, this financial backing would provide the funds to create a website and facilitation center where interested teachers would be trained to use HPST. 
Eventually, as more teachers become interested in framework, HPST could be modified to include math and science courses. This would universalize the framework making it curriculum. The training center would then morph and become the Pombo Institute for Visionary Education (PIVE). 


\section{POSTLUDE}

\section{Overview}

It is important to note that in the prelude I chronicled what narratives were and articulated the purpose of storytelling. Moreover, I discussed how personal and professional identity was part and parcel of historical narrative. Additionally, I unpacked how this lived experience found in narrative coupled by the HPST process could possibly create a new educational perspective for teachers and students. In the postlude, I underlined presumptions regarding power within historical narrative, how these were open to challenge and question. Also, I unpacked what this means for students, their identities, the assumptions that those identities often carry, and how HPST confronted them with these ideas.

\section{Why Narratives?}

As I have previously mentioned in the prelude, Barthes (1975) reminded us that narratives are numberless, articulated by language, present in every age, place, or society, international, trans-historical, and trans-cultural: it is simply like life itself (p. 79). Narratives encompass aspects dealing with psychological reality and of historiography, vis-à-vis people, places, and epochs. Additionally, these stories are cultural tools which individuals can utilize to make sense of history. Family narratives played an essential role in my life because these stories are intrinsic to Cuban culture. 
Being a first generation Cuban-American, I learned so much from these narratives. In return, they gave me a sense of purpose, continuity, and understanding of my overall place in American society. William Pinar's (1975) reminded us that in accordance to The Method of Currere "one must regress and there find the past...intact...entered and lived in...thus the object of this part of the method is to observe oneself or others functioning, in the past" (pp. 8-9). Professionally, as a historian, Social Studies teacher, and now a teacher educator, I comprehended the importance of narrative and often used them in my own teaching because document analysis has become a key element required by the Common Core. Pinar (1975) articulated that he wanted to try to understand the contribution my formal studies make to my understanding of my biography...I can look at my life in a linear way, acknowledging its actual multi-dimensional character, but limiting my view to a linear one, to make it more manageable...And if I chart these choices and circumstances on a time line, and then begin to describe (as I remember it now)...I see that there is coherence. Not necessarily logic alone, but a lived one, a felt one. The point of coherence is the biography as it is lived (p. 1).

Moreover, I have asked my students to perform this kind of self-reflection in order to immerse themselves in history as put forward by the Common Core legislation.

As already mentioned, drawing from both my passion for narratives and the need students have to be able to analyze them, I eventually created the HPST framework whose purpose was just that. HPST aligns with Barton and Levstik's (2004) definition of narrative highlighting the historiographical, philosophical, and social cultural components they possess. These frames are significant because students can seemingly use them to organize, deconstruct, and synthesize analysis from historical narratives. 


\section{My views about myself as a researcher}

At the beginning of my Doctoral program, I remember discussing the possible topic of my dissertation with a classmate. During this conversation, I explained to him that my intention was to create a framework to be used for narrative analysis.

Additionally, this tool would be offered to students so as to hopefully create a better learning environment in a Social Studies classroom. Moreover, I added that HPST (which at the time of this conversation did not even have a name yet) was original work. I truly wanted to come up with original work because all my professors urged me to do so, but also according to them "I would contribute in some way to my larger academic community." To be rather honest, I did even know how I would take my idea and create a feasible and solid line of research. At that point, I had not met the study's participant nor did I know that my research eventually would metabolize into being a case study. Again, all I knew was that I really wanted to help students analyze narrative properly.

My friend looked me straight in the eyes, smiled sheepishly and said, "Wow José that is rather ambitious of you... do you understand that original work will make your dissertation be harder to finish because it will take longer to write and more challenging to defend."At that point, I truly did not understand how right my friend was. It must be said, however, that all the chess pieces aligned when I first conceptualized the HPST, crafted the familiarization workshops, met the participant, and she started to implement. True to qualitative research methodology, this case study was very long, involved, and emerged not only as the implementations of the HPST were done. The study came to fruition afterwards — upon reflection — and through much thought, analysis and the 
consequential writing process of all the observations, interviews, and artifacts this teacher offered me.

\section{The Teacher Participant}

Meeting and working with the participant was incredible. It is important to mention that I gravitated towards her on a personal level initially because she is a Cuban American. Also, her family's stories are very similar to mine. Later, when I learned that her professional life mirrored my own, our fates inexplicably coalesced. This teacher, via a series of several deep conversations, demonstrated to me that she truly understood that narratives could be a powerful teaching tool.

The participating teacher is a very seasoned teacher. Her knowledge, expertise, and dedication to this study were very much appreciated. I absolutely categorized her as my study's biggest asset. She was not only just the participant of this research, but during the course of the study, our relationship bloomed into an amazing friendship. I understood that it was meant for us to meet and work together. Besides the official appointments made for interviews and/or observations of this teacher, I had direct access to her and hence called or texted her whenever the need arose. This fact reassured me greatly and made the writing of my dissertation much more solid.

\section{Social Studies Teachers' Awareness of their Students' Attitudes and Positions}

At this point, a very important question arose: What happens to Social Studies teachers when they come to find out what the attitudes and positions of their students are? At the end of Implementation One, that utilized the graphic novel Persepolis, the 
participant felt a bit of trepidation because she realized that some of her students did not fully understanding the Philosophical frame. When she related this to me in the post implementation interview, I suggested she re-implement this session at a later date. I felt that this re-implementation would serve to continue important discussions and hopefully to re-teach the needed content giving students another opportunity to possibly learn analytic skills. By the end of Implementation Two, this teacher shared that more students now possibly understood P. This fact relieved both of us. However, now in retrospect, it should not have come as a surprise. Having going through three years of course work to acquire a Bachelor's degree in history, I came to understand that the philosophical paradigm that emerges out of and because an historical event occurred was the hardest for me to fully comprehend. For example, when one reads a narrative about the first wave of Cuban immigration, the dates or chronology, the establishment of enclaves and the particulars of the how, who, and what are very apparent. The why or -for our intended purposes- the $\mathrm{P}$ is the hardest to unravel. In the case of the first way of Cuban immigration the $\mathrm{P}$ was communism.

\section{Systemic Issues in Social Studies}

Some Social Studies teachers refer to textbooks and handouts rather than storytelling and questioning. In testament to this, the participant mentioned to me that during one of the HPST implementations, her school's administration asked her if a veteran teacher (who had been working with MDCPS for over 20 years) could observe this lesson because his evaluations were unsatisfactory. This, her administration hoped, would give the instructor new teaching ideas and/or strategies that would motivate and 
rejuvenate his passion for teaching. Throughout the lesson, the participant articulated that all "the teacher did was sit in the back of the class and stare at his cellular phone." Moreover, when the participant asked him to engage with the students joining in the gallery walk activity, he declined by saying, "This seems to be very involved...I do not have time do this is in my classroom." Before the end of the lesson, the participant commented that the teacher excused himself and left the implementation.

Is this lack of motivation endemic of Social Studies? Or are these teachers just burnt out by their administrators, colleagues, and students? How could these teachers be motivated? Would both veteran and first year teachers benefit from using narrative, restory, and provocation in their teaching? All these questions shed light on systemic issues not only in the area of Social Studies, but are challenges that we all, as teachers, unfortunately face in U.S. education today.

Moreover, school administrators have reduced the frequency of Social Studies teaching further aggravating this issue. Passe (2006) unpacked that

social studies has always been a backburner subject, attended to after the higherpriority subject areas have been addressed. Even when a state or district mandates a minimum amount of time for social studies, reports from schools indicate that some teachers still managed to overlook this designation in the plan book...they run out of time (pp. 189).

Additionally, the quality of Social Studies teachers also are being called into question. In Miami Dade County, Social Studies teachers are not required to attend a teacher's college or acquired a Bachelor's degree in Education. The only requirement is that an individual 
- have a four year degree from an accredited university (for example in History),

- Take and pass both the General Knowledge Test (GKT) and the Social Studies content area tests—which are examinations that county and state authorities require for certification (CPALMS, 2019).

Possible questions for further research could be the following:

1) Would an individual possessing a Bachelor's degree and who has passed the required state certification tests be qualified enough to teach Social Studies?

2) Where would his or her pedagogical knowledge coming from?

3) Would his or her teaching experience come from? and

4) Would this person be able to transmit the "content" learned from his or her undergraduate studies adequately in a classroom environment?

\section{Concluding Thoughts}

In conclusion, creating the HPST Framework has changed my life. HPST has not only served as fodder for this dissertation, but it has brought upon me a new outlook. I now better understand Social Studies education and I am happy that HPST is a part of that. Moreover, this dissertation has given me an opportunity to express and pay tribute to all those family narratives I hold dear. Additionally, this research has utilized my professional educational experiences as a student, teacher, and teacher educator. I gift the HPST to students, teachers, and colleagues in this field and out. Hopefully, the HPST Framework can serve as a beneficial tool for the Social Studies. 


\section{REFERENCES}

Anapilotis, A., Bastin-Miller,A., Buchansky, H., McRea, C., Quail, S., Sansait, R., Ward, D. \& Weir, A. (November 27, 2016).Research methods-a research blog.[Blog post].Retrieved from researchmethods-school.blogspot.com/2011/11/restorying.ht ml\#more.

Barthes, R. (1957). Mythologies, Seuil: Paris. p. 79.

Baumann, F. and Bergeron, B. (1993). Story map instruction using children's literature: effects on first graders'comprenhesion of central narrative elements. Retrieved from files.eric.ed.gov/fulltext/ED506767.pdf.

Betti, E. (1962). Hermeneutics as the general methodology of the Geisteswissenschaften. Reprinted in Contemporary Hermeneutics: Hermeneutics as Method, Philosophy, and Critique, edited by Josef Bleicher. London and Boston: Routledge and Kegan Paul, 1980.

Bernstein, R. (1983). Beyond objectivism and relativism: science, Hermeneutics, and praxis. Philadelphia: University of Pennsylvania Press.

Bidwell, A. (2014).The History of Common Core State Standards. para 6. In U.S. News. Retrieved from www.usnews.com/news/special-reports/articles/2014/02/27/thehistory-of-common-core-state-standards.

[Biography.com]. (November 7, 2012). Christopher Columbus - Explorer|Min Bio.[Video.File].Retrieved from www.youtube.com/watch?v=My8VdNZ8Qo.

Bogdan, R. \& Biklen, S.K. (1998). Qualitative research for education: An Introduction to Theory and Method. Boston, MA: Allyn \& Bacon.

Bogdan, R \& Biklen, S.K. (2007). Qualitative research for Education. Boston: Pearson.

Brazofsky, R. (2019). Miami Dade County Public Schools Social Studies Pacing Guide. Miami, Florida: Dept. of Social Studies.

Bruner, M. (2002). Efficient and Effective Use of the Textbook. Retrieved from phschool.com/eteach/social_studies/2001 05/essay.html.

Byrd, L. (2016). 52 weeks of directors: Marjane Satrapi. [Photograph]. Make Art History. Retrieved from laurencbyrd.wordpress.com/2016/01/19/52-weeks-of-directorsmarjane-satrapi. 
Bryman, A., Lewis-Beck, M., \& Futing Liao,T. (2003). The Sage Encyclopedia of Social Science Research Methods, 3 Vol. boxed set, Sage.

Bryski, C. (2009). Increasing the social studies reading comprehension of middle school of middle school students with learning disabilities. Western Governors University Press.

Busselle, R. and Bilandzic, H. (2008). Fictionality and perceived realism in experienced stories: a model of narrative comprehension and engagement. Communication

Theory

18 , p. $255-280$.

Cain, C. (1991).Personal stories: identity acquisition and self-understanding in Alcoholics Anonymous. Ethos, 19: 210-253.

Colby, S. (2008). Energizing the History classroom. Historical Narrative Inquiry and Historical Empathy: Texas A\&M University. Retrieved from www.socstrpr.org/files/Vol\%203/Issue\%203\%20\%20Winter,\%202008/Practice/3.3.5.pdf.

Collins, P. and Gallinat, A. (2010). The ethnographic self as resource. Bergham Books: New York.

Chubarov, A. (2001). The fragile empire: a history of imperial Russia. New York: Continuum.

CPALMS, (2017). Para.2. Retrieved from www.cpalms.org.

Crusius, T. (1991). A Teacher's Introduction to Philosophical Hermeneutics. In NCTE Teacher's Introduction Series (pp. 16). Urbana, IL. National Council of Teachers of English.

Czarniawska, B. (2004). Narratives in social science research: introducing qualitative methods. London, UK: Sage Publications.

Davidson, C. (2010). Transcription matters. Journal of Early Childhood Research, 8(2), 115-131.

Dederen, R. (1974). Introduction to Hermeneutics, ed., Gordon M. Hyde, A Symposium on Biblical Hermeneutics (Washington, D. C.: Biblical Research Institute, 1974), pp. 1, 2).

Dilthey, W. (1982). The status of rationality assumption in interpretation and in the explanation of action, Dialectica, 36: 301-316. 
Dole, J. V., S. Greer, E. \& Wardrop, J. (1991). Effects of two types of pre-reading Instruction on the comprehension of narrative and expository text. Reading Research Quarterly, 26:2: 142-159.

(2019). Doral Academy student demographics. Retrieved from Doral Academy website: www.doralacademyprep.org.

Ebbesen, S. (1990). Boethius as an Aristotelian commentator, in Sorabji (1990), 373-91. Robertson, D.W., Jr (1946). "A Note on the Classical Origin of "Circumstances" in the

Medieval Confessional". Studies in Philology. 43(1): 6-14.

Eckstein, H. (1995). Case study and theory in Political Science. Sage Publication: CA.

Elias, A. (2010) Using fiction to teach American History in middle school: affects on student Engagement. Retrieved from files.eric.ed.gov/fulltext/ED513433.pdf.

Feagin, J., Orum, A., \& Sjoberg, J. (1991). A case for the case study. The University of North Carolina Press: Chapel Hill and London.

Fin, C. (2012). The war against the common core. Featured on Fordham Institute's Flypaper [Blog post]. Retrieved from educationnext.org/the-waragainst-the-common-core.

Foundation for Florida's Future, (2017). Retrieved from www.socialstudies.org/sites/default/files/2017/Jun/c3-framework-forsocial-studies-rev0617.pdf.

Gadamer, H. (1975). Truth and method. Continuum Publishing Group: New York. Retrieved from science.jrank.org/pages/9618/Hermeneutics-Gadamer-HisCritics.html">Hermeneutics - Gadamer And His Critics $</ a>$.

Gernsbacher, M., Robertson, R., Palladino, P. \& Werner N. (2004). Managing mental representation during narrative comprehension. Discourse Processes, 37(2): 145-164.

Hammersley, M. (2010).Reproducing or constructing? Some questions about transcription

in social research. Qualitative Research, 10(5), 553-569.

Heidegger, M. (2002). The origin of the work of art. Translated by Julian Young and Kenneth Haynes. London: Cambridge.

Heidegger, M. (1927/1962). Being and time. J. Macquarrie and E. Robinson (transl.), New York: Harper \& Row. 
Hilburn, J. and Fitchett, P. (2012). The new gateway, an old paradox: immigrants and involuntary Americans in North Carolina history textbooks. Theory \& Research in Social Education 40(1): 35-65.

Howe, T. (2011). Authorial intention. Blog post from Howe Random. December 21, 2018.

Retrieved from tahowe.wordpress.com/2011/12/23/authorial- intention/.

Iran, Sabrina. [Username]. (February 18, 2015). 100 Years of Beauty - Ep 3 |Cut. [Video File].Retrieved from www.youtube.com/watch?v=G7XmJUtcsak.

Kawulich, B. (2005). Participant observation as a data collection method. Qualitative Social Research Forum, 6(2). Retrieved from www.qualitative-research.net/index.php/fqs/article/view/466/996.

Kelsey Cheney (November 6, 2013). Peter the Great: A Biography. [Video File]. Retrieved from www.youtube.com/watch?v=463djtBQ4Lk.

Klyuchevsky, V. (1958). Peter the Great. (Liliana Archibald, Trans).New York: Macmillan.

Kreis, S. (2002).The journal of Christopher Columbus (1492). The History Guide. Retrieved from historyguide.org/earlymod/columbus.html\#biblio.

Lawrence, B. (1984). Historical perspective: using the past to study the present. Academy of Management Review, Vol. 9, No. 2, p. 307-312.

Lee, C. and Tsai I. (2004). No kidding-exploring the effects of stories through the window of Schema Theory. Association for Educational Communications and Technology,27th, Chicago, IL, October 19-23.

Lejeune, P. (1975). Le pacte autobiographique. Paris: Seuil.

Lichtman, M. (2013). Qualitative research in education: a user's guide. 3rd ed. SAGE Publications: Thousand Oaks, California.

Lindquist, T. (2010).Why \& How I Teach with Historical Fiction. Retrieved from https://gse.uml.edu/rtt/tah/8/cds/cd1/docs/1.pdf.

Mahoney, E. (2019). DeSantis takes aim at Common Core in executive order. Tampa Bay Times. Retrieved from www.tampabay.com/florida-politics/buzz/2019/01/31/desantistakes- aim-at-common-core-in-executive-order aim-at-common-core-in-executiveorder.

Martell, C. and Hashimoto E. (2011). Throwing out the history textbook: changing social studies texts and the impact on students. Online Submission, paper presented at 
the Annual Meeting of the American Educational Research Association (New Orleans,

LA, Apr 8-12, 2011).

Marshall, C. and Rossman, G. (1989). Designing qualitative research. Newbury Park, CA: Sage.

Massie, R. (1981). Peter the Great: His life and times. New York City: Ballantine Books.

Moules, N. J. (2002). Hermeneutic inquiry: paying heed to history and Hermes - an ancestral, substantive, and methodological tale. International Journal of Qualitative Methods.1 (3), Article 1. Retrieved from http://www.ualberta.ca/ ijqm.

National Council for the Social Studies. (2013). The college, career, and civic life (C3) framework for Social Studies state standards: guidance for enhancing the rigor of K-12 Civics, Economics, Geography, and History.

National Council for the Social Studies Task Force on Teacher Education Standards (NCSS). (2002). National standards for social studies teachers (Vol. 1). Silver Spring, MD: National Council for the Social Studies. Retrieved from http://downloads.ncss.org/NCSSTeacherStandardsVol1-rev2004.pdf.

Narayan, K. (1993). How narrative is a native anthropologist, American Ethnologist 95(3): 671-86.

Nokes, J. (2013). Building students' historical literacies. Routledge Francis Taylor Group: New York and London.

O’Reilly, K. (2009). Key concepts in ethnography. London: Sage Publications LTD.

Passe, J. (2006). New challenges in elementary Social Studies. The Social Studies Retrieved from americanhistoryrules.com/ed315/wp content/uploads/2013/08/EJ773731.pdf.

Pérez, L. (2001). Growing up Cuban in Miami. Ethnicities: children of immigrants in America. 91-126.

Pinar, W. (1975). The method of "currere." Paper presented at the Annual Meeting of the American Research Association: Washington, D. C., April 1975.

Pinar, W. (2012). What is curriculum theory. Routledge Francis and Taylor Group: NYC.

Pombo, J., Mena, Y., \& Mathews, S. (2018). HPST Framework: learning about Iran through historical inquiry for students. International Journal for Cross- 
Disciplinary Subjects in Education (IJCDSE), Volume 9, Issue 2.

Pombo, J., and Giust, A. (2015).Using the HPST Framework to improve reading comprehension with students with intellectual disabilities in a university setting. Manuscript submitted for publication.

Pombo, J., Mena, Y., \& Mathews, S. (2017). An island in transition: how narratives can help students interpret Cuba's future by its past. Manuscript submitted for publication.

"Race to the Top,"n.d., para 1. In the White House President Barack Obama. Retrieved from obamawhitehouse.archives.gov/issues/education/k-12/race-to-the-top.

Ramberg, B.T., and Gjesdal, K. (2005). Hermeneutics: Stanford Encyclopedia of Philosophy. ISSN 1095-5054. Retried from stanford.library.sydney.edu.au/archives/sum2016/entries/hermeneutics.

Reed-Danahay, D. (1997). Introduction. In D. Reed-Danahay (Ed.), Auto/Ethnography: rewriting the self and the social. Oxford: Berg. (pp. 1-17).

Reynolds, D. (2001). Interpreting the self: autobiography in the Arabic literary tradition. Berkeley: University of California Press.

Richardson, L. (1997). Fields of play: constructing an academic life. New Brunswick, N. $\mathrm{J}:$ Rutgers University Press.

Richardson, L. (2000). Evaluating ethnography. Qualitative Inquiry, 6(2), 253-255.

Richardson, L. (2007). Writing: A method of inquiry. In N. K. Denzin \& Y. S. Lincoln. (Eds.) Handbook of Qualitative Research, (2nd ed., pp. 923-948). Thousand Oaks, CA: Sage Publications.

Riessman, C.K. (2002). Doing justice: positioning the interpreter in narrative work, in W. Patterson (ed), Strategic Narrative: New Perspectives on the Power of Personal and

Cultural Storytelling, Lanham MA and Oxford UK, Lexington Books, 2002, pp.195216.

Riessman, C.K. (2003). Performing identities in illness narrative: masculinity and multiple sclerosis, Qualitative Research, 3(1).

Sally (No last name given). (2016). What is provocation. Retrieved from fairydustteaching.com/2016/09/what-is-a-provocation.

Satrapi, M. (2003). Persepolis- the story of a childhood. Pantheon Books:Paris, France. 
Schunk, D. H. (2012). Learning theories: an educational perspective (6th ed.). Pearson: Boston.

Smith, S. and Watson, J. (2010). Reading autobiography: a guide for interpreting life narratives. Minnesota: University of Minnesota Press.

Stake, R. (1995). The art of case study research. Sage Publication: California.

Stygles, J. (2014). Building schemas: exploring content with song lyrics and strategic reading. The Language and Literacy Spectrum, 24, p. 101-114.

Tapiero, I., VandenBroek, P., \& Quintana, M. (2002). The mental representation of narrative as networks: role of necessity and sufficiency in the detection of different types of causal relations. Discourse Processes, 34(3), 237-258.

Think-Pair-Share. (n.d.). Student Handouts. Retrieved from studenthandouts.com.

Tolin, D. (1862). The First Landing of Christopher Columbus in America Great Art and Artists /Blog. March 24, 2018. Retrieved from greatartandartists.blogspot.com/2018/03/the-first-landing-of-christopher.html.

Tracy, S. (2010). Qualitative quality: eight "big-tent" criteria for excellent qualitative research. In Qualitative Inquiry 16(10) 837-851. Arizona State University.

Vershinin, A. (2015). Army reforms. [Paul Delarouche (1838) Photograph]. Russia Insider. Retrieved from russia-insider.com/en/2015/02/04/3141.

Vygostsky, L. S. (1997). Educational psychology. Classics in Soviet Psychology Series. Translated by Robert Silverman. St. Lucie Press: Boca Raton, Fl.

Wang, H. and Koyama, T. (2014). An analysis and review of the literature and a three-tier video modeling intervention model. El Sevier. Volume 8, Issue 7. July 2014, Pages 746-758.

Weimer, M. (2012). Four Levels of Student Reflection. Faculty Focus. Retrieved from facultyfocus.com/articles/teaching-and-learning/four-levels-ofstudent-reflection.

Williams, G. (1984).The genesis of chronic illness: narrative reconstruction. Sociology of Health \& Illness, 6(2):175-200.

Wineburg, S. (2001). Historical thinking and other unnatural acts. Temple University Press, Philadelphia. The historical project. (n.d.) Retrieved from historicalthinking.ca/continuity-and-Change.

White, H. (1984). The question of narrative in a contemporary historical theory. History 
and Theory, Vol. 23, No. 1, 1-33 Retrieved from www2.southeastern.edu/Academics/Faculty/jbell/white.pdf.

Young, F. (1987). Biblical Exegesis and the formation of Christian Culture. London: Cambridge 


\section{APPENDICES}

\section{Appendix A}

\section{HPST workshop Power Point}

Slide 1-Gallery Walk Examples- Que Pasa USA audio Clip

https: $/ /$ www.youtube.com/watch? $v=q 9 H h f 8 \mathrm{kEJIg} \& \mathrm{t}=88 \mathrm{~s}$
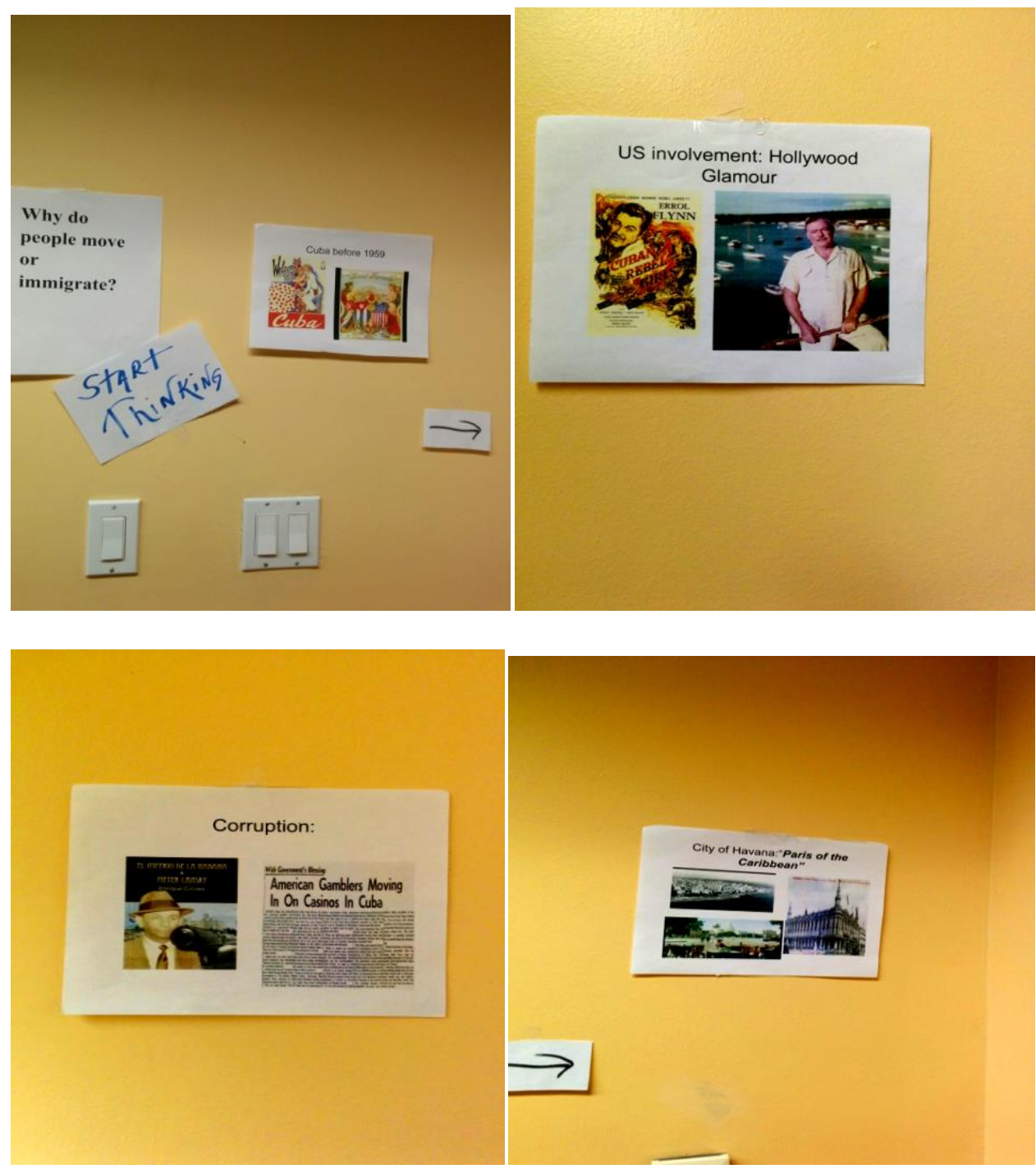

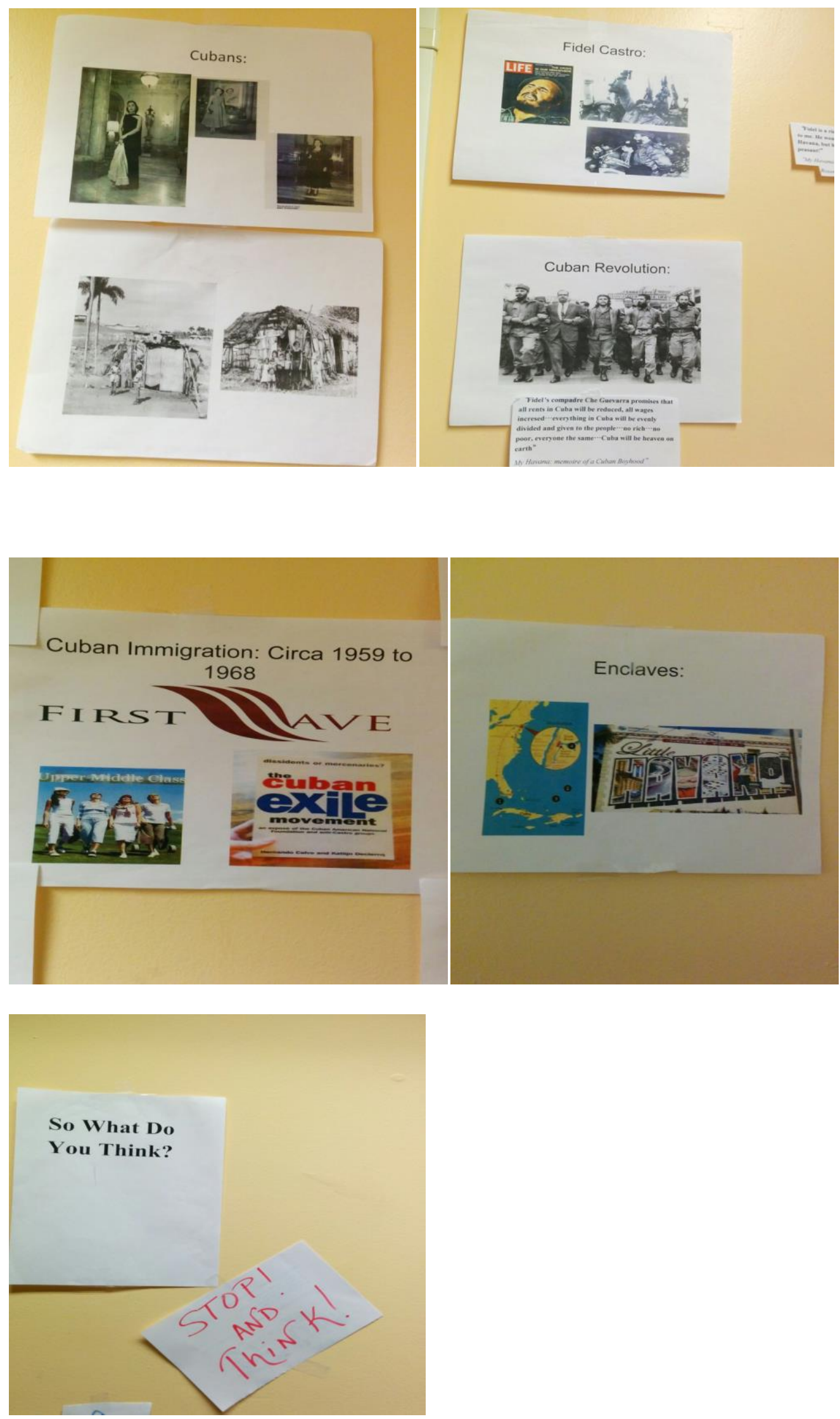


\section{Slide 2- What does HPST stands for:}

- This acronym stands for Historical, Philosophic, Societal, and a Takeaway Framework

\section{Slide 3- Purpose of the HPST Framework}

The HPST Framework when applied to an historical narrative will:

- help extract content knowledge

- create higher order connection making

- be used as a platform for student dialogue

- be utilized as a deliverable form of student assessment

- provide students will an authentic learning experience

\section{Slide 4- How does the HPST Framework work}

1. Interactive Level: which is composed by three interconnected elements, namely the: author, text and reader/student (hermeneutic circle).

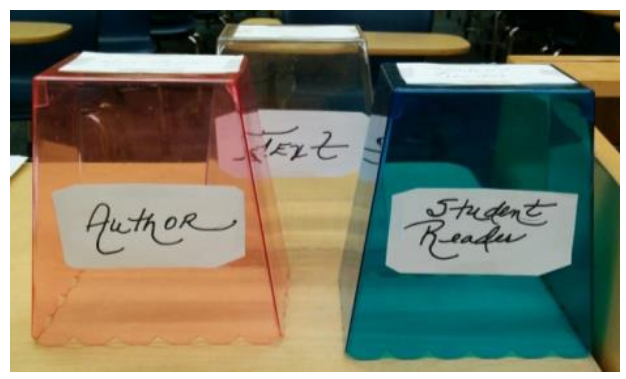

2. Analytic Level: is composed by four frames: historic, philosophic, societal, and a “personal” takeaway (or student reaction).

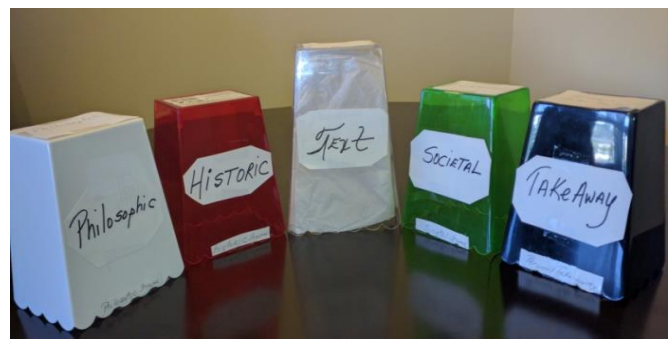




\section{Slide 4- What type of narratives can be used:}

- This framework mainly targets written text (s), but could extend to visual and or auditory narratives as well.

\section{Slide 5-Example of Text Selection}

- My Havana: Memories of a Cuban Boyhood written by Rosemary Wells (for lower grades).

- Next Year in Cuba authored by Gustavo Perez Firmat (for grades 9-12).

\section{Slide 6-Student Group Assignment}

- Group students per frame:

(example: a historical, philosophical, and a societal group)

or

- Group with one student covering each of the frames:

(example: group X-composed of three students. One covering historic frame another with the philosophic frame, and the last with the societal frame)

- All students regardless of group must offer a personal takeaway

\section{Slide 7-Student's Roadmap}

- Start of the analysis process

- The teacher's introduction to the lesson

- This roadmap has of two elements:

1) background information- composed of the professional and personal information of the author and an image.

Teacher can directly give this to students or have students conduct their own research on the author. 
2) Is a vocabulary, concept, essential question (s), and or terms that will be:

given to student which reflects desired content

used by student while reading the narrative.

\section{Slide 7- Student's Roadmap \#1 Example}

Mary Wells Is an American writer and illustrator of children's books. She is well known for the Max and Ruby series, which follows the everyday adventures of sibling bunnies, curious three-year-old Max and bossy seven-year-old Ruby.

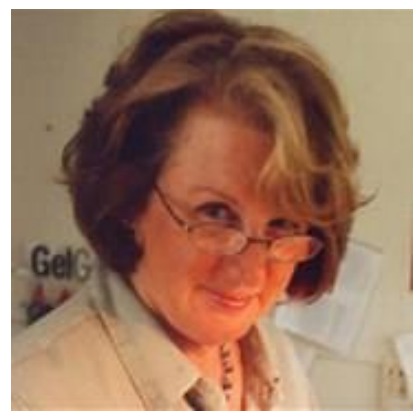

Gustavo Firmat is a Cuban American and is affiliated with Columbia University. The author has written other pieces, namely: Idle Fictions; The Cuban Condition; Do the Americas Have a Common Literature.

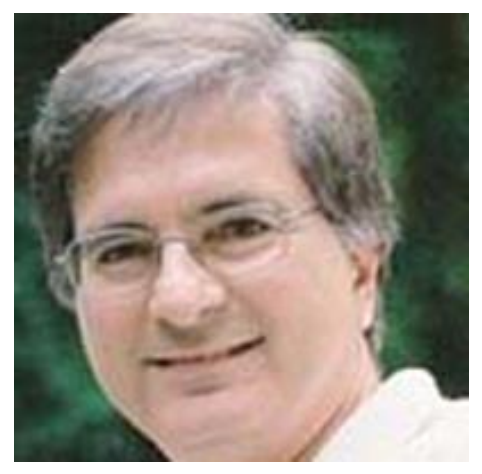

Slide 8- Student's Roadmap \# 2 Example

- Historical Frame

Havana

Dates such as 1959 to1969 
First wave of Cuban immigration

- Philosophic Frame

Communism

- Societal Frame

Castro/ Batista

social economic level of first wave of Cuban immigrants

\section{Slide 9- Student Assessment}

Students working in their assigned group according to frame (the historical, philosophic, and or societal) will:

create a deliverable using selected excerpts from the narrative itself that describe,

exemplify, answer, and or justify the vocabulary, concepts, essential question (s), and or terms listed on Student's Roadmap \# 2 for their assigned frame.

\section{Slide 10- Historical Frame}

Students will be searching for passages that describe:

1. the historic issue or occurrence itself

2. what, where, and how of the particular historical event

3. Four Cs: context, causes, continuity, and change over time

4. Timeframe or timelines

5. Dates

6. Geographic locations

\section{Slide 11- Philosophic Frame}

Students will be exploring passages that reflect the belief (s) of a time period, school (s) of thought, public opinion, psychological paradigm, and or "-isms" etc. 


\section{Slide 12- Societal Frame}

- Students will be searching for text excerpts that chronicle people and the underpinnings and nuances of culture within the period (such as: food, entertainment, religion, tradition celebrations, morals, and values).

\section{Slide 13- Takeaway Frame}

- $\quad$ student reaction

- gives students an active and participatory voice

- Most important part of lesson

- Every student regardless of assigned group MUST react, reflect, and connect what they have learned from using the HPST Framework.

- This student takeaway will be included in the final deliverable.

- $\quad$ Serve as platform for classroom discussions

\section{Slide 14- Knowledge Showcase}

- This last step will be a final presentation composed by the bringing together and exhibiting all the analysis (via selected excerpts) the student groups found.

- Included is each student's takeaway

- Can serve as final teacher assessment 


\section{Appendix B}

\section{Participant Lesson Plan}

Unit: Revolution

Lesson Title: Iranian Revolution

Lesson Type: Integrating Narratives/Graphic Novels

- Essential Question: Could the Iranian Revolution been prevented? If so what could have been done to stop it?

○ How are images used to portray her POV and why does she have this POV?

\section{NCSS Themes:}

- $\quad$ Time, Continuity, and Change: by studying and understanding the historic events of the Iranian Revolution.

- $\quad$ Power, Authority, and Governance: the students will need to understand the foundation and development of power, authority, and governance to identify reason behind the Iranian Revolution.

- $\quad$ People, Places, and Environment: students will understand how a location and environment influences civic issues.

\section{Florida Sun Shine State Standards:}

- $\quad$ LAFS.910.RH.2.4 Determine the meaning of words and phrases as they are used in a text, including vocabulary describing political, social, or economic aspects of history/social studies.

- $\quad$ SS.912.W.8.10: Explain the impact of religious fundamentalism in the last half of the 20th century, and identify related events and forces in the Middle East over the last several decades.

- $\quad$ SS.912.W.9.1: Identify major scientific figures and breakthroughs of the 20th century, and assess their impact on contemporary life.

- $\quad$ Use geographic terms and tools to analyze case studies of regional issues in different parts of the world that have critical economic, physical, or political ramifications.

- $\quad$ SS.912.G.4.1: Interpret population growth and other demographic data for any given place.

\section{Objectives:}

The students should be able to... 
- With previous knowledge analyze the outcome of the Iranian Revolution

- Identify the importance of religion to the Middle East from the Lecture

- Understand the historical relevance of the Sunni and Shite split in Iranian politics.

- What is fundamentalism and the social manifestations it represents?

\section{Materials/Equipment:}

1. Pictures of Women's fashion, tape and labels for Gallery Walk.

2. YouTube Clip (Persepolis)

https://www.youtube.com/watch?v=UvoEFKZqT44

3. You Tube Clip: Women's dress code in Iran (https://www.youtube.com/watch?v=uwofxdWvlXQ)

4. HPST Framework Student Roadmap

5. PowerPoint (Iranian Revolution)

6. Dry erase marker

\section{Procedures:}

Day 1: Persepolis movie trailer on YouTube, PPT, and Gallery Walk

- PowerPoint to go along with this Unit describing the timeline in Iranian history (known as Persia)

- Show hook of the Walking Gallery of politics influencing women's fashion.

Day 2: Students will discuss the graphic novel, Persepolis they read at home. We will extract the social, philosophical, historical, and take home from the novel using HPST Framework.

\section{Introduction-}

- Hook: Show students a Walking Gallery of the Political Changes that have influenced women's fashion in Iran from the 20th century forward.

- Discuss how fashion is political?

- Introduce novel Persepolis and ask which year the novel could take place by looking at the women's hair styles. 
Main Activity 1: History of Iran PPT.

Students will be able to understand how Persia moved from being a Zoroastrian nation under Cyrus the Great to a Muslim nation after the conquest of the Muslim Caliphates beginning 7 th century.

- The fundamentalism of the Sunni and Shiite split will determine the antiwestern Iranian Revolution which was a fundamentalist Shiite revolution under the Ayatollah Khomeini.

Main Activity 2: Walking Gallery of Political Changes and Fashion

- Discuss the predictions and conclusions students formulate after seeing the altered appearance of women in Iran from 1910-2010 (Pay special attention to 1980)

\section{Main Activity 3: HPST Framework Student roadmap}

Students will split up into HPST groups assigned by the teacher. Different excerpts from the novel will be sued to complete a HPST Framework Student roadmap

- Students will begin by compiling the information they gained about the author (done at home) to establish her class status, education, and values, that determined the POV of the novel, Persepolis.

- Students will provide evidence from the text to support their Historic, Societal, and Philosophic conclusions from the authors POV.

- Students will integrate multiple disciplines including history, sociology, and philosophy to generate a consensus of the social milieu present in Iran

Concluding Activity: Class discussion and personal take-away discussed

- What did you learn from studying the Iranian Revolution from a young girl's perspective?

- What lesson will you take with you?

- Is this applicable to your current life?

- Was social reform inevitable? What steps could have produced a different outcome?

\section{Modifications:}

The use of a graphic novel accommodates the needs of ESE/ESL students making the lesson ESE/ESL minded from the inception.

\section{ESOL Strategies:}


Breakdown of Iranian Revolution and Iranian history with many images in the PowerPoint to enhance comprehension of visual learners.

\section{Student Evaluation/Assessment:}

The students were able to...

- With previous knowledge analyze outcome of the Iranian Revolution

- Determine the social ramifications of politics.

- The power of images and graphic novels to express social issues.

- Identify the author's biases whether justified or not.

- Identify and classify historic, philosophical, and social aspects presented in the novel while realizing how they work together to create perspective.

- Determine whether the novel is a primary or secondary source.

\section{Teacher Evaluation/Teacher Reflection:}

\section{MIVCA}

Meaningful: This lesson plan is meaningful to the students because it will show how the Shah was considered a dictator yet brought "social progress" to Iran. The Ayatollah Khomeini and the Iranian Revolution brought back life under an Islamic state and many Iranians such as the young girl in the novel Persepolis, fought back the social changed being brought forth. Both leaders were not ideal and impacted people's lives differently. Students will reflect on the power of media and graphic novels and question why did revolution occur in the first place and if it was preventable.

Integration: This lesson is unique because it integrated elements of literature, media, and fashion to explore the same topic. The lesson allows the students to use the lenses of historians, sociologists, and popular media to determine the reasons for revolution and the reactions fostered by the people.

Active: Students will engage in the Walking Gallery and the use of the HPST in groups to engage in critical thinking from the sensory items they witnessed in the gallery and later reading and online video segments. Learning is active and constant.

Appendix- Video part of Hook Activity 

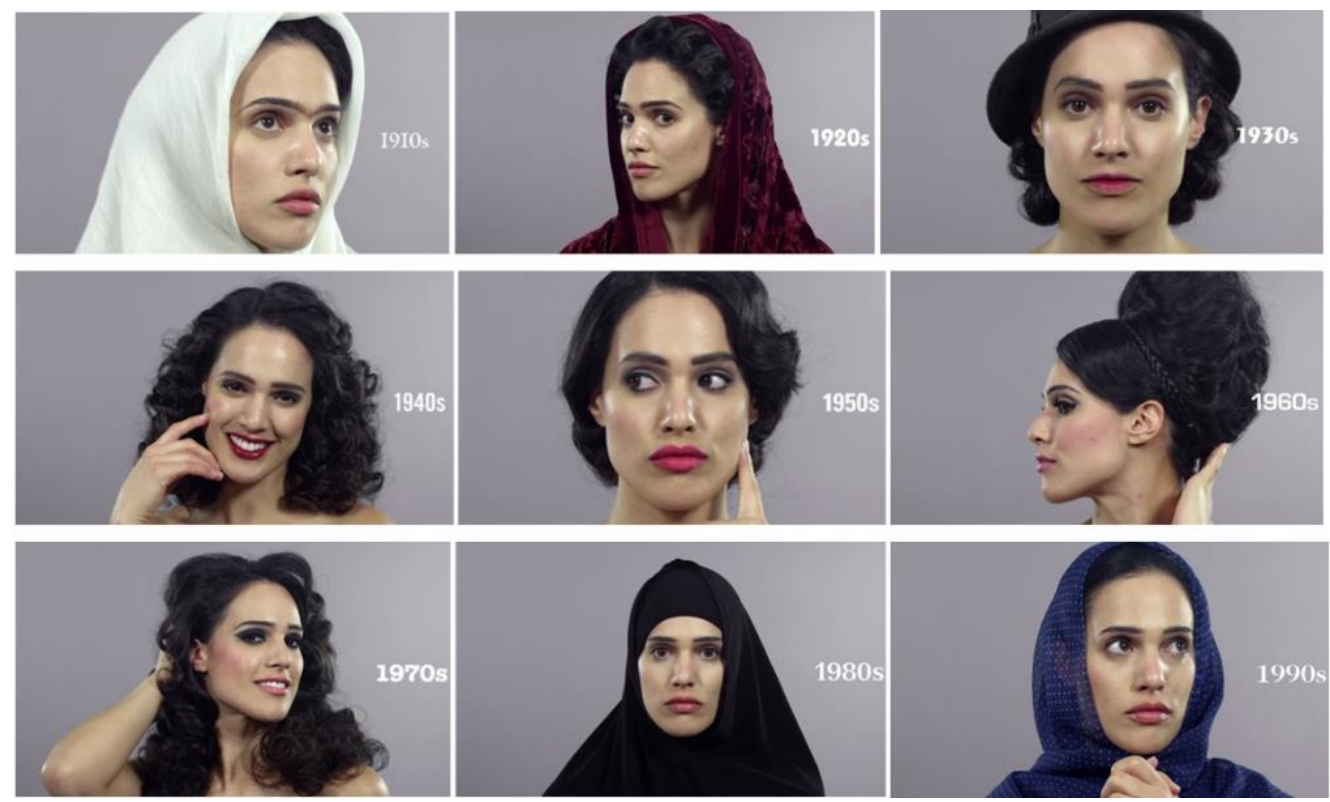

Images Source: http://www.viralspell.com/100-years-of-beauty-shows-how-femalefashion-andbeauty-have-evolved-in-iran-over-the-past-century/

Gallery Walk images

Marjane Setrapi-author of Persepolis 


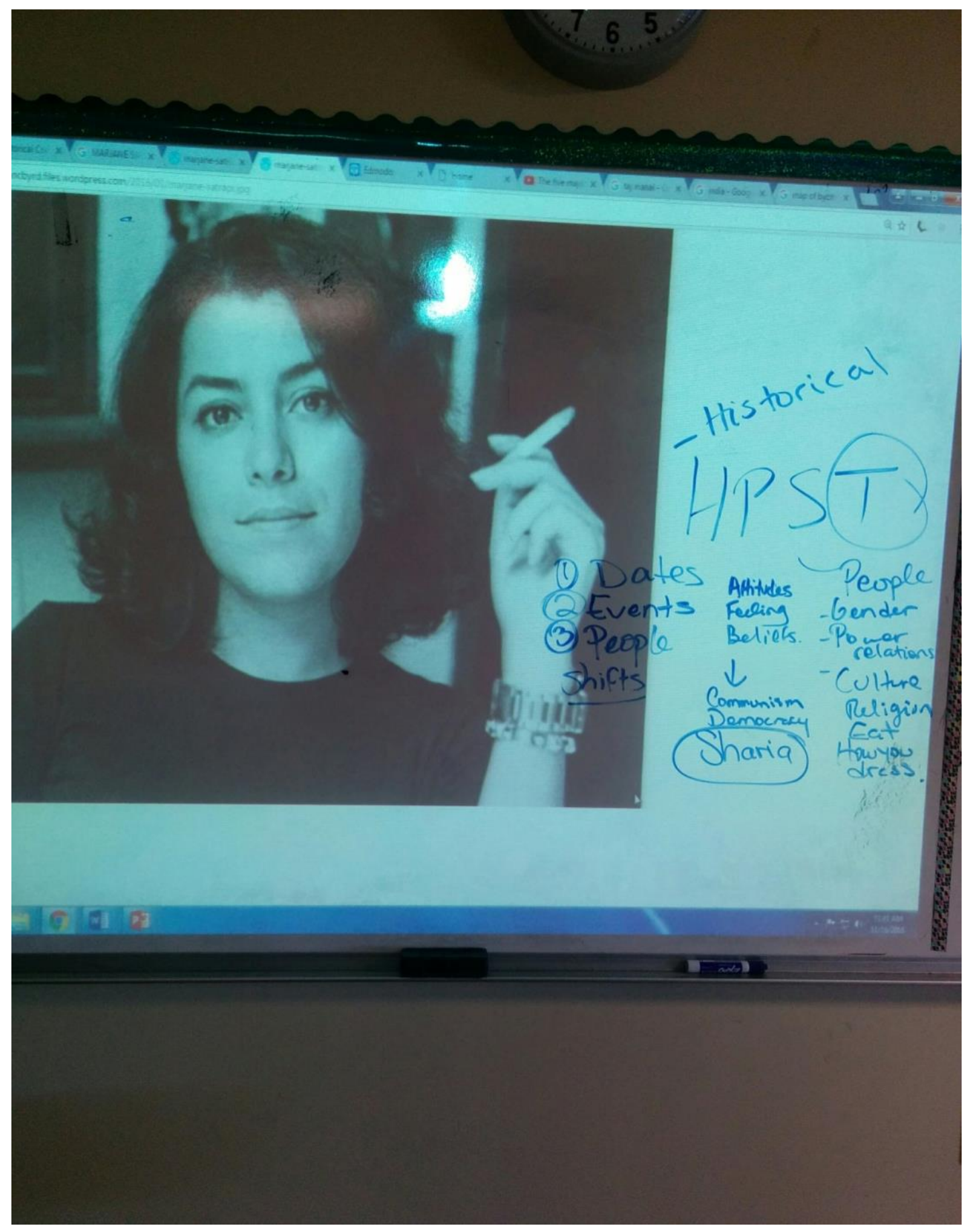


Why Does

Revolution

Happen?
START

Thinking
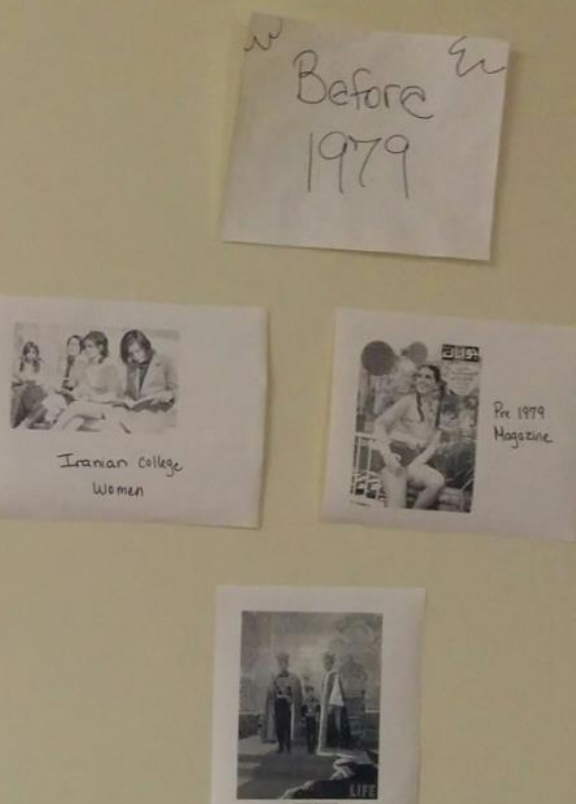

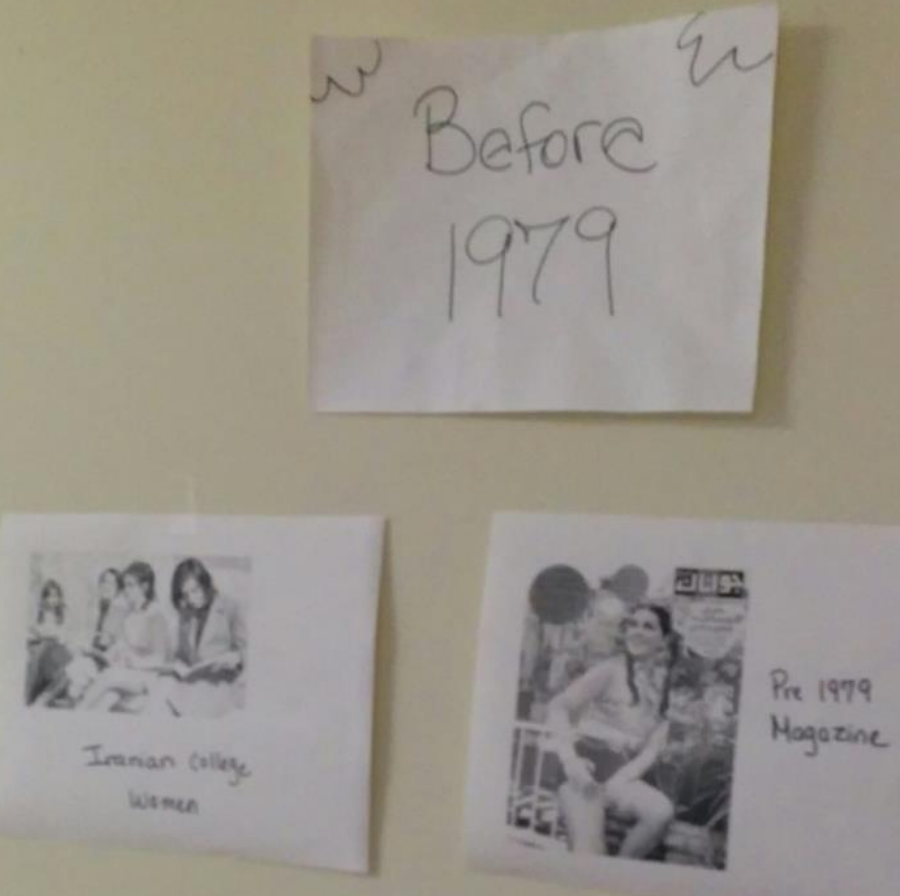

Thinking

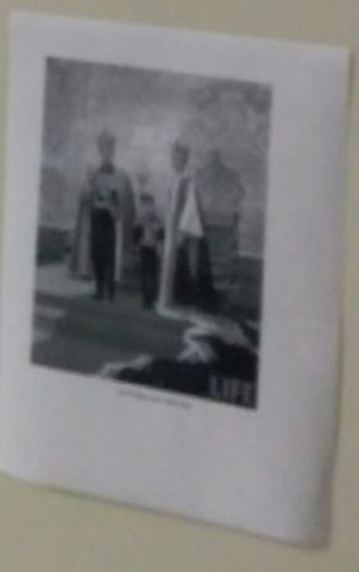



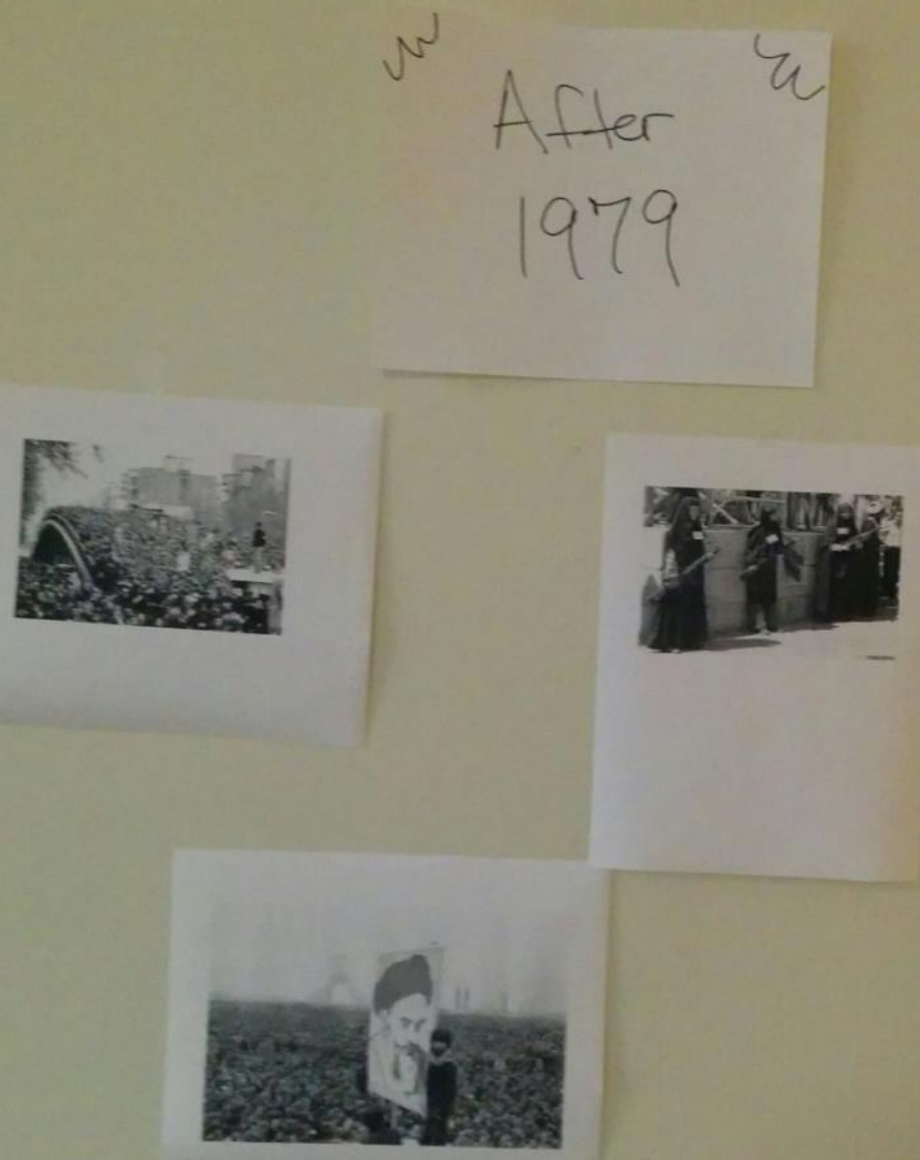
Reflect ox your thinking

194 


$$
\begin{aligned}
& \text { What } \\
& \text { Do You Think? }
\end{aligned}
$$

195 
Excerpts from the text: Source: http://knopfdoubleday.com/2009/06/30/the-veil-frommarjane-satrapis-persepolis/

\section{O THE VEIL}
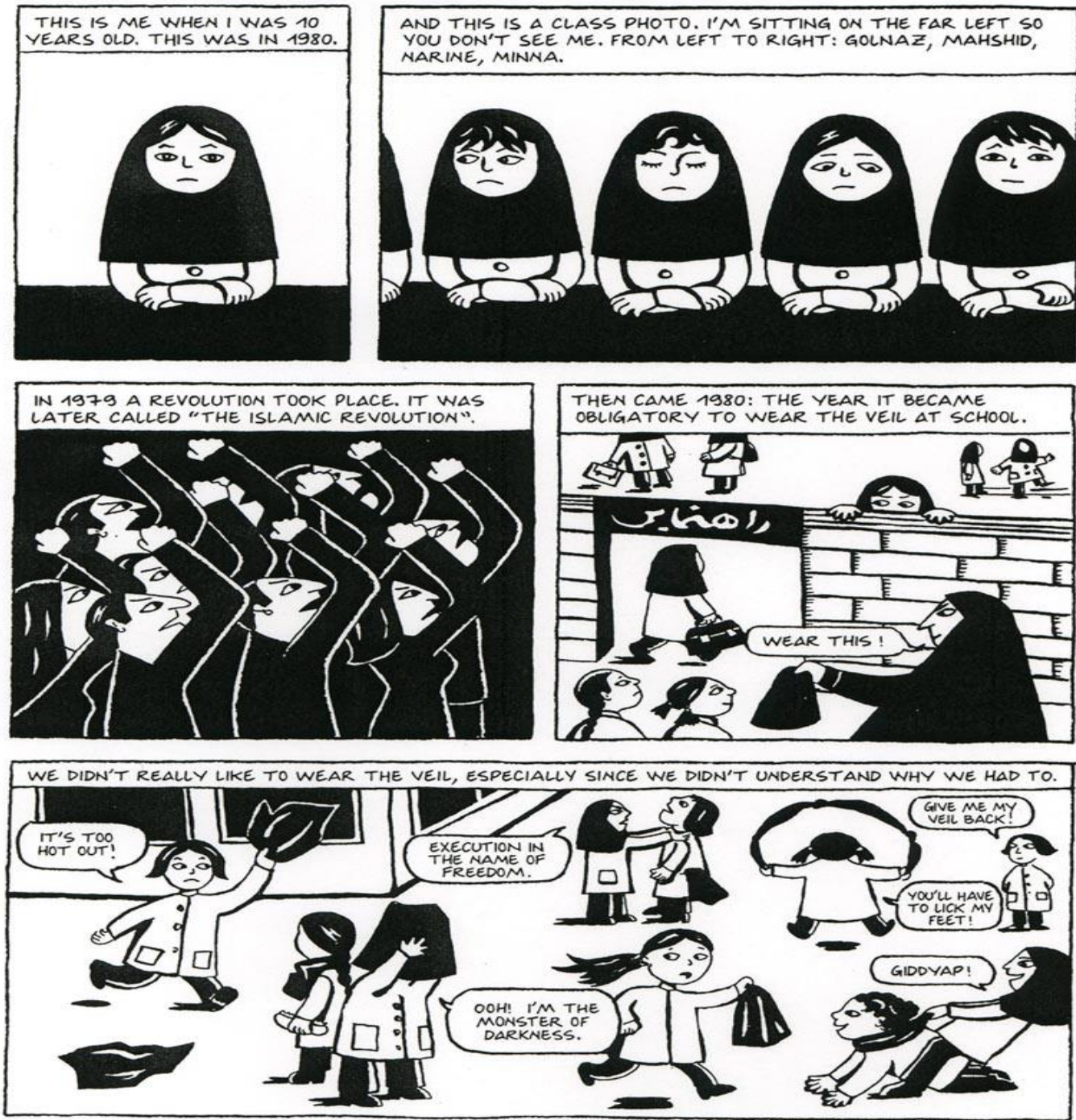

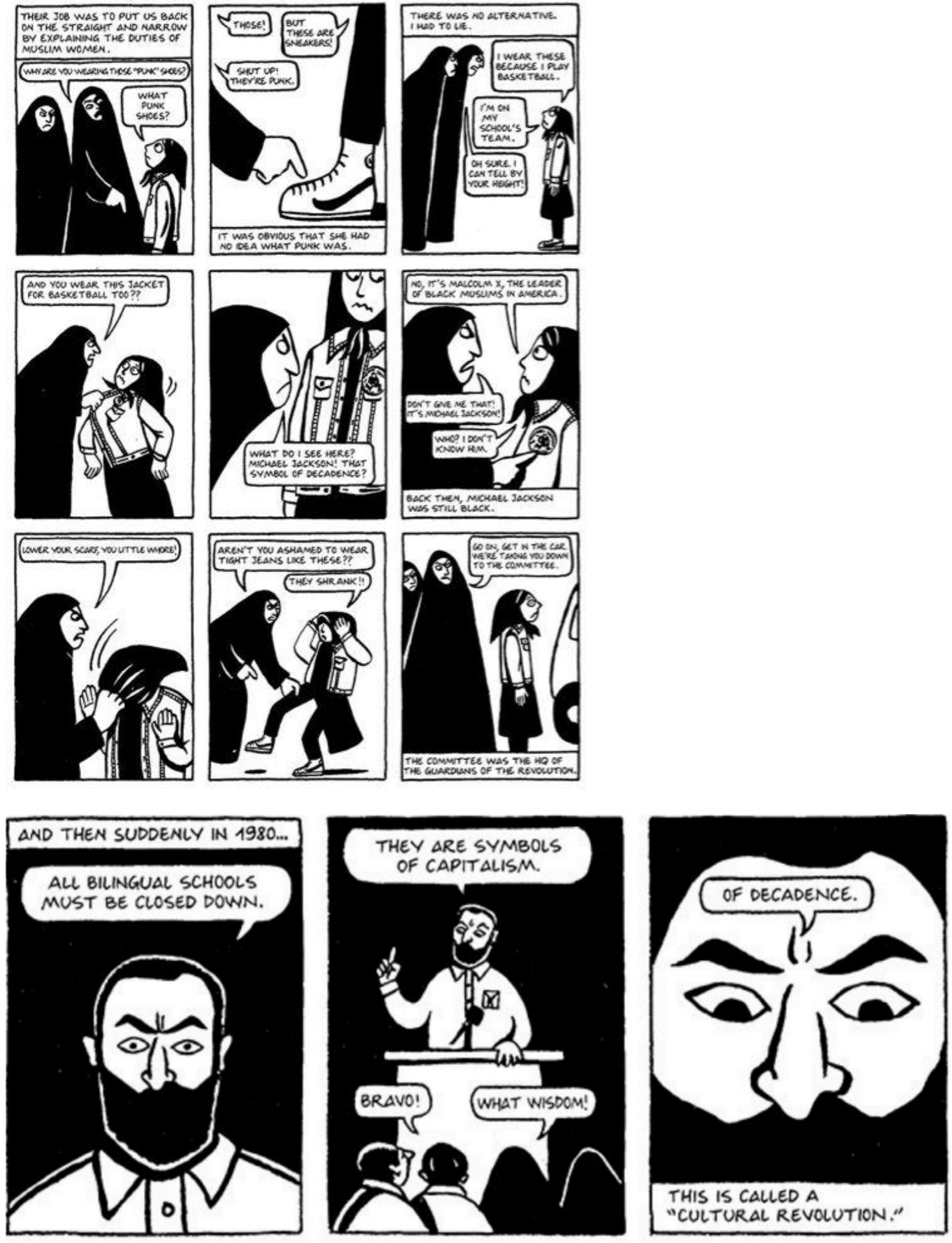


\section{HPST Framework Student Roadmap}

\section{Persepolis}

Author's Background information: Refer to Satrapi's picture in Gallery Walk

HISTORICAL

PHILOSOPHICAL

\section{SOCIETAL}
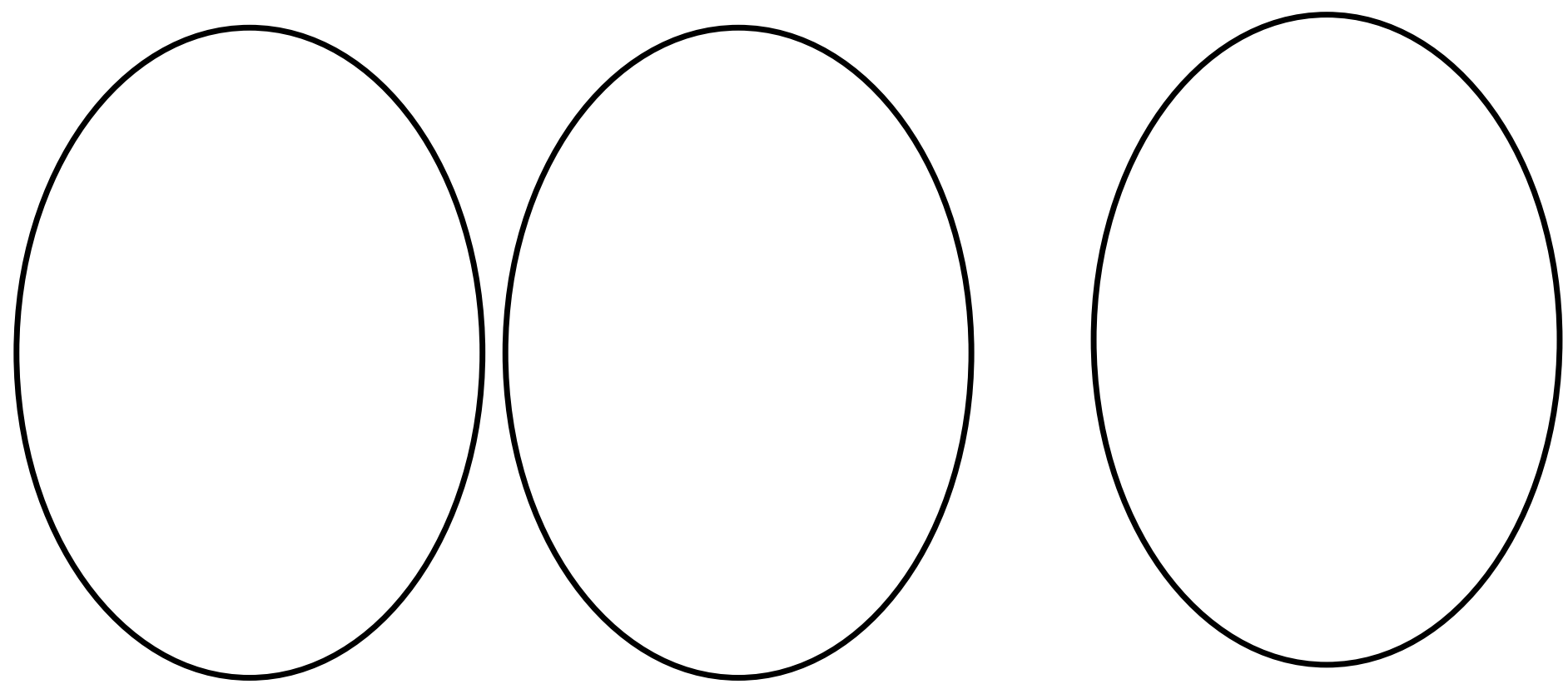


\section{Appendix C}

\section{High School Consent Letter}

\section{DORAL 1 II}

To Whom It May Concern:

Doral Academy hereby consents to allow Jose Pombo to conduct research at our school. We consent to the use of student work as research tools for data gathering and observations to be conducted with the intention to benefit our students. The purpose of this study to offer pre and in-service teachers a pedagogic application for document analysis useable based on the findings of student work at Doral Academy using the Historical, Philosophical, Societal, and Take-Away Framework. The researcher is allowed to do the following:

1. Review and analyze the curriculum unit that includes the H-P-S-T Framework

2. Allowed to visit classrooms to observe implementation of the H-P-S-T Framework

There are no foreseeable risks to us being involved as a participating school in this study. It is expected that this study will benefit society by offering pre and in-service teachers an additional teaching methodology. To our understanding there is no cost or payment required for allowing access to the researcher. Our school name will remain anonymous and student names

confidential. We are participating in good faith that all ethical IRB protocols will be followed.

Doral Academy's participation in this research is voluntary, and we will not be penalized or lose benefits if we refuse to participate or decide to stop.

Signature..2. May 23, 2018

Print Name... Daniel Gonzalez 


\section{Appendix D}

Gallery Walk images for various implementations

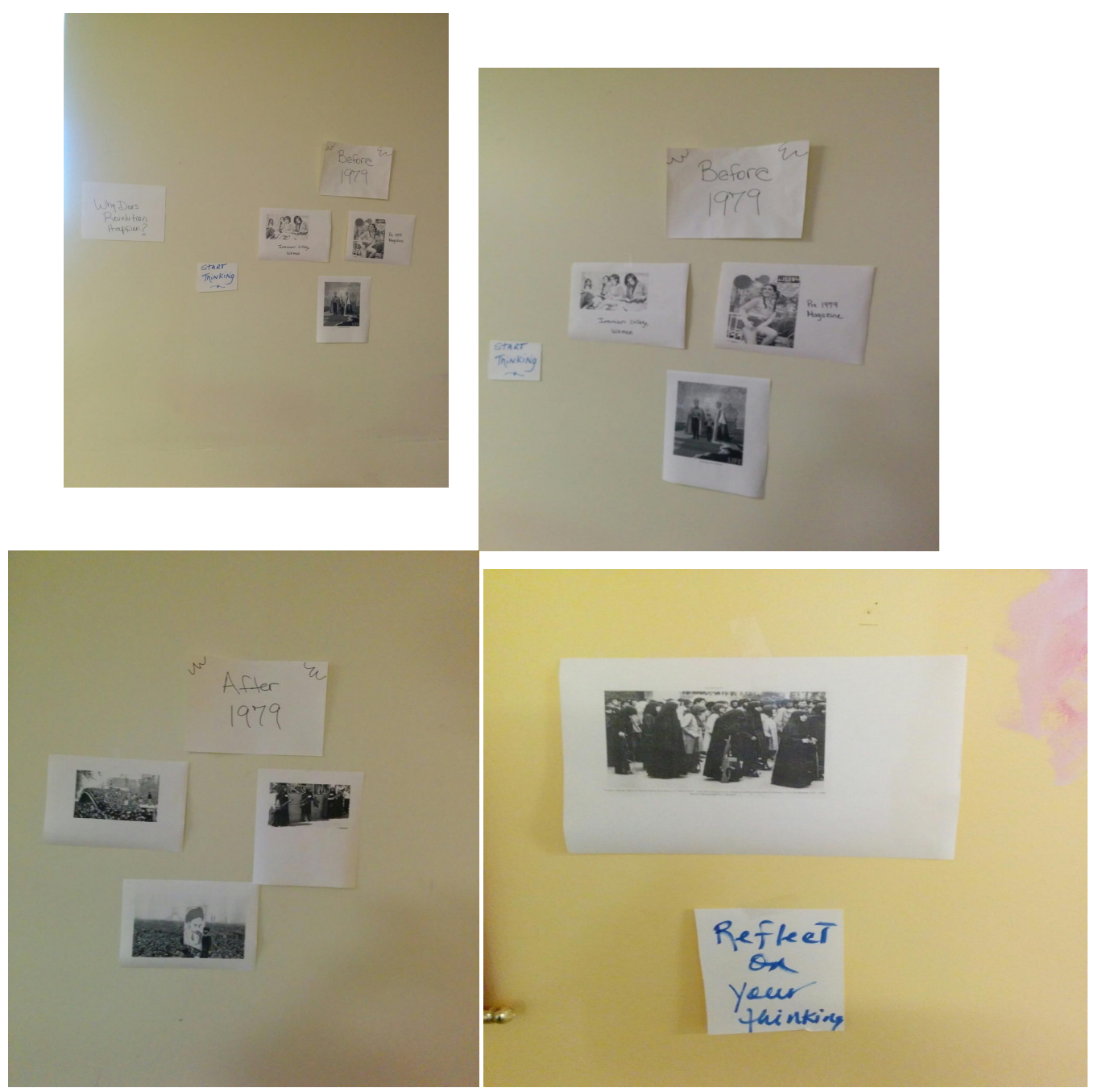



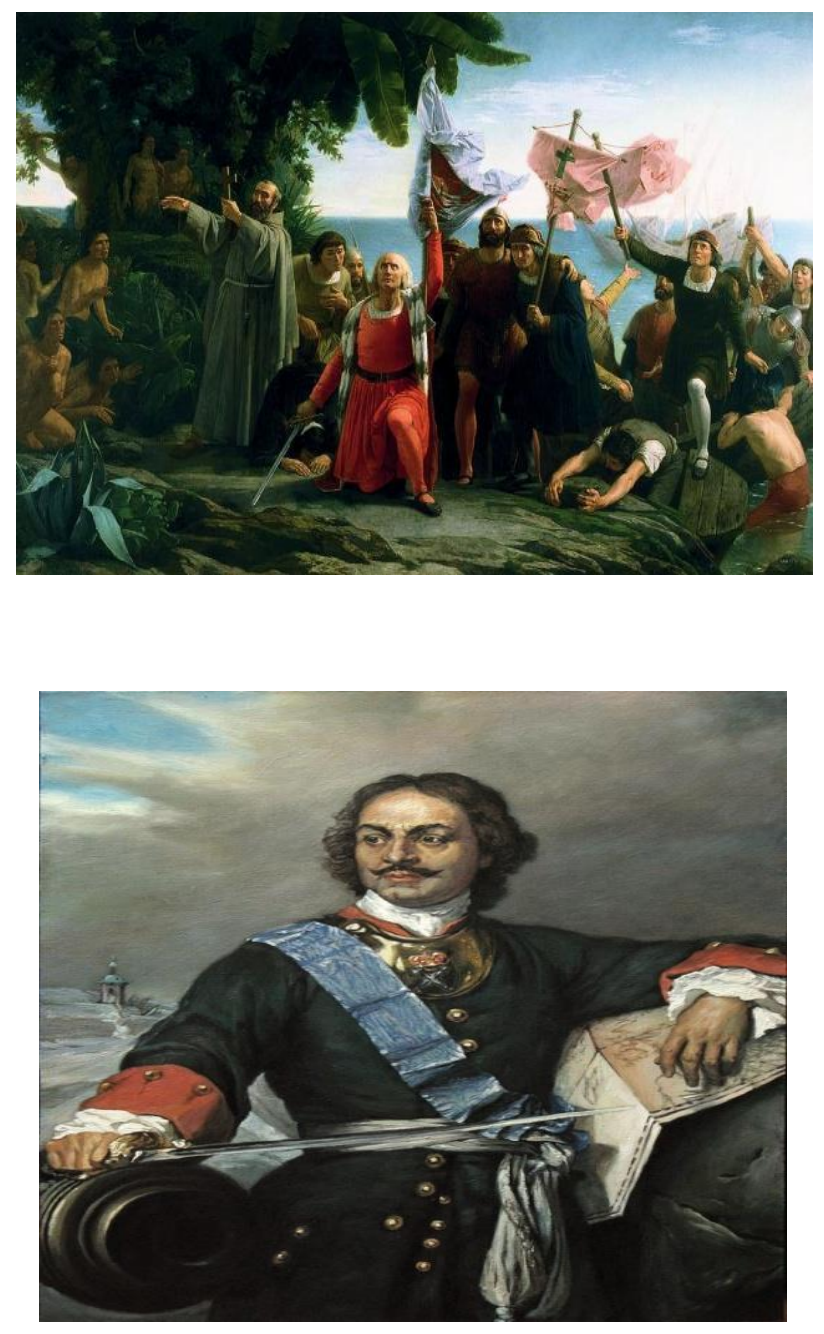


\section{Appendix E}

\section{Excerpts from texts used}
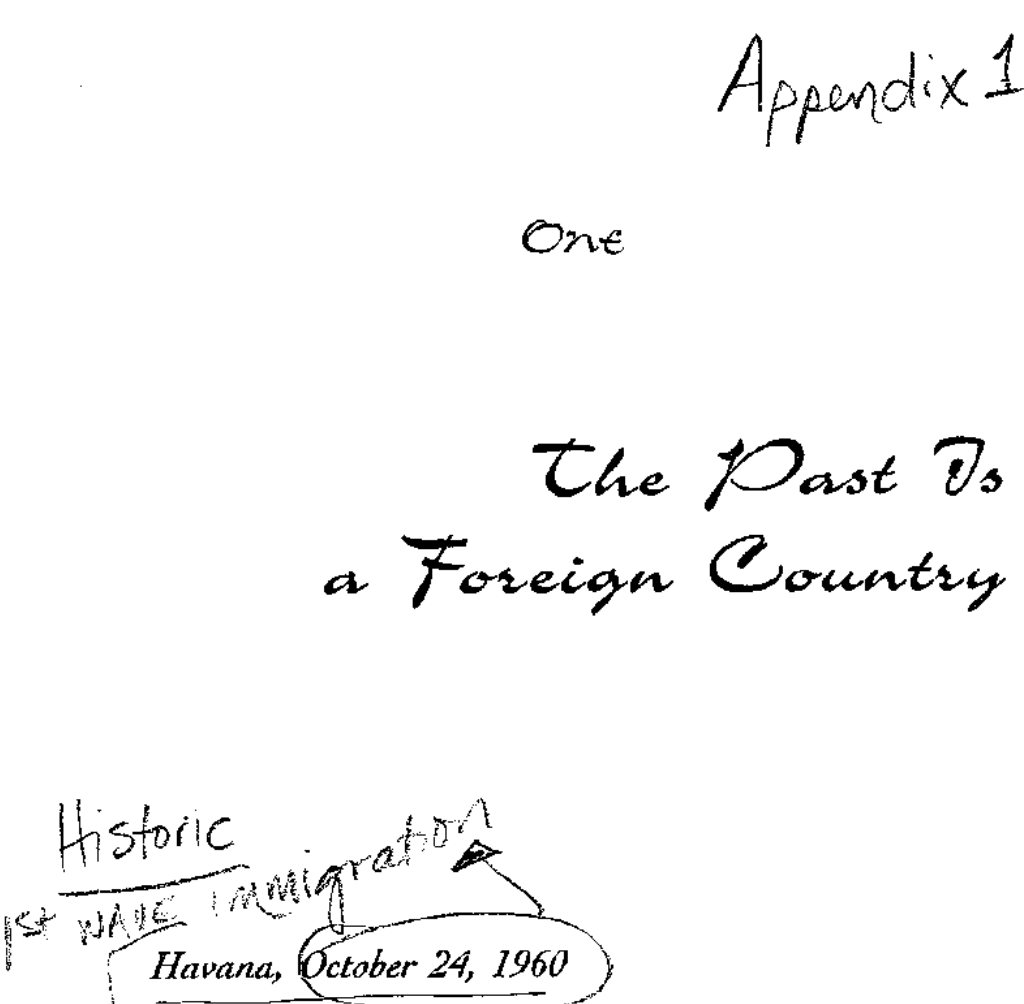

That morning Nena, my mother, woke us up earlier than usual. It was a school day, but we weren't guing to school. In the hallway outside my bedroom the queue of suitcases stretched all the way to the front door. For several years I had been coming to the States once or twice a year, always taking the City of Havana, the overnight ferry to Key West. From there we would drive or take a train to Crowley, Louisiana, the rice capital of America, where my father did business. At first $I$ was the only one of the four children old enough to travel with my parents; later my brother Pepe also came, and on the last trip Carlos had been there too. Only Mari, the baby of the fannily, had not best to el norte leefore. As usual, I got up that roming lookhng forward to sleaping ahourd the ship and waking up) 
the next day to the sight of the sandbars ranged along the Keys like pillows.

We arrived at the pier a couple of hours before the ferry was scheduled to sail. I had been here many times before, since my father's food wholesaling business, which we always called el alma-

(V) cén, was only a few blocks away. (An almacén, literally, is a store-

1. house, but in Cuba the term referred primarily to food wholesalers

and distributors; almacén was short for almacén de víveres, a store-

3 house of eatables.) This morning my aunt Cuca drove us to the

5 dock, where my father joined us. After our suitcases were opened

I and checked, some question arose about his passport. The ferry's

i departure was delayed for an hour. Finally, the problem was

C. straightened out and sometime in the early afternoon the City of

Havana began to inch away from the pier. My aunt waved goodbye. We waved back. Pepe and I clutched the small metal safes with the money that we had saved to spend on our next trip to the States.

E Always the best part of these trips was getting a chance to load up

if on war toys of various vintages, which my brother and I bought by

the dozens at the five-and-ten in Crowley.

C W When this scene took place, I was eleven years old, my broth

ers, Pepe and Carlos, were nine and seven, and-my-sister, Mari, had 15 : turned five three weeks earlier. Although (Fidel Castro had been in C. power less than two years. Cuba was on the fast track to commu- $/ 1$

i. nism. The man who was going to save Cuba from years of dictatorial

- rule yould turn out to be the worst tyrant in Cuban history. tyach

of the wealth of the country had already fallen into government

-3 American-owned enterprises. Ten days earlier, on October 14, the

a regime had promulgated a law confiscating almacenes and other

A. large, Cuban-owned businesses. A few days after the almacén was

5 confiscated, my parents clecicled to leave the comntry. By then al-

in most 100,000 other Cubans hiad fled, mostly professionals, antre-

if prenenrs, and whitemesllar worken's who had already lost their jobs 


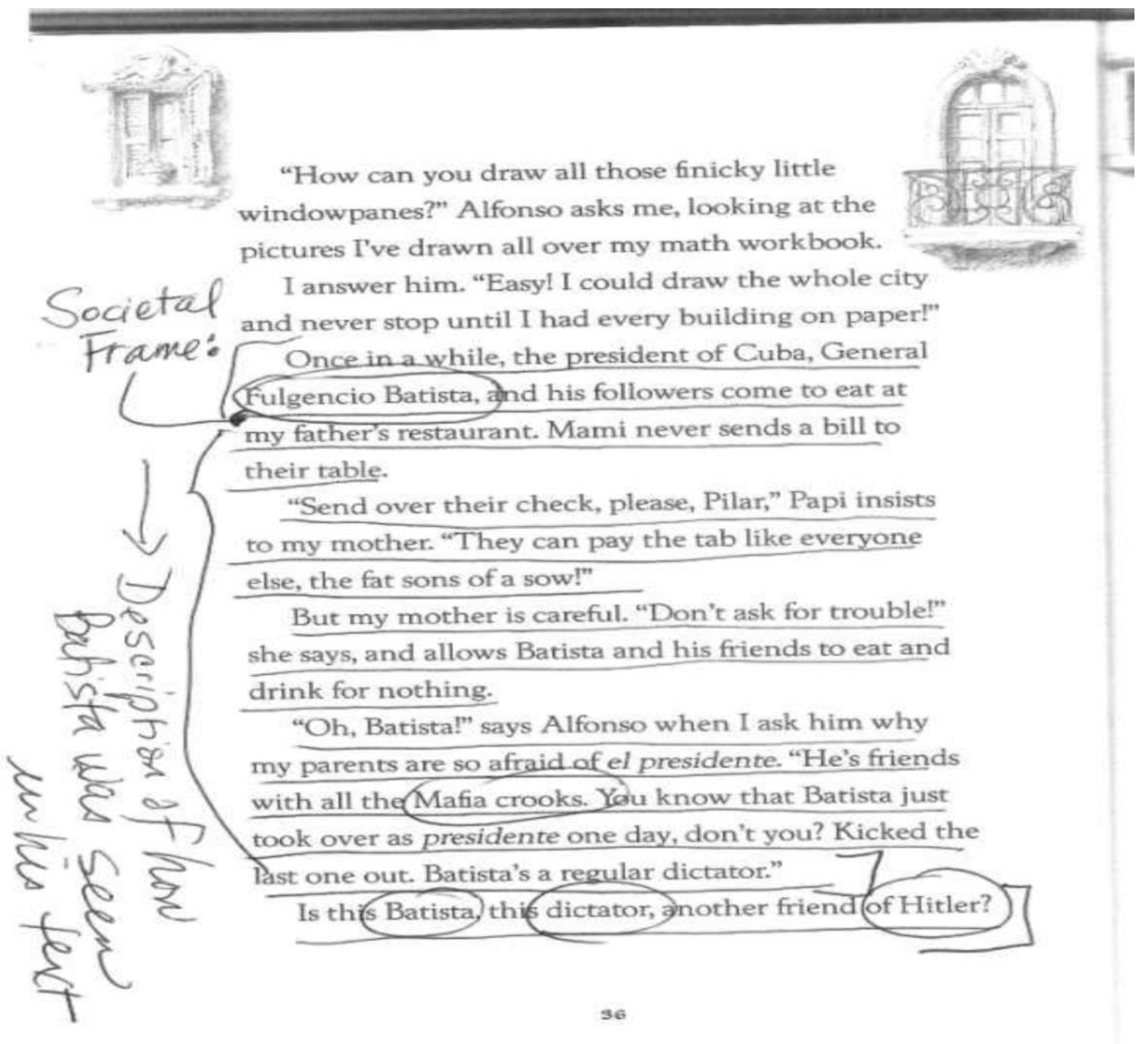


VITA

JOSE M. POMBO

\section{EDUCATION \& HONORS/AWARDS}

2013 Master of Science in Curriculum \& Instruction: Social Studies

Education. Florida International University, Florida. NCATE Accredited

2009 Bachelor of Arts Degree in History: Florida International

University, Florida

Robert R. Bellamy Scholarship. 2012-2014. Graduate Need

Grant. 2012- present Teach Grant. 2012-2014. Teacher Emeritus Award at Doral High

School. 2013

\section{PUBLICATION}

Pombo, J. Mathews, S., M., and Mena, Y. (2017). "HPST: Learning about Iran through Historical Inquiry for Students." International Journal for Cross Discipline Education. 